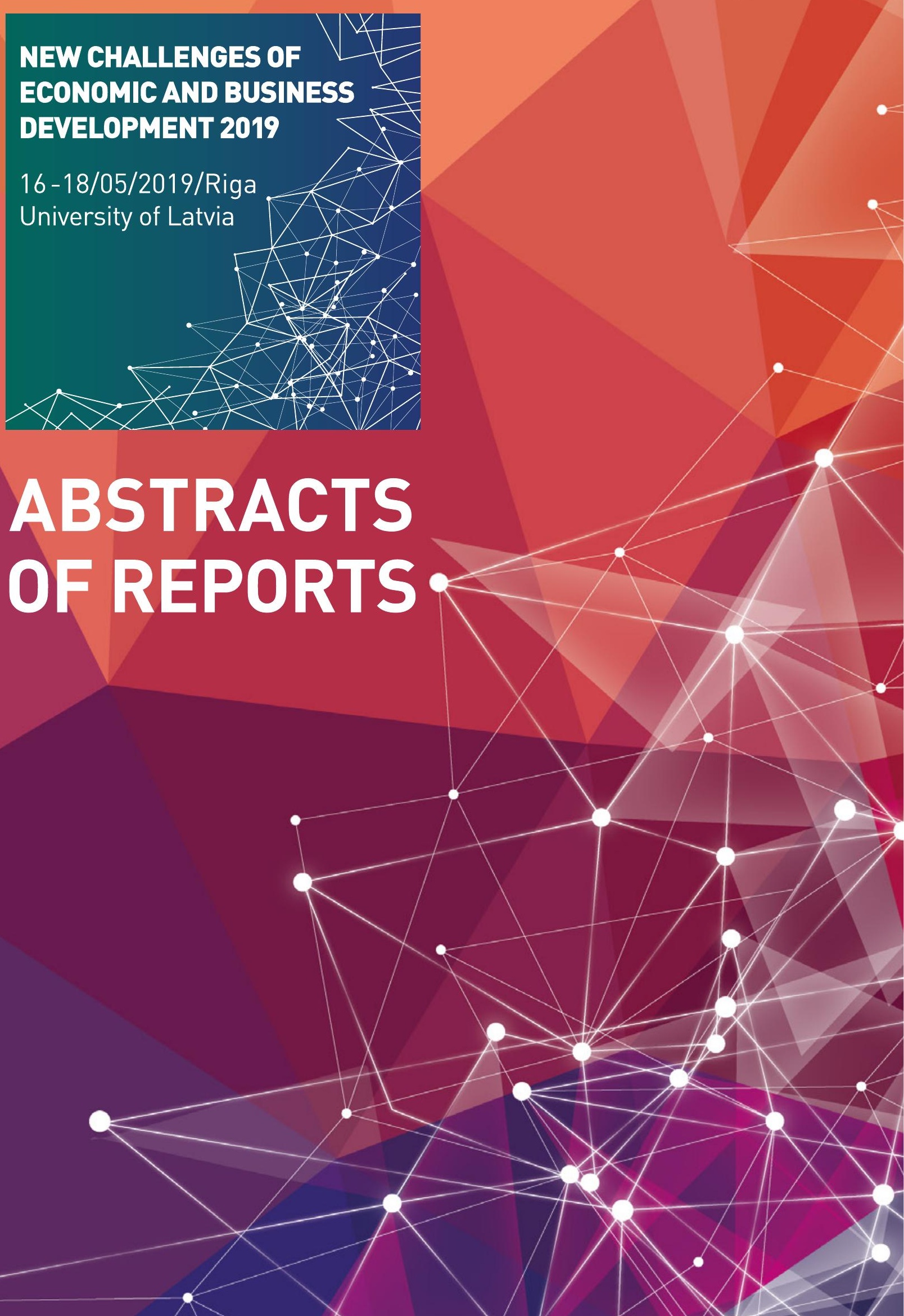




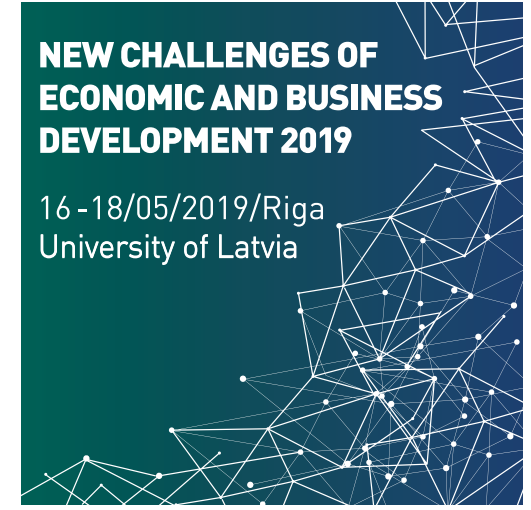

International Scientific Conference

"New Challenges of Economic and Business Development - 2019: Incentives for Sustainable Economic Growth"

\section{Abstracts of Reports}

Organised by Faculty of Business, Management and Economics, University of Latvia

May 16-18, 2019

Riga, University of Latvia 
The 11th international scientific conference "New Challenges in Economic and Business Development - 2019: Incentives for Sustainable Economic Growth”: Riga, Latvia, May 16-18, 2019. Abstracts of Reports. Riga: University of Latvia, 2019, 168 p.

\section{Scientific Programme Committee}

Chairperson, Dr. Inna Romanova, Professor, University of Latvia (Latvia)

Dr. Jean David Avenel, Professor, University Paris-Est Creteil (France)

Dr. Signe Balina, Professor, University of Latvia (Latvia)

Dr. Alan Barrell, Professor, University of Cambridge (United Kingdom)

Dr. Frank Bezzina, Associate Professor, University of Malta (Malta)

Dr. Gundars Berzins, Professor, University of Latvia (Latvia)

Dr. Andrejs Cekuls, Professor, University of Latvia (Latvia)

Dr. Rasa Daugeliene, Associate Professor, Kaunas University of Technology (Lithuania)

Dr. Vida Davidaviciene, Professor, Vilnius Gediminas Technical University (Lithuania)

Dr. Tomasz Dorozynski, Assistant Professor, University of Lodz (Poland)

Dr. Ksenija Dumicic, Professor, University of Zagreb (Croatia)

Dr. Margarita Dunska, Professor, University of Latvia (Latvia)

Dr. Nicolas Gavoille, Associate Professor, Stockholm School of Economics in Riga (Latvia)

Dr. Simon Grima, University of Malta (Malta)

Dr. Arto Haveri, Professor, Tampere University (Finland)

Dr. Mihails Hazans, Professor, University of Latvia (Latvia)

Dr. Gundars Kaupins, Professor, Boise State University (USA)

Dr. Jan Koernert, Professor, University of Greifswald (Germany)

Dr. habil. Natalia Kuznetsova, Professor, Saint Petersburg State University (Russia)

Dr. Pierpaolo Marano, Associate Professor, Università Cattolica del Sacro Cuore (Italy)

Dr. Marco Menichetti, Professor, University of Liechtenstein (Liechtenstein)

Dr. Eda Merisalu, Professor, Estonian University of Life Sciences (Estonia)

Dr. Shin'ya Nagasawa, Professor, Waseda University (Japan)

Dr. Josef Neuert, Professor, University of Salzburg (Austria)

Dr. Tiiu Paas, Professor, Tartu University (Estonia)

Dr. Gunnar Prause, Professor, Tallinn University of Technology (Estonia)

Dr. Janis Priede, Professor, University of Latvia (Latvia)

Dr. Alari Purju, Professor, Tallinn University of Technology (Estonia)

Dr. Trond Randoy, Professor, University of Agder (Norway)

Dr. Jurgita Raudeliuniene, Professor, Vilnius Gediminas Technical University (Lithuania)

Dr. Ramona Rupeika-Apoga, Professor, University of Latvia (Latvia)

Dr. Lilita Seimuskane, Assistant Professor, University of Latvia (Latvia)

Dr. Bruno S. Sergi, Professor, University of Messina (Italy), Harvard University (USA)

Dr. Biruta Sloka, Professor, University of Latvia (Latvia)

Dr. Baiba Savrina, Professor, University of Latvia (Latvia)

Dr. Ligita Simanskiene, Professor, Klaipeda University (Lithuania)

Dr. Irina Solovjova, Associate Professor, University of Latvia (Latvia)

Dr. habil. Inna Steinbuka, Professor, University of Latvia (Latvia)

Dr. Erika Sumilo, Professor, University of Latvia (Latvia)

Dr. Eleftherios Thalassinos, Professor, University of Piraeus (Greece)

Dr. Osman Titrek, Professor, Sakarya University (Turkey)

Dr. Inesa Voroncuka, Professor, University of Latvia (Latvia)

Dr.habil. Renata Walczak, Professor, Warsaw University of Technology (Poland) 


\section{Conference Organizing Committee}

Chair: Dr. Inna Romanova, Vice Dean for Research, Professor, Faculty of Business, Management and Economics, University of Latvia

Dr. Gundars Berzins, Dean, Professor, Faculty of Business, Management and Economics, University of Latvia

Dr. Andrejs Cekuls, Professor, Faculty of Business, Management and Economics, University of Latvia

Dr. Margarita Dunska, Professor, Faculty of Business, Management and Economics, University of Latvia

Dr. Janis Priede, Professor, Faculty of Business, Management and Economics, University of Latvia

Dr. Ramona Rupeika-Apoga, Professor, Faculty of Business, Management and Economics, University of Latvia

Dr. Biruta Sloka, Professor, Faculty of Business, Management and Economics, University of Latvia

Dr. Erika Sumilo, Professor, Faculty of Business, Management and Economics, University of Latvia

Evija Ansonska, Public Relations Manager, Faculty of Business, Management and Economics, University of Latvia Liene Berzina, Public Relations Specialist, Faculty of Business, Management and Economics, University of Latvia

Sofija Kristele, Executive Director, Faculty of Business, Management and Economics, University of Latvia

Kristine Liepina, Dean Assistant, Faculty of Business, Management and Economics, University of Latvia

\section{Reviewers}

Abstracts and papers submitted to the "New Challenges in Economic and Business Development - 2019: Incentives for Sustainable Economic Growth" have been double-blind reviewed.

\section{LEGAL NOTICE}

The University of Latvia, nor any person acting on its behalf may be held responsible for the use to which information contained in this publication may be put, nor for any errors which may appear despite careful preparation and checking. 


\section{Contents}

Contemporary Management and Business Innovations

Kristine Bokse, Henrijs Kalkis, Zenija Roja

CHALLENGES OF ERGONOMICS IN CONTEMPORARY BUSINESS ENVIRONMENT

Norbert G. Brink

OBJECTIVES OF VIRTUAL SYSTEM SUPPLIERS - A CASE STUDY

Martins Danusevics

RETAILERS AND DECLINING POPULATION IN LATVIA: BUSINESS TENDENCIES AND DECISIONS

Zanda Davida

ECONOMIC ANALYSIS IN LEGAL ARGUMENTATION OF UNFAIR COMMERCIAL PRACTICE

Igor Dukeov, Madara Apsalone, Ilona Baumane-Vitolina, Jukka-Pekka Bergman, Erika Sumilo

A FIRM'S ORGANIZATIONAL INNOVATION AND ORGANIZATIONAL LEARNING ABILITIES

Viktorija Janaviciene, Vladislav V. Fomin

SYSTEMATIC MAPPING OF ECONOMICS AND MANAGEMENT LITERATURE ON BLOCKCHAIN APPLICATION IN

ORGANIZATIONS

Aina Joppe, Ilze Sproge

TAX POTENTIAL VS BUDGET REVENUE POTENTIAL

Nadezda Kanygina, Tatiana Solovey

THE PERSPECTIVES OF ORGANIC AGRICULTURE IN RUSSIA AND ITS CONTRIBUTION TO SUSTAINABLE

DEVELOPMENT. COMPARISON WITH THE WORLD PRACTICE

Rene Lauck

INDICATORS FOR MEASURING TRANSFORMATIONAL AND TRANSACTIONAL LEADERSHIP

Eduards Lielpeters

PUBLIC ADMINISTRATION IN LATVIA. OPPORTUNITIES OF DIGITAL DEMOCRACY

Jelena Luca

MEASUREMENT OF ORGANIZATIONAL INNOVATION - IN SEARCH FOR THEORETICAL FRAMEWORK

Vadim Mantrov

BUSINESS MODELS EMPLOYED IN ONLINE PLATFORMS: THE PERSPECTIVE OF LATVIA

Ludmila Masko, Pavel Pankou

THE CONTROL OF TRANSACTIONS WITH DERIVATIVES IN THE NON-FINANCIAL ORGANIZATIONS IN THE REPUBLIC OF BELARUS

Jurgita Pauzuoliene, Ilvija Pikturnaite

SOCIAL RESPONSIBILITY OF HIGHER EDUCATION INSTITUTIONS: YOUTH ATTITUDE

Jurgita Raudeliuniene

THE MODEL FOR FORMATION STRATEGIC DECISIONS OF ORGANIZATION'S KNOWLEDGE POTENTIAL

MANAGEMENT

Maximilian Schausberger

ACCELERATORS - CATEGORIZING A NEW FORM OF COOPERATION

Ralf Schechowiz

INTERIM MANAGERS IN THE CFO ROLE IN MEDIUM-SIZED COMPANIES: A PILOT STUDY ON INFLUENTIAL

FACTORS

Ligita Simanskiene

DO WE NEED TEAMWORK? NEW CHALLENGE FOR ORGANIZATIONS

Armands Svikis, Andrejs Cekuls

BASIC COMPONENTS FOR SUCCESSFUL BUSINESS PERFORMANCE: IN SEARCH FOR A MODELING OF THEORETICAL FRAMEWORK

Inesa Voroncuka, Inese Ratanova

FACTORS OF THE INNOVATION ECOSYSTEM BY EXAMPLE OF LATVIAN TECHNOLOGICAL STARTUP

Ksenija Dumicic, Berislav Zmuk, Toni Milun

HOW DO SELECTED RECENT ECONOMIC AND SOCIAL DEVELOPMENT INDICATORS INFLUENCE EMPLOY-

MENT RATES IN EUROPEAN UNION COUNTRIES 
Norbert Nindl

INDICATORS FOR ARTIFICIAL INTELLIGENCE SUPPORTED DECISION MAKING 36

Robert Philipp, Laima Gerlitz, Gunnar Prause

SMART CONTRACTS FOR ENTREPRENEURIAL COLLABORATION IN LOGISTICS NETWORKS

Kristine Rozite, Signe Balina, Rita Freimane

DIGITAL COMPETENCE RATING AND ECONOMIC DEVELOPMENT IN THE EU

\section{Financial Services, Accounting and Finance}

Neli R. Abramishvili, Nadezhda A. Lvova, Natalia S. Voronova

IS IT POSSIBLE TO ASSESS THE CORPORATE MARKET VALUE IN THE EMERGING MARKET?

Ieva Aizsila

AUDIT PROCESS: PROFESSIONAL ETHICS AND INDEPENDENCE EFFECTIVE DESIGN - CASE STUDY IN LATVIA 42

Siarhei Baslaviak

DEVELOPING CORPORATE BOND MARKET IN BELARUS

Kristina Bojare

THIS TIME WILL BE DIFFERENT? BUILD-UP OF CYCLICAL SYSTEMIC RISKS AND ACTIVATION OF THE COUNTERCYCLICAL CAPITAL BUFFER IN CESEE BANKING SECTORS

Larisa Bule, Inna Romanova, Ramona Rupeika-Apoga

LATEST TRENDS IN ASSESSING PENSION REFORMS

Svetlana Bychkova, Dmitry Eliashev, Elena Zhidkova

ACCOUNTING POLICIES OF AGRO-INDUSTRIAL COMPLEX COMPANIES AS A KEY ELEMENT OF THE

CONTROLLING SYSTEM IN THE CONDITIONS OF THE DIGITAL ECONOMY

Svetlana Bychkova, Dmitry Eliashev, Elena Zhidkova

FORMATION OF INNOVATION AND INVESTMENT STRATEGY OF DEVELOPMENT OF AGRIBUSINESS BUSI-

NESS STRUCTURES IN THE CONDITIONS OF ECONOMIC TRANSFORMATION

Andrejs Cekuls, Maximilian-Benedikt Koehn

BITCOIN AND STOCK MARKET INDICES: ANALYSIS OF VOLATILITY'S CLUSTERS DURING THE BITCOIN

BUBBLE BASED ON THE DYNAMIC CONDITIONAL CORRELATION MODEL

Alessandro Danovi, Jessica Tanghetti

VULTURE INVESTING IN ITALY .

Valdone Darskuviene

BRIDGING SUSTAINABILITY GOALS AND CORPORATE PERFORMANCE: INSIGHTS FROM EMPIRICAL

STUDY ON SCANDINAVIAN AND BALTIC LISTED COMPANIES

Ivita Faitusa

THE VALUE-ADDED INTERNAL AUDIT IN PUBLIC ADMINISTRATION IN LATVIA

Andre Farrugia

CHANGES IN THE INSURANCE ENVIRONMENT: A REVIEW OF THE OPERATIONAL IMPLICATIONS ON

UNDERWRITING

Anna Gierusz, Agnieszka Poblocka

TAX INCENTIVES TO PARTICIPATE IN OCCUPATIONAL PENSION SCHEMES: THE PERSPECTIVE OF AN IN-

DIVIDUAL

Colin Glinkwoski, Jorn von Elsenau

HISTORICAL BACKGROUND OF BALTIC CREDIT INSTITUTIONS

Viktor V. Ivanov, Nadezhda A. Lvova, Natalia V. Pokrovskaia

FINANCIAL INCENTIVES OF ECONOMIC GROWTH IN EMERGING MARKETS: EVIDENCE FROM RUSSIA .......... 55

Irina Japparova, Ramona Rupeika-Apoga

MAIN FACTORS OF EMOTIONALLY ATTACHED CUSTOMER IN RETAIL BANKING OF LATVIA

Rasa Kanapickiene, Ieva Stankeviciute, Almute Grebliune

EVALUATION OF TANGIBLE ASSETS ACCOUNTING INFORMATION DISCLOSURE QUALITY IN THE PUBLIC

SECTOR: THE CASE OF LITHUANIA

Hendrik Kimmerle

THE PRINCIPAL-AGENT PROBLEM WITHIN SUSTAINABLE INVESTING

Maximilian-Benedikt Koehn, Andrejs Cekuls

A BEHAVIOURAL FINANCE EXPLANATION OF SPECULATIVE BUBBLES: EVIDENCE FROM THE BITCOIN

PRICE DEVELOPMENT 
Beata Kotowska

NON-FINANCIAL REPORTING IN THE MICRO ENTERPRISES IN SELECTED EUROPEAN COUNTRIES

Kaspars Kravinskis

IMPLICATIONS OF FUZZY DELPHI METHOD IN ASSESSING THE EFFICIENCY OF FINANCIAL LITERACY

PROMOTION

Marshia Mamo, Sharon Seychell, Simon Grima

SOURCES OF FINANCE IN THE IGAMING INDUSTRY: THE CASE OF MALTA

Marco J. Menichetti

IMPACT INVESTING - AN ACCEPTABLE NICHE EXISTENCE?

Matthias Paschke

THE IMPACT OF PERSONNEL REDUCTIONS ON THE SUCCESS OF GERMAN SAVINGS BANKS

Dancho Petrov

BLOCKCHAIN IN FINANCIAL INDUSTRY: BETWEEN INFLATED EXPECTATIONS AND DISILLUSIONMENT ...... 65

Kristine Petrovska

NOVEL USAGE OF NETWORK MODELLING. SYSTEMIC RISK IN BANKING

Zhanna Pisarenko, Natalia Kuznetsova

GREEN AND INFRASTRUCTURE INVESTMENT - AN IMPORTANT AREA OF PENSION REFORMS FOR

TRANSITIONAL ECONOMIES

Agnieszka Poblocka, Ewa Spigarska, Grzegorz Krzykowski

BAYESIAN MODEL OF PROVISION FOR EMPLOYEE RETIREMENT BENEFITS

Galina Reshina, Nataliya S. Plaskova, Natalya A. Prodanova

INNOVATIVE ASSETS: IMPROVING THE METHODOLOGY OF ACCOUNTING, ANALYTICAL AND ESTIMATION

PROCEDURES

Svetlana Saksonova, Arina Matvejeva

EVALUATION OF INTERNAL AUDIT ACTIVITY EFFECTIVENESS IN RISK ASSESSMENT OF ANTI-MONEY

LAUNDERING AREA: A CASE OF LATVIAN BANK “N”.

Svetlana Saksonova, Ludmila Rozgina

PIE STATUTORY AUDIT MARKET CONCENTRATION: EVIDENCE FROM LATVIA

Ruta Sneidere, Inga Bumane

THE CHALLENGES FOR THE PROFESSION OF ACCOUNTANT IN THE CHANGING GLOBAL ECONOMIC

ENVIRONMENT

Irina Solovjova, Inna Romanova, Ramona Rupeika-Apoga, Svetlana Saksonova, Marina Kudinska, Aina Joppe

ASSESSMENT OF BANK FINANCIAL HEALTH IN LATVIA ....

Dzeina Steinberga, Ruta Sneidere

HISTORY OF CASH FLOW STATEMENT AND PRACTICES IN LATVIA AND OTHER STATES

Rasa Subaciene

EVALUATION OF THE IMPACT OF STATE SUPPORT AND CORPORATE INCOME TAX EXEMPTIONS ON THE

FINANCIAL CONDITION OF SOCIAL ENTERPRISES

Daiva Tamuleviciene

EVALUATION OF THE POSITION OF THE SUBJECT OF CONTROLLING IN MEDIUM-SIZED COMPANIES

Maria Tissen, Ruta Sneidere

TURNOVER RATIOS AND PROFITABILITY RATIOS CALCULATION METHODS: THE BOOK OR AVERAGE VALUE 77

Wangchao Yuan, Thomas Walker, Stefan Wendt

FIRM AND COUNTRY-LEVEL DETERMINANTS OF GREEN INVESTMENTS: AN EMPIRICAL ANALYSIS

Human Development and Efficiency

Annija Apsite

WORK AND LIFE BALANCE - THE NEW AGE MANAGEMENT MATTER

Ilze Boitmane, Inesa Voroncuka

THE ROLE AND TENDENCIES OF DEVELOPMENT OF THE SOCIAL MEDIA IN HUMAN RESOURCES

MANAGEMENT

Martin Josef ten Bosch

IMPACT OF DECISION- MAKING IN NON-PROFIT ENTERPRISES OF DISABLED LIVING STATIONS

Ilze Buligina, Biruta Sloka

ENCOURAGING EMPLOYERS’ INVOLVEMENT IN THE TRAINING OF FUTURE LABOUR FORCE 
Lauris Gruntmanis, Andrejs Cekuls

THE IMPACT OF THE LATVIAN LOCAL GOVERNMENT REFORM ON ECONOMIC DEVELOPMENT . 85

Frank W. Hager

THE MODERATING ROLE OF SENSE OF COHERENCE BETWEEN PERCEIVED SUPERVISORY SUPPORT AND

JOB BURNOUT SYMPTOMS

Kristine Lece

ECONOMIC ACTIVITY CHANGES DUE TO SOCIO-DEMOGRAPHIC FACTORS

Wojciech Popczyk

ANTHROPOLOGICAL FAMILY TYPE AND ITS IMPACT ON SUCCESSION PLANNING IN FAMILY BUSINESSES -

RESEARCH REPORT .

Karlis Purmalis, Sandra Jekabsone, Edgars Kassalis

EVALUATION OF LABOR SKILLS IN LATVIA ...

Uldis Rozevskis, Rita Freimane, Juris Krasts, Rita Zuka

PROCESS MODELING ELEMENTS, PATTERNS AND SCOPE

Aija Staskevica, Margarita Dunska

THE ASPECTS OF COMPETENCY IN THE CONTEXT OF EDUCATION SITUATION IN LATVIA

\section{Industries and Productivity}

Daira Baranova

TRENDS AND DRIVERS OF PRODUCTIVITY GROWTH IN LATVIA

Wjatscheslav Baumung, Herbert Gloeckle, Vladislav V. Fomin

APPROACH FOR A PRODUCTION PLANNING AND CONTROL SYSTEM ARCHITECTURE WITH INTEGRATION

INTO AN ENTERPRISE RESOURCE PLANNING SYSTEM FOR THE USE OF ADDITIVE MANUFACTURING

Pawel Dobrzanski, Leon Olszewski

STRUCTURAL CHANGE PATH AND ECONOMIC GROWTH PERFORMANCE OF POLISH ECONOMY

Rita Freimane, Janis Priede, Roberts Skapars

DYNAMICS OF REAL LABOUR PRODUCTIVITY AND REAL COMPENSATION IN LATVIA

Herbert Gloeckle, Wjatscheslav Baumung, Vladislav V. Fomin

ENTERPRISE RESOURCE PLANNING SYSTEMS: A CONCEPT CONCERNING THE SPECIAL OPPORTUNITIES

AND REQUIREMENTS OF ADDITIVE MANUFACTURING

Sandra Jekabsone, Irina Skribane

PRODUCTIVITY DYNAMICS AND THE PRODUCTIVITY TRAP: PROBLEMS AND SOLUTIONS IN LATVIA

Maciej Urbaniak

THE ROLE OF PROCESS IMPROVEMENT TOOLS AS CRITERIA OF EVALUATATION OF SUPPLIERS IN

PRODUCTION SECTOR

International Economics and Globalization

Liga Andersone

EU'S ASSISTANCE PROGRAMMES IN SUPPORT TO SUSTAINABLE ECONOMIC GROWTH IN CENTRAL ASIA .... 105

Kristine Berzina

TOURISM ASSOCIATION DEVELOPMENT TENDENCIES IN LATVIA

Johannes Bramboeck

THE IMPACT OF ECONOMIC GROWTH ON QUALITY MANAGEMENT SYSTEMS IN PHARMACEUTICAL

INDUSTRY

Vida Davidaviciene, Alma Maciulyte-Sniukiene

THE IMPACT OF INTERNATIONAL TRADE ON EU MEMBER STATES PERFORMANCE

Marcis Dzelme

DECENT WORK AND ECONOMIC GROWTH IN THE TIMES OF FOURTH INDUSTRIAL REVOLUTION

Tatiana Isachenko, Natalia Navrotskaia

DIGITALIZATION AS A CHALLENGE FOR THE MULTILATERAL TRADING SYSTEM

Anna H. Jankowiak

CLUSTER POLICY INSTRUMENTS FOR DEVELOPMENT - A COMPARATIVE STUDY OF VARIOUS CLUSTER

POLICIES

Anna H. Jankowiak, Szymon Mazurek, Winand Dittrich

APPLICATION OF THE LOGIC MODEL IN MEASURING THE EFFECTIVENESS OF CLUSTER POLICY 


\section{Anetta Kuna-Marszalek}

GREEN BONDS MARKET - MAIN TRENDS AND DEVELOPMENT PERSPECTIVES

Szymon Mazurek

FEATURES OF THE NETWORK MARKETS LEADING TO CROSS-INDUSTRY COOPERATION

Oliver Menk

THE ROLE OF CONFIDENCE IN AN EFFICIENT HUMAN LEADERSHIP

Natalia A. Navrotskaia, Svetlana G. Gorbushina, Natalya Y. Sopilko

ASSESSMENT OF INVESTMENT FOR SUSTAINABLE DEVELOPMENT: CHALLENGES AND PROSPECTS

Pawel Pasierbiak

CHINA'S ROLE IN EAST ASIAN ECONOMIC INTEGRATION SINCE AFC - EVOLUTION AND PROSPECTS

Inna Steinbuka, Martins Zemitis

LATVIA'S ECONOMIC PERSPECTIVES: EXPLOITING GLOBALIZATION THROUGH EU MEMBERSHIP

Joanna Stawska, Ewa Stawasz-Grabowska

HOW DO THE POLICY MIX DETERMINANTS AFFECT CREDIT RATINGS OF SELECTED EU COUNTRIES?

Ann-Kathrin Teltz

THE IMPACT OF DIGITALIZATION ON THE SUCCESS OF BUSINESS INTERNATIONALIZATION RELATING TO GERMAN SMALL AND MEDIUM SIZED FINTECHS

Monika Wojtas, Tomasz Bialowas

PROSPECTIVE CONSEQUENCES OF THE TRADE WAR BETWEEN THE UNITED STATES AND CHINA

Monika Wojtas, Tomasz Bialowas

THE UNITED STATES' TRADE POLICY TOWARDS THE EUROPEAN UNION AND DEVELOPMENT OF BILATERAL

TRADE FLOWS

Algimants Kontauts, Jie Jiang

CHINA'S FAMILY PLAN POLICY REFORM AND ITS POTENTIAL EFFECTS ON ITS GENERAL ECONOMIC

DEVELOPMENT

Mihails Kozlovs

EMIGRATION AND REMITTANCES PATTERN ANALYSIS IN LAGGING BEHIND BALTIC REGIONS: CASE

STUDIES OF NARVA, DAUGAVPILS AND VISAGINAS

Tiiu Paas, Maryna Tverdostup

MOBILITY OF LABOUR AND IMMIGRANTS’ INTEGRATION: HOW TO DECLINE IMMIGRANTS-NATIVE WAGE ..... 127 Anna Zasova, Anna Pluta

SHIFTING TAX BURDEN FROM LABOUR TO PROPERTY: THE CASE OF LATVIA

\section{Life Quality and Income Inequality}

Elena Dubra

SOCIAL INEQUALITY AND CONVERGENCE PROBLEMS IN THE EU

Silvija Kristapsone, Silvija Bruna

CHANGES IN THE SUBJECTIVE ASSESSMENT OF QUALITY OF LIFE IN LATVIA AND THE EUROPEAN UNION:

RESULTS EUROPEAN QUALITY OF LIFE SURVEY 2016

Juris Krumins, Atis Berzins, Aleksandrs Dahs, Denize Ponomarjova

HEALTHY AND ACTIVE PRE-RETIREMENT AND RETIREMENT AGES: ELDERLY INEQUALITY IN LATVIA ........ 133

Indra Samite, Maris Purgailis

FACTORS INFLUENCING THE DECREASE IN INCOME INEQUALITY IN LATVIA

Nataliia Spiridonova

THE RELATIONSHIP OF WAGE LABOR AND CAPITAL AND THEIR DEVELOPMENT IN THE FORMS OF SOCIAL

PARTNERSHIP

Anda Batraga, Daina Skiltere, Jelena Salkovska, Santa Bormane, Aija Legzdina

INFLUENCE OF INTEGRATED MARKETING COMMUNICATION TOOLS UPON CONSUMERS’ BUYING

DECISIONS IN THE CONTEXT OF SUSTAINABILITY

Liga Bitane

ADDING A MORAL DIMENSION TO THE LUXURY BRAND VALUE 
Liga Braslina, Anda Batraga, Daina Skiltere, Aija Legzdina, Girts Braslins, Eva Cildermane

IMPROVED INNOVATIVE PRODUCT STRATEGY ASSESSMENT MODEL IN MARKET RESEARCH CONTEXT ...... 141 Janis Duboviks

THE EVALUATION OF MARKETING COMMUNICATIONS AND THE AWARENESS ABOUT HIV AMONG THE RESIDENTS OF LATVIA

Alfred Konrad

THE IMPACT OF CUSTOMER SATISFACTION ON DEALER LOYALTY IN THE AUTOMOBILE RETAIL INDUSTRY:

A LITERATURE REVIEW

Aija Legzdina, Annemari Sperlina, Ilgvars Rukers

THE IMPORTANCE OF BRAND FOR INFLUENCING CONSUMER BEHAVIOUR IN SOCIAL NETWORK PLATFORMS 144

Ilze Medne, Kristine Berzina, Aija van der Steina

TOURISM SERVICE ATTRIBUTE INFLUENCE ON OVERALL TOURIST SATISFACTION LEVEL IN RIGA ................. 145

Elina Radionova-Girsa

B2P MARKETING: ONLINE COMMUNICATION CHALLENGE

Ronalds Skulme

THE CALCULATION OF CROWDFUNDING CAMPAIGN SOCIAL MEDIA COSTS

Biruta Sloka, Sergejs Volvenkins, Kate Cipane

MAIN FACTORS INFLUENCING INTERNET SHOP SUCCESS

Evgeniya Tonkova

APPLICATION-BASED MARKETING - FROM REALITY TO THE FUTURE

Andzela Veselova

A COMPARISON OF BUSINESS EXCELLENCE MODELS

Regional Development and Public Governance: Europe's Economic Future 151 CNatalija Cudecka-Purina, Dzintra Atstaja, Rudite Vesere

THE GOALS OF WASTE FRAMEWORK DIRECTIVE AS MECHANISM SECURING TRANSITION TO CIRCULAR

ECONOMY

Pawel Dobrzanski

INCOME DISPROPORTION BETWEEN CENTRAL AND EASTERN EUROPE REGIONS

Elena Dorina, Olga Meshcheryakova

THEORETICAL BASES OF THE PUBLIC-PRIVATE PARTNERSHIP IN THE IMPLEMENTATION OF THE LOGISTIC

INFRASTRUCTURE OF THE REPUBLIC OF BELARUS

Tomasz Dorozynski

IMPORTANCE OF INSTITUTIONS FOR LOCATION CHOICES MADE BY COMPANIES WITH FOREIGN CAPITAL ...... 156 Ineta Lakstigala, Signe Balina

THE DEMAND OF PUBLIC ADMINISTRATION MANAGEMENT'S STAFF COMPETENCES IN THE FUTURE .......... 157

Magdalena Myszkowska

HOW TO IMPROVE THE FUNCTIONING OF THE EU SINGLE MARKET FOR SERVICES

Inese Pelsa, Signe Balina

ELECTRONIC PROCUREMENT SYSTEM - INSTRUMENT FOR IMPLEMENTING GREEN PUBLIC PROCUREMENT:

ANALYSIS OF THE LATVIA'S EXPERIENCE

Linda Rinkule

CHALLENGES IN PROPER FUNCTIONING OF INTERNAL MARKET - NON-FOOD PRODUCT MARKET

PERSPECTIVE

Evija Rusite, Biruta Sloka

IS IT POSSIBLE TO RISE THE POSITION OF HIGHER EDUCATION INSTITUTIONS IN RANKINGS ...

Svetlana Saksonova, Tatiana Papiashvili

SMALL BUSINESS IN A SMALL COUNTRY AND THE ROLE OF GOVERNMENT (THE CASE OF GEORGIA)

Samanta Savickaite

PERSONALISATION - AN INNOVATIVE APPROACH TO HEALTHCARE SERVICE DELIVERY IN WELFARE

ECONOMICS

Janusz Swierkocki

EFFECTS OF SPECIAL ECONOMIC ZONES POLICY IN POLAND - A SURVEY OF EMPIRICAL STUDIES

Kateryna Tiulkina

REGIONAL DEVELOPMENT WITH CONSIDERING ECOLOGICAL FACTORS 
$12 \begin{aligned} & \text { UNIIEESIIT OF LATIIA } \\ & \text { FACULYT OF BUSINESS, } \\ & \text { MANAGEMENT } \\ & \text { AND ECONOMICS }\end{aligned}$

Evgeniya Tonkova, Dancho Petrov, Sevdalina Hristova

INVESTMENT IN HIGH TECHNOLOGIES AND ITS ROLE FOR ENHANCING THE COMPETITIVENESS OF THE NATIONAL ECONOMY

Karlis Vilerts

SUITABILITY OF THE EXPENDITURE BENCHMARK: THE CASE OF LATVIA 


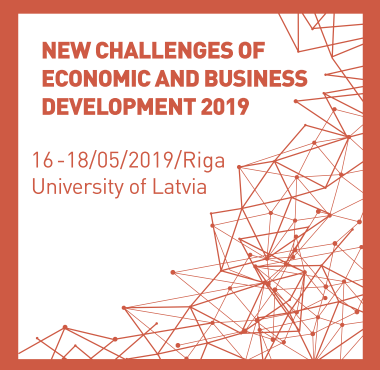

\section{Contemporary \\ Management and Business \\ Innovations}

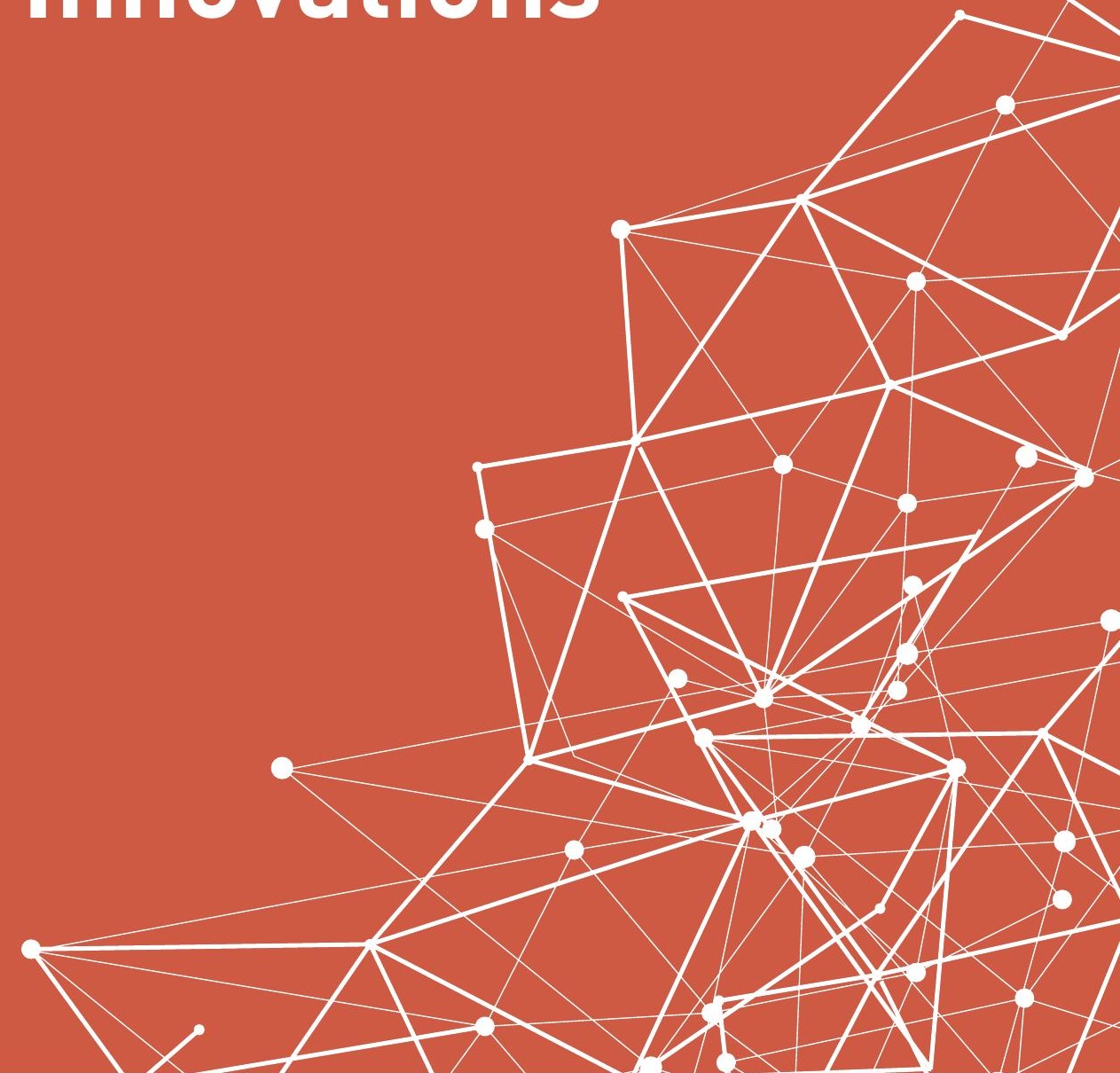




\title{
CHALLENGES OF ERGONOMICS IN CONTEMPORARY BUSINESS ENVIRONMENT
}

\author{
Kristine Bokse, University of Latvia \\ Henrijs Kalkis, University of Latvia \\ Zenija Roja, University of Latvia
}

\section{Key words: ergonomics, business, work environment, cognitive factors JEL code: $M 19$}

Nowadays, the business environment in Latvia, as elsewhere in other countries, is dramatically changing and influenced by demographic challenges - aging workforce, the high pace of technological changes, economic globalization. Improving and modernizing jobs also increases the pace of work. This rapid technological development can have an impact on the quality of life of employees, productivity and quality of production. One of the main conditions for sustainable development of an enterprise is creation of qualitative work environment, emphasizing human centered approach and implementing ergonomics in business operations. Thereby work in safe, healthy and ergonomically favorable work conditions is not only human but also economic necessity.

The aim of research is to discover ergonomics development and its challenges in contemporary business environment, based on literature review.

Research is based on monographic, logic constructive, analytical and comparison methods utilization to systemize and analyze latest literature on Ergonomics and contemporary business environment.

To replace work of humans already there are used today robots, systems, programs and algorithms. However, the role of human and human factors in the work process will only increase as cognitive factors will be more important in the future. Today in business environment in the center is thinking human. It means that Employees must be able to predict, dare, act today to be ready for the future. The twenty-first century employee has new challenge and competence - uncertainty tolerance. Hence one of the possibilities for improving business efficiency is ergonomics - a scientific discipline that explores the interactions between human and other elements of the system and helps to improve human well-being and the functioning of other systems in order to improve human well-being and the overall performance of the work system through the theory, principles, data and methods.

It should be noted that many organizations in the near future will take care of the work environment in accordance with the requirements of the standard ISO 450001 "Occupational health and safety management systems", in which importance is focused to the quality of a safe working environment, incl. ergonomic requirements. Hence, ergonomics will play a key role to provide competitive work environment risk assessment, eliminate errors in work process, prevent injuries and accidents at work, adapting work requirements to the physical and mental capabilities of workers in today's business environment.

Available literature on contemporary ergonomics and its importance in the business environment shows that ergonomic approach can play a crucial role in improving work productivity, product quality and in preventing accidents and injuries. Such approach leads to establishment of competitive business environment. 


\section{OBJECTIVES OF VIRTUAL SYSTEM SUPPLIERS - A CASE STUDY}

\section{Norbert G. Brink, University of Latvia}

Key words: virtual system supplier, virtual corporation, small and medium-sized suppliers, objectives, goals

JEL code: A10, L14, L21, P13

In the last four decades, the industry has changed significantly. While there has been a reduction in the life cycles of both products and technologies, the complexity inherent in industrial production has grown. The process of globalization brings many new challenges. Especially the entire automotive industry is dominated by a few but very large system suppliers. Small and medium-sized suppliers are under pressure to change. Basic strategy changes and new organizational models are required. One possibility is the network-like collaboration of various companies as a virtual system supplier (hereinafter called "VISYSUP").

The goals that the individual companies pursue can be quite different. Based on a complex literature research possible targets could be worked out. A case study and a questionnaire survey are used to determine which goals are really important to the participants and which are not. In addition, the results are subjected to a factor analysis in order to discover collective terms for the goals. The Kaiser-Meyer-Olkin criterion or measure of sampling adequacy (MSA) is used to test the suitability of the goals for the application of the factor analysis.

From the goals elaborated in the case study and their realization can be deduced among other things hints for the strategic decision to establish a VISYSUP. Through the joint production of products that cannot be produced on their own, VISYSUPs seem to increase their knowhow, increase customer orientation and satisfaction, and implement innovations faster. A cost reduction, however, is hardly achieved by this organizational form. 


\section{RETAILERS AND DECLINING POPULATION IN LATVIA: BUSINESS TENDENCIES AND DECISIONS}

\section{Martins Danusevics, University of Latvia}

Key words: retailing, demographics, saturation, concentration

JEL code: C01, C22, D80

The last two decades in Latvian retail market have seen a bit paradoxical development. On one hand the population has steadily declined, with an especially significant decline after Latvia became member of the EU and after the economic turmoil around 2009. On the second hand, the retail market has grown steadily and seems to skill keep on growing. New chains are expanding in Latvia, turnover is increasing, and new stores are opened on a yearly basis.

The aim of the paper is to understand the tendencies of the retail market in Latvia and the factors influencing its further growth, as well as possible limitation to growth. Author analyses these two tendencies and how the declining population can sustain the growing retail market. Research is based on several methods. Market trend analysis using trend models is used to extrapolate the main indicators of the sector. Market saturation is estimated for a projection of possible level of development that can be obtained at current tendencies using extrapolation models with an upper bound. Concentration comparison is done using HHI and CR methods both in time and by comparing it to neighbouring countries, since other Baltic states are in a similar situation. Evaluation of approaches used by retailing companies is done to understand, how the retail chains are making their decisions in the uncertainty of further business opportunities. A projection for following years shows a continuing growth of retailing market albeit with an increased level of concentration and a steady move from small to large store formats. 


\section{ECONOMIC ANALYSIS IN LEGAL ARGUMENTATION OF UNFAIR COMMERCIAL PRACTICE}

\section{Zanda Davida, University of Latvia}

Key words: economic analysis, consumer, unfair commercial practice, limitation period JEL code: D11, D18, 030

In recent years, the question of the applicability of the three-year limitation period (laid down in Article 406 of the Commercial Law of Latvia) to the compulsory land lease relationship between consumer and merchant has been substantially raised in the legal and economic environment of Latvia. The discussion between law scientists about the resolution of the issue is controversial and sharp because the solution will have a significant impact on Latvia's future economic, legal and social development. Considering the legal discourse and ambiguity of the application of the limitation period, as well as the significance of the predicted economic impact in Latvian society and sustainable development of the state, researchers and appliers of law enforcers (including the court) in the process of dispute solving must be considered the principles of fairness and proportionality. Estimation of these principles should also include the use of economic considerations and economic analysis. The conclusions of economic analysis should be a significant argument in the legal settlement of the dispute. So far, there is not much developed legal and economic science cooperation in resolving such disputes in Latvia. It has often led to unfair and disruptive legal solutions to the Latvian economy and society.

The aim of the research is to analyse the place of economic considerations in legal argumentation in the light of a case of unfair commercial practice in Latvia. To reach the aim, system analysis, comparison, historical, case study, forecasting, and scientific publications research methods were carried out.

After summarizing findings of the study, it was concluded that the result of application and understanding of limitation period framework will have a significant impact on the successful economic development, the favourable business environment in Latvia and public loyalty to the state. It is important for the appliers of law to choose the fairest and most proportionate solution to this dispute considering all the circumstances. Therefore, the main conclusion is drawn that in the legal disputes, which is significant for public and where the law does not give a clear answer the appliers of law must particular evaluate necessary of using economic analysis of law and if it is needed - must use it.

The research results are applicable for modernization of understanding and application of normative acts and promotion of cooperation between law and economic sciences. The theses of his study have the potential for future research. 


\title{
A FIRM'S ORGANIZATIONAL INNOVATION AND ORGANIZATIONAL LEARNING
}

\section{ABILITIES}

\author{
Igor Dukeov, Lappeenranta University of Technology, Finland \\ Madara Apsalone, University of Latvia \\ Ilona Baumane-Vitolina, University of Latvia \\ Jukka-Pekka Bergman, Lappeenranta University of Technology, Finland \\ Erika Sumilo, University of Latvia
}

\begin{abstract}
Key words: innovation, organizational innovation, organizational learning, knowledge management, organizational culture
\end{abstract}

JEL code: $D 83, O 31$

Many recent studies are dedicated to the problem of innovation activity of a firm as a mean of improving its overall performance. Various kinds of innovation activities in a firm usually are closely interrelated with each other. While the majority of studies focus on technological - product and process - innovation, the investigation of non-technological - marketing and organizational - innovation (ORI), has increasingly attracted the interest of researchers during the last decade. Organizational culture and organizational learning are important drivers of such innovation. For instance, a collaborative culture, trust and open-mindedness encourage new initiatives and ideas, while learning helps not just to improve skillsets and abilities of individual employees, but can also greatly contribute to strategic knowledge management and building a resilient, innovative organization.

This study examines the relationship between a firm's organizational learning ability and its organizational innovation performance. The authors consider such factors as Learning Intention - seeing learning as a key investment and organizational commitment to it, and Openness - open-mindedness and organizational culture open to new ideas and worldviews. This study contributes to the theory of ORI by finding the answer to the question what impact these factors could have on ORI development in a firm.

The findings are based on a quantitative analysis of more than 150 small and medium-sized enterprises surveyed in Russia and Latvia. The survey questions measuring ORI performance were developed in line with the widely used definition introduced in the OECD - Eurostat Oslo Manual. The scales for organizational learning were adopted from the previous studies elaborated this area of a firm activity. The survey compared a firm's innovation performance to that of its closest competitors.

This research demonstrates that some of the elements of organizational learning positively influence ORI activity. The results also suggest that Latvian companies differ from Russian ones in terms of their organizational learning intention. 


\section{SYSTEMATIC MAPPING OF ECONOMICS AND MANAGEMENT LITERATURE ON BLOCKCHAIN APPLICATION IN ORGANIZATIONS}

\section{Viktorija Janaviciene, Vilnius University}

\section{Vladislav V. Fomin, Vilnius University}

Key words: literature mapping, blockchain application, economics and management studies JEL code: $O 32$

The relationship between knowledge management and innovation has been one of the most explored topics in management studies for many years. The introduction of computers and related digital technologies has been changing the way knowledge is managed in organizations, but digital innovation itself was imposing new requirements on what knowledge organization must possess in order to innovate and stay modern. During the last decade, a number of authors were calling for re-visiting innovation and management theories in the light of the paradigmatic changes in processes leading to the creation and adoption of new digital technologies in the enterprise. Blockchain technologies have recently emerged as paradigm-breaking technologies, thus potentially requiring novel skills and knowledge from the adopting or innovating company.

As blockchain is still in the introductory stage of its life cycle, skillset and organizational knowledge needed for implementation and development of blockchain innovations, has not been categorized nor widely explored yet. The goal of our research is to conduct exploratory literature review in the field of organizational management and economics in order to map the frequencies of topics related to blockchain application in organizations.

Obtained results will become the stepping stone towards a larger research aimed at exploring the relationship between the use of blockchain technology and organizational knowledge management process.

Obtained findings will also help innovation-oriented organizations to improve knowledge process and understand the direction in which changes in knowledge management practices are needed in the context of blockchain-related product innovation. 


\section{TAX POTENTIAL VS BUDGET REVENUE POTENTIAL}

\section{Aina Joppe, University of Latvia \\ Ilze Sproge, University College of Economics and Culture}

Key words: taxation, Latvia, tax potential, budget revenue, shadow economy

JEL code: $H 2, H 3, P 52$

The major Latvian tax legislation enacted in December 2017 not only invites raise up personal income tax and reduce corporate tax income in government budget, at a time when the nation will need more revenue for retirement, health costs, and other factors which will increase government spending.

Yet the nation is facing long-term fiscal challenges that will require more revenue, not less. The law therefore weakens the tax system's ability to deliver on its core responsibility: raising sufficient revenue to adequately finance critical national needs and avoid spiraling debt and interest burdens.

There is no need to bring an already serious tax burden if the country's share of the shadow economy represents $24.7 \%$ of GDP (Friedrich Schneider of the European Union (EU) informal economy study)

The aim of the research is to display that not only with tax increases can increase budget revenue.

Research methods used in this research: Literature review on tax revenue and efficiency, empirical analysis of data.

The Paper analysis suggests that reducing complexity of the tax system, and adopting tax measures policy and administrative - to incentivize formal payments for business transactions through banking channels, including electronic payments can prove useful in reducing informality. In addition, using information technology solutions to improve tax enforcement against shadow economy transactions, particularly measures to plug tax evasion directly related to transactions with the shadow economy, would be most effective. 


\section{THE PERSPECTIVES OF ORGANIC AGRICULTURE IN RUSSIA AND ITS CONTRIBUTION TO SUSTAINABLE DEVELOPMENT. COMPARISON WITH THE WORLD PRACTICE}

\section{Nadezda Kanygina, Institute for complex strategic studies \\ Tatiana Solovey, Saint-Petersburg State University}

Key words: organic agriculture; farming, CSR; sustainable development

JEL code: $013, Q 10$

Recent years agriculture has been considered as one of the most actively developing sector of economy in Russia but there are some niches that are not developed sofar. For example organic farming is promising to be a very perspective project that would positively contribute to sustainable development of Russian economy. The aim of our work is to study the prerequisites and preparedness of Russia to implementation of organic farming on its territory and investigate the advantages and disadvantages of transition from conventional to organic agriculture in Russia.

The first part of the research work is devoted to description and analysis of current state of agricultural companies in Russia. In addition a comparative analysis of the results of the all-Russian Agricultural Census for years 2006 and 2016 was performed that allowed to highlight most important changes and tendencies in Russian agriculture over the last decade. The fact is that Russia currently possesses great reserves of longfallow lands that are perfectly suited for organic farming, besides the development of this sector could positively influence the employment in rural areas. However according to the current statistics there are very few organic farms in Russia, usually it's considered as something exotic and its contribution to the regional gross production is negligible.

At the next stage the main laws in agriculture sector are examined, including the Federal law about organic products (№ 280 of 3th August 2018) that will come into force in January 2020 and interstate standard of organic production, production regulations, processing, labelling and implementation (GOST 33980-2016). In 2 years the standardization system will be more severe. We're trying to picture how such farming corporations, private farms and individual entrepreneurs will survive in new conditions. In order to create the more complete overview we analyze the nonfinancial reports of the biggest agricultural companies in Russia. We have selected four largest companies according to the ranking of the leading magazine in the sphere of agriculture in Russia “Agroinvestor” ("Leaders of Russian arable land. Top 22 agricultural holdings by land in processing"). On the basis of the above standards we have made 20 evaluation criteria. We used the method of content analysis, having studied the materials of the official website of companies, articles in specialized journals and reporting of these companies. 


\section{INDICATORS FOR MEASURING TRANSFORMATIONAL AND TRANSACTIONAL LEADERSHIP}

\section{Rene Lauck, University of Latvia}

Key words: transformational leadership, transactional leadership, content analysis, indicators JEL code: 030 , 015

Leadership has become an essential research field in management science. Research shows that leadership is a complex phenomenon, which has led to a substantial amount of studies in the past to improve the understanding of this research field. Literature and empirical studies addressing leadership reveal that research is still fragmented and studies are not conducted in a uniform framework. This leads to the fact that research results are partly comparable due to different definitions and interpretations.

In recent years, transformational and transactional leadership gained attention by several scholars. In brief, transformational leadership stimulates and enhances the performance of the followers. In this respect, the leader transforms and motives the subordinates to achieve higher organizational goals by embodying a role model. In addition, the leader becomes a mentor by considering the individual needs and wants. Consequently, this fosters creativity and individuals consider their work as essential. In contrast, transactional leadership conveys clear goals and structures which are based on an exchange model. Therefore, the employees are obliged to follow the instructions to achieve the company goals. Moreover, the subordinates do not have the allowance to make own decisions. In case of deviations, the superior takes corrective measures.

The aim of this paper is to identify indicators for measuring transformational and transactional leadership in order to offer a uniform research framework.

The author performs a content analysis to evaluate the current state of science to identify indicators for measuring transformational and transactional leadership. To gain a holistic view, the author uses scientific books and databases such as Emerald, Springer Link, EBSCO, Science Direct, Sage Journals, JSTOR and Taylor and Francis.

The preliminary research results show that numerous indicators describe transformational and transactional leadership, which contribute to the theoretical and practical implications in leadership research. 


\section{PUBLIC ADMINISTRATION IN LATVIA. OPPORTUNITIES OF DIGITAL DEMOCRACY}

\section{Eduards Lielpeters, University of Latvia}

Key words: decision-making process, digital democracy, public administration, political engagement, social media

JEL code: $L 86, M 15,031$

Activities that are done by public administration must provide and constantly improve comfortable and supportive living conditions for citizens of the country. To ensure that decisions made by the public administration are really meeting the needs of citizens it is advisable to engage citizens in the decision-making process. Latvian public administration provides such possibilities but usually citizens must search for this information in institution's home page or become a member of the non-governmental organisation, that are acting as representatives of citizens in different advisory boards and committees. Thus, in reality, only a small part of citizens are engaging in the decision-making process. Since the development of web 2.0 academia is looking to the social media and other tools of digital democracy as a solution for this problem hoping that it could be the way to encourage citizens ' political engagement. The aim of the research is to analyse if in Latvia social media and other tools of digital democracy can be used by the public administration to foster political engagement and what are the limits and obstacles that are influencing Latvian public administration to use tools that 21 st century provides.

In the study publications and academic literature about the development of digital democracy and the use of social media for political engagement are analysed. As well as, the decision-making process in the Latvian public administration and statistical data about the use of internet and social media in Latvia are collected and evaluated. Results of the study suggest that there are many international examples from which Latvian public administration can learn how to use social media and tools of digital democracy for political engagement. Nevertheless, there are also identified several common challenges that public administrations in other countries are facing when starting to develop their digital democracy strategies. It is concluded, that learning from common challenges and adopting best practices from the foreign experience could be relatively easy for public administration in Latvia, considering that large part of citizens are reachable online, institutions already are using social media for one-way communication and there are several pilot projects for other tools of digital democracy as well.

Results of the research can be used practically by Latvian public administration to develop more clever digital democracy strategies. For the academia this research is providing a useful milestone for further theoretical studies how social media and tools of digital democracy can be used for political engagement in Latvia as this Latvian situation, for now, is not explored sufficiently. 


\section{MEASUREMENT OF ORGANIZATIONAL INNOVATION - IN SEARCH FOR THEORETICAL FRAMEWORK}

\section{Jelena Luca, University of Latvia}

Key words: organizational innovation, measurement of organizational innovation, theoretical framework, organizational innovation definitions

JEL code: $O 3$

In an increasingly globalised economy organizational innovations are considered to be highly important factor for the company to develop and be competitive. Organizational innovations take place in companies in different fields and parts of the world but to perform organizational innovations in the company it is necessary to identify the right indicators. Accordingly, a number of recent papers in the literature for managers and scientists it is a challenge to search the perfect metric as organizational innovation measurement is a very difficult task to perform and they have different forms what is the main problem in recent studies. Recent studies have pointed out several points necessary for the analysis - data usable not only for analysis itself but for the policy making as well; and measurement framework to capture the organizational innovations.

This paper combines different definitions of organizational innovations applicable with the system approach, looking at different metrics, coming to the conclusion that for development of effective innovation measurement it is needed to develop a conceptual framework for the statistical measurement. The purpose of this paper is to illustrate information that would help to understand the concept of organizational innovation and how it can be measured in different ways, in case different metrics are developed. This paper assesses developments in currently performed studies looking at measurement of organizational innovation based on recent issue of Oslo manual and studies in Europe to create theoretical framework for further studies. Results can be used for measuring organizational innovation more effectively as well as implementation of organizational innovations. 


\section{BUSINESS MODELS EMPLOYED IN ONLINE PLATFORMS: THE PERSPECTIVE OF LATVIA}

\section{Vadim Mantrov, University of Latvia}

Key words: online platform, business model, triangle structure, consumer, legal framework JEL code: $K 40, K 42, K 49$

Online platforms are recognised as one of business models which are used in economic activities for enhancing sale of goods or provision of services. From the economic point of view, online platforms represent a separate and specific type of a business model allowing to maximise profits and lower expenses by sellers or service providers. From this point of view, an online platform may be based on a direct relationship or a triangle structure involving a platform operator, a consumer and a seller or a service provider. At the same time, use of business models should comply with existing legal framework, especially with consumer protection law.

The problem issue relates to legal boundaries of the use of business models embodied in internet platforms from the point of view of legal framework. That problem is already acknowledged in Latvia considering different court disputes in relation to assessment of business models upon which internet platforms in question are based.

The research aim relates to exploring business models employed in online platforms that are available for Latvian consumers (i.e. purely domestic internet platforms and international internet platforms) and boundaries of the use of these business models within legal framework in close conjunction with developments of Latvian court practice. The study is, however, limited to consumers only as non-consumers shall be researched separately. Main results of the study would relate to establishing business models employed in internet platforms available for Latvian consumers which do not comply with legal framework and elaborating general criteria that could allow to assess incompliance of business models to be used in internet platforms from the legal perspective. Implications of the study would relate both to economic and legal analysis of the use of internet platforms which are available for Latvian consumers and the boundaries of their use. These implications will be specifically reflected in conclusions that will be drawn in the result of the study.

Research methods to be used will be based on the methodology of economics and law mainly involving comparative, inductive and deductive, systematic and analytical scientific methods. 


\section{THE CONTROL OF TRANSACTIONS WITH DERIVATIVES IN THE NON-FINANCIAL ORGANIZATIONS IN THE REPUBLIC OF BELARUS}

\section{Ludmila Masko, Polotsk State University \\ Pavel Pankou, Polotsk State University}

Key words: derivatives, control procedures, hedging, risk

JEL code: $G 13$, M19

Nowadays derivatives as a risk management instruments can be the source of increased risk themselves. Non-financial institutions are more likely to use derivatives to hedge market risks rather than to engage in speculative strategies in order to profit from short-term changes in market variables, which priori implies an increased level of risk. Hedging with derivatives can be considered as a less risky activity than speculation, however we cannot say that it is absolutely risk-free. Unfair actions in the department of finance, errors in the development and implementation of the hedging strategy, counterparty defaults on derivatives - all these are potential losses for the company, which applies hedging. In order to eliminate or minimize the negative consequences, which may occur from the presence of derivatives in the portfolio of the organization, wellstructured control procedures are necessary. The aim of the study is to develop such control procedures. For this purpose general scientific research methods were used: analysis, synthesis, generalization, induction, deduction, observation. Methods of theoretical research: idealization, formalization, method of logical analysis, classification.

According to the results of the study, the factors that increase the risk of applying derivatives in nonfinancial organizations were identified. They are the following: specificity of derivatives, the risk of unfair actions of employees and contractors, low creditworthiness of counterparties, difficulties in reflecting derivatives in financial statements, etc. Taking into account the identified factors controlling procedures on transactions with derivatives for non-financial organizations of the Republic of Belarus was proposed. Those techniques will provide non-financial organizations confidence that non-core risks, associated with derivatives, are under the control of both responsible managers and senior management, which will convince investors in the reliability of investments in such organizations. 


\section{SOCIAL RESPONSIBILITY OF HIGHER EDUCATION INSTITUTIONS: YOUTH ATTITUDE}

\section{Jurgita Pauzuoliene, Klaipeda State College of Applied Sciences \\ Ilvija Pikturnaite, Klaipeda State College of Applied Sciences}

\section{Key words: higher education institutions, social responsibility, youth \\ JEL code: 12 , M14, J13}

The spread of corporate social responsibility philosophy and practice is observed for two decades. Corporate social responsibility (CSR) refers to companies taking responsibility for their impact on society. The European Commission believes that CSR is important for the sustainability, competitiveness, and innovation of EU enterprises and the EU economy. Global, European and national institutions struggle to accelerate countries and companies involvement in Global compact agreement, sustainable development goals, and other social responsibility activities. While companies' reports present the practice and examples of social responsibility implementation scientists scrutinize the peculiarities of this philosophy. Studies that are conducted in the context of analysis of corporate social responsibility most often address the notion of corporate social responsibility itself, ethical principles and their importance for the society, employees, the impact on the competitiveness of an organization, brand, innovation etc. Notwithstanding that, institutions of higher education are greatly affecting the diffusion of progressive theories and philosophies there are no surveys of social responsibility implementation in higher education institutions.

The aim of the research is to investigate the attitude of youth to corporate social responsibility of higher education institutions. In the article we raise problematic questions: How do young people understand social responsibility? How does higher education institutions implement socially responsible initiatives in their activities? What is the main benefit of a social responsible? Are higher education institutions implementing enough socially responsible activity?

Analysis of research literature sources, systematization, synthesis, generalization, and comparison were applied it the theoretical level. Quantitative research and data processing methods were applied in the empirical research. The collected empirical data were processed using the SPSS (Statistical Package for the Social Sciences) programme. In the data processing, descriptive statistics was used, such as percentiles, mean, mode and standard deviation. The data was also processed by one-factorial dispersal analysis (ANOVA). To assess the reliability, or internal consistency, of a set of scale, Cronbach's alpha coefficient was used.

The survey was conducted in higher education institutions of Lithuania, in the survey participate more than 300 students. The results of the research revealed that youth perceive social responsibility as charitable or voluntary activities. According to respondents, socially responsible organizations most take care of the environment and less attention is given to social problems. More than $50 \%$ of respondents could call themselves socially responsible citizens, contributing to environmental sustainability and other issues that are relevant to society.

Summarizing the results of the research we provided the conclusions and recommendations for higher education institutions. 


\title{
THE MODEL FOR FORMATION STRATEGIC DECISIONS OF ORGANIZATION'S KNOWLEDGE POTENTIAL MANAGEMENT
}

\author{
Jurgita Raudeliuniene, Vilnius Gediminas Technical University
}

\begin{abstract}
Key words: knowledge management, knowledge management potential, strategic decisions, formation, model
\end{abstract}

JEL code: $M 10, D 83$

In the context of globalization and transformations, efficient knowledge potential management is a powerful tool for increasing the efficiency of organizations. Knowledge potential is defined as a whole of organization's resources and market opportunities, its complex evaluation and efficient management create preconditions for satisfying changing customers' needs, creating mutual value, uniqueness, and leadership in the marketplace. Most scientists and practitioners emphasize that the crucial components of an organization's knowledge potential should be integrated and balanced in the assessment of knowledge management, because in the complexity and uncertainty of knowledge management environment it is difficult to forecast and anticipate the results the organization is trying to achieve. As a consequence of this, the factors, approaches, and methods of the assessment of the factors that influence the external and internal knowledge potential are evaluated controversially. Different approaches that analyze the aspects of knowledge potential management and assessment interpret and evaluate organization's knowledge potential differently. In this research these problems are analyzed by integrating contemporary management approaches and theories, different attitudes of scientists towards external and internal factors that influence knowledge potential, and their evaluation aspects. The aim of this research is to propose a model for formation of strategic decisions of organization's knowledge potential management which includes a multiple criteria system. The proposed model for formation strategic decisions of organization's knowledge potential management is characterized by a complex evaluation, it simplifies the process of the formation strategic decisions, creates preconditions for identifying problematic areas and opportunities of organization's knowledge potential management, choosing a knowledge strategy, and forming a subset of strategic decisions for eliminating the identified problematic areas. To create the model of formation strategic decisions of organization's knowledge potential management, the principles of the balanced scorecard model application, multiple criteria assessment methods, and the results of an empirical research conducted by the author linked to the formation of organization's strategic decisions were integrated. The novelty of this research is linked to the structured results of the empirical study which created preconditions for: determining the definition of organization's knowledge potential, forming the conceptual model for strategic decisions formation of organization's knowledge potential management, compiling a multiple criteria system, and, based on this, selecting the knowledge strategy, and forming the subset of the strategic decisions of organization's knowledge potential management for further evaluation. 


\section{ACCELERATORS - CATEGORIZING A NEW FORM OF COOPERATION}

\section{Maximilian Schausberger, University of Latvia}

Key words: open innovation, startup accelerator programs

JEL code: $M 13$

Accelerators have helped over 6,000 start-ups, such as Airbnb and Dropbox, by providing mentorship and easy access to funding throughout their earliest stages. Those ventures went on to raise more than $\$ 26 \mathrm{bn}$ in follow-on investments (Christiansen 2017). As more and more corporates, universities, venture capitalists and others are joining the club and initiating their own accelerators in different ways and with different goals, a variety of different configuration options of accelerators exist on the market. While previous entrepreneurship literature (Cohen, Hochberg 2014; Regmi et al. 2015; Weiblen, Chesbrough 2015; Kohler 2016) is mostly focused on accelerators backed by venture capital funds and their role in enhancing start-up success, research on more recent forms of accelerators backed by corporates or governmental institutions is recent and lacks comprehensive data sources and a consistent theoretical lens to study the phenomenon. Therefore, this paper aims at establishing a new categorization of start-up accelerator programs.

The approach to develop a model with a new categorization of accelerators including configurational factors is based on a literature review of open innovation and accelerator theories as well as the classification of accelerators from studies of other authors. Hence, papers published on accelerators and open innovation on Web of Science - Social Science Citation Index, Emerald and Elsevier's Scopus - are reviewed and analysed. Thereby this paper analyses the literature and provides an overview of the different points of view adopted in conceptualizing open innovation in the accelerator domain.

By summarizing the findings, the paper results in a new categorization framework for accelerator programs. This framework will enable further research on the success of the new forms of accelerators. Governments, venture capitalists and corporates can use this knowledge to provide framework conditions for new companies so that they can develop. They can frame their corporate innovation activities according to the findings of this research by choosing from a clearly categorized list of accelerator types according to their goals. Finally, start-ups gain a framework of accelerator types, which they could participate in to potentially increase their future business success. 


\section{INTERIM MANAGERS IN THE CFO ROLE IN MEDIUM-SIZED COMPANIES: A PILOT STUDY ON INFLUENTIAL FACTORS}

\section{Ralf Schechowiz, University of Latvia}

Keywords: interim management, CFO, influential factors, pilot study

JEL code: $M 12$

Purpose - The ideal chief financial officer (CFO), a senior executive with responsibility for the financial affairs of a company or other institution, is either seen as a glorified "bean counter" or as a Yeti. Expectations are high and seem to be overwhelming. The CFO should manage an efficient finance organization and give business insights to manage performance and strategy. Those heroes are given the name "Value Integrators" or "Performance Accelerators" as they outperform in optimize performance, provide calculable insights, cover risk management and support rational decision-making. Working as an Interim CFO inside a medium-sized company will create much pressure as it is "Management with a constrained duration, in which a manager is appointed from outside the organization to perform an assignment for a limited period, after which the manager will leave the organization." This study aims to provide Interim Managers in CFO roles in medium-sized businesses ideas how to contribute to the success of a company within the limited time they have their assignment. This paper covers the conceptual approach to research and assesses whether the research is feasible by conducting a pilot study with interim managers of 45 countries.

Design/methodology/approach - A literature review looks into Interim Management, the CFO role in medium-sized businesses, and contributions a CFO can make. Performance theories of successful managers are reflected. The process of the pilot study is shown. An innovative approach to getting access information to such a specific target group is described.

Findings - Even following Dillman's Tailored Design Method does not automatically lead to high response rates. The pilot study revealed 14 complete answers. The reliability of the constructs and scales was tested. Everything fitted quite well, except scales to measure personality. Neuroticism and tolerance showed unacceptable Cronbach's-Alpha-values. Cause probably lies in the small sample size.

Research limitations/implications - Future research should consider interim managers in different countries, incentives to increase response rates and to use multipliers to increase the reach.

Originality/value - The paper has value for researchers of Interim Management and clarifies the success factors of an interim $\mathrm{CFO}$ role. 


\section{DO WE NEED TEAMWORK? NEW CHALLENGE FOR ORGANIZATIONS}

\section{Ligita Simanskiene, Klaipeda University}

\section{Key words: team, organization, methods}

JEL code: $L 22$, M12

Nowadays, under the conditions of globalization, organizations are trying to survive or to take bigger market; however, the question of teamwork remains topical. People still need to be a part of a smaller group (team), so to say - organizations need teams. Teamwork is a set of values that encourage behaviours such as listening and responding constructively to views expressed by others, giving others the benefit of the doubt, providing support to those in need and recognizing the interest and achievements of others. To achieve good teamwork is necessary to have methods (techniques) that lead to a goal. The research problem comes out of observations that there is insufficient understanding of the conception of teamwork in organizations, still there are lack of knowledge what team methods to use. Thus the questions arise: How can we define teamwork in nowadys organizations? What team work methods we are using in organizations? What is a new challenge arise? The aim of the research is to define the concept of teamwork and used methods in changing world.

The research methods included analysis, comparison, synthesis, summarization and empirical research using qualitative interview. Respondents for this research were chosen using convenience sampling: wellknown business people and personal contacts were invited to interviews. All the interviews were conducted orally using a set of seven questions. The sequencing of the questions was flexible allowing to follow up with the responses in order to get specific indepth answers to each question. Interviews with managers and emploeeys were conducted from 25 to 45 minutes. This is longnitudial research and take over 300 organizations from 2010 till 2018 years. 


\title{
BASIC COMPONENTS FOR SUCCESSFUL BUSINESS PERFORMANCE: IN SEARCH FOR A MODELING OF THEORETICAL FRAMEWORK
}

\author{
Armands Svikis, University of Latvia \\ Andrejs Cekuls, University of Latvia
}

Key words: business performance, efficiency, competitiveness

JEL code: M10, M19

Whenever a business enterprise is established, there is a certain design of the basic common components that determines business successful performance. The understanding and proper development of these most significant components give an opportunity to become more efficient and more flexible in terms of competition and future growth. In addition, the theoretical combination of these elements may form a business model and the essence of this model is in defining the manner by which the enterprise delivers higher shareholders value of the enterprise by optimization and focused usage of resources.

The purpose of this paper is to propose literature review for understanding the basic common components by examining the current researches done by scholars to clarify most common basic components determine business performance and to create new theoretical and limited framework/ business model for further empiric analysis. The research results may help as an incentive to companies more clearly focus their activities to achieve better outcome from used resources which might results to become or stay competitive. 


\title{
FACTORS OF THE INNOVATION ECOSYSTEM BY EXAMPLE OF LATVIAN TECHNOLOGICAL STARTUP
}

\author{
Inesa Voroncuka, University of Latvia \\ Inese Ratanova, University of Latvia
}

Key words: commercialization of technologies, innovation, innovation ecosystem, start-up JEL code: 030, M10, M13

An innovative environment boosts technological innovativeness through the implementation of new technologies. At the same time, an innovative environment draws from technological innovation knowledge, which stimulates its development. The most innovative economies exemplify the strong link between the economy and science. The leading role of start-ups in EU economy is determined by a range of advantages originating from dynamic process of formation thereof, namely producing large number of new ideas, innovative projects diversification, creation of new jobs. Innovation takes place within an ecosystem of multiple factors. Any factor missing from the innovation ecosystem is the problem for new ideas from being generated or evolving into viable commercial products. At the same time, it should be noted, that a key indicator of EU innovation leaders is the effective commercialization of their technological innovations.

The purpose of this paper is to analyze the set of factors and conditions conducive to the successful development of innovative entrepreneurship environment and technological start-ups in Latvia. Tasks of the study are to define the set of factors and conditions of innovative entrepreneurship environment and the determinants, that have significant impact to the growing of number technological start-ups in Latvia. The methodological basis for the article is made up of the laws, regulations and guidelines of the Republic of Latvia, analysis of literature supplemented by national and international reports, scientific publications of foreign authors, also research carried out by the authors using expert interview and a survey of entrepreneurs.

Results of researches show that the main determinants of the innovation ecosystem are administrative requirements, government supported developments, financial resources, academic-industry collaborations, research and development, commercialization, market dynamics, entrepreneurial culture. Moreover, key feature of start-ups is that these are indicators of favorable innovative environment, since fast increase of startups number in a country is an indicator in process of forming and development of ecosystem of innovative entrepreneurship. 


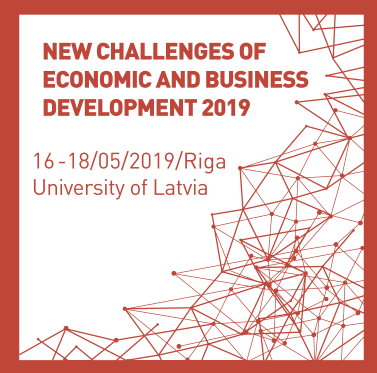

\section{Data Challenges}

\section{in Business and}

\section{Economics}

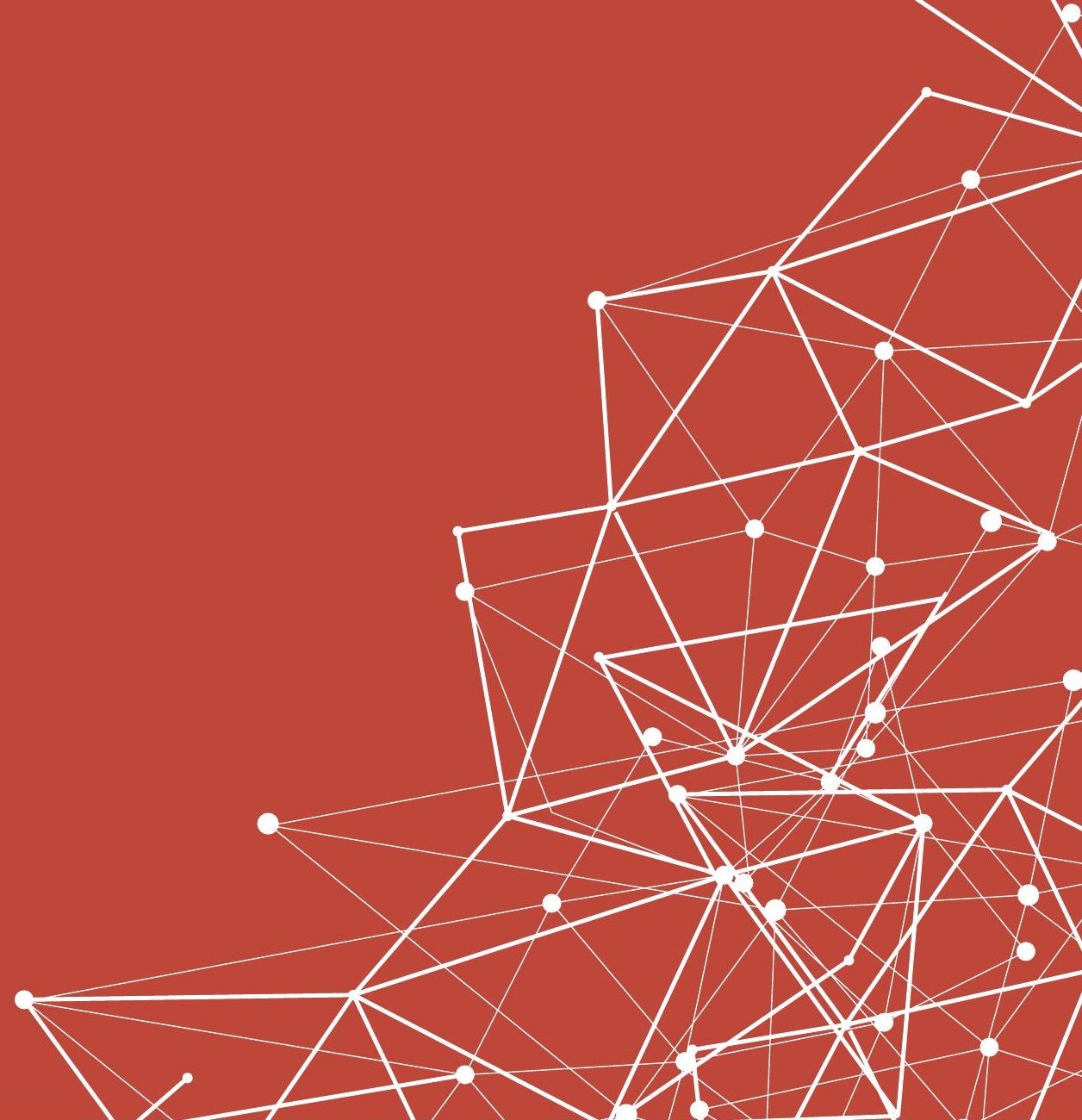





\title{
HOW DO SELECTED RECENT ECONOMIC AND SOCIAL DEVELOPMENT INDICATORS INFLUENCE EMPLOYMENT RATES IN EUROPEAN UNION COUNTRIES
}

\author{
Ksenija Dumicic, University of Zagreb Faculty of Economics and Business \\ Berislav Zmuk, University of Zagreb Faculty of Economics and Business \\ Toni Milun, College for Applied Computer Engineering “Algebra”
}

Key words: adult participation in learning, dendrogram, digital skills, European Union, OLS regression modelling

JEL code: $C 21, D 83, E 24$

In this paper, the best-fitted trend and forecasting models for Employment rate for EU-28 were estimated; the influence of four development indicators on this rate in EU-28 countries in 2017, using correlation and regression analysis, was enlightened; and finally, cluster analysis using all the variables for these countries was performed.

The cubic trend appeared to be the best-fitted model describing the Employment rate dynamics from 2001 to 2017, having the highest coefficient of determination. Easier to explain, the estimated linear trend, shows a yearly increase of 0.27 percentage points absolutely, whereas the estimated exponential trend, shows a relative yearly increase of 0.4 percentage points.

Employment rate correlates positively and weakly with Gross Domestic Product (GDP) per capita in Purchasing Power Standards (PPS) and Percentage of individuals using the internet for looking for a job, with correlations of 0.36 and 0.35 , respectively. It depends positively with Percentage of adults participating in learning, with correlation of 0.5 , and with Percentage of individuals having basic or above basic overall digital skills with correlation of 0.62. Based on OLS simple linear regression model for 27 countries in 2017, which was statistically significant with p-value of 0.0006, if Percentage of individuals having basic or above basic overall digital skills would increase by one percentage point, the regression value of Employment rate would increase by 0.26 percentage points, with regression coefficient of variation of $6.16 \%$.

Since the research hypotheses was that countries with similar Employment rates would gather within the same clusters, taking into account the remaining four development indicators, for testing this claim a hierarchical cluster analysis was performed. Since within certain (among four) clusters, a mixture of countries with both extremely positive and negative Employment rates were gathered, a research hypotheses was not proven, which might be explained by moderately weak to weak correlations. 


\section{INDICATORS FOR ARTIFICIAL INTELLIGENCE SUPPORTED DECISION MAKING}

\section{Norbert Nindl, University of Latvia}

Key words: artificial intelligence, decision making, content analyses, indicators JEL code: $031, D 70, D 80$

Decision making can be considered as a core part of management science and management practice. Research shows that decision making is a complex research field which has led to a substantial amount of studies for a deeper understanding. The famous representative Herbert Simon linked in his research Artificial Intelligence (AI) and decision making to describe dependencies of his framework of AI for understanding intuition in decision making.

In recent years AI reached a rapid momentum reflected by famous implementations with incredible results leading to amazement by the possibilities of cognitive computing on one hand and fear of machines replacing humans on the other hand. Artificial Intelligence that applies a broad band of techniques ranging from neural networks, genetic algorithms, speech and pattern recognition, to deep learning. Technologies to make business decisions or to generate key information to support business decision making. This rapid development of AI technologies gained attention to several scholars. Literature and empirical studies addressing the impact of AI to decision making reveal that research is still fragmented and studies are not conducted in a uniform framework. This leads to the fact that research results are partly comparable due to different definitions and interpretations.

The aim of this paper is to identify indicators for measuring AI supported decision making in order to offer a uniform research framework.

This paper reviews academic literature associated with "artificial intelligence" and "decision making" to evaluate the development and research trends to identify the indicators. Publications from the last two decades are analysed with bibliometric methods. The publications are from journals indexed in Science Citation Index Expanded, Social Science Citation Index and Arts \& Humanities Citation Index.

The preliminary research results show that numerous indicators describe AI supported decision making which contributes to the theoretical and practical implications in decision making research. 


\title{
SMART CONTRACTS FOR ENTREPRENEURIAL COLLABORATION IN LOGISTICS NETWORKS
}

\author{
Robert Philipp, Wismar University \\ Laima Gerlit, Wismar University \\ Gunnar Prause, TalTech University
}

Key words: entrepreneurial collaboration, smart contracts, block chain, logistics networks JEL code: $M 16,031,033$

Smart contracts target to reduce transaction costs including arbitration and enforcement costs by realising trackable and irreversible transactions by using block chain technology for distributed databases. But the role of smart contracts can go beyond cost reductions by facilitating entrepreneurial collaboration of crossorganizational business-processes and enabling trans-national networks of entrepreneurs and SMEs to enter into new business sectors which are currently still closed due to high entry barriers or to domination of big players.

The authors participate in several EU projects related to transnational entrepreneurship, regional development and service networks in the context of green logistics and sustainable supply chain management. Especially, the logistics sector is well-known for dominating global players that try to limit entrepreneurial activities of small companies by using closed organisational structures and dedicated IT systems. Nevertheless, scholars highlighted the growth potential of entrepreneurial activities in the area of logistics services in sustainable supply chain management and green transportation under new regulatory and organisational frame conditions based on collaborative structures of entrepreneurs and SMEs. The foundation and the organisational support for entrepreneurial collaborations in such logistics-related networks can be realised by the implementation of decentralized autonomous organizations based on block chain technology and smart contracting.

This paper discusses the research question how and to which extent smart contracting and block chain technology can facilitate the implementation of collaborative business structures for sustainable trans-national entrepreneurial activities in logistics networks. The research is based on expert interviews, surveys and case studies from several EU projects with a focus on the ongoing project "Connect2SmallPorts" which investigates the digitalisation of small and medium-sized ports in Southern Baltic Sea Region. The research results will showcase and assess the reduction potential of administration costs by using smart contracting in the case of ship calls. 


\title{
DIGITAL COMPETENCE RATING AND ECONOMIC DEVELOPMENT IN THE EU
}

\author{
Kristine Rozite, University of Latvia \\ Signe Balina, University of Latvia \\ Rita Freimane, University of Latvia
}

Key words: information and communication technologies, digital competence rating, economic development

JEL code: $\mathrm{C29}$, O30, $\mathrm{CO2}$

Diffusion of information and communication technologies (ICT) in different areas has accelerated the growth of the global economy. It has large impact to the business by transforming processes, creating new services, industries. ICT development requires new technologies and new approaches to innovate and integrate. The European Commission stated: "The Internet and digital technologies are transforming the lives we lead, the way we work - as individuals, in business, and in our communities as they become more integrated across all sectors of our economy and society". The access to high-speed digital infrastructures, skills of the effective usage of highly developed digital technologies represents the prerequisite productivity and the social inclusion in the digital economy.

Development of new technologies and applications demands respective skills and competences of the citizens. That also leads to problems related to measurement of the level of digitization of the economy. There are several institutions that evaluate digital competences. The Digital Economy and Society Index (DESI), developed by the European Commission, is a composite index that summarises relevant indicators on Europe's digital performance and tracks the evolution of EU member states in digital competitiveness.

The aim of the paper is an empirical verification of the assumption that ICT factors (measured by DESI components) affect national economic development. This study uses statistical and econometrical methods to examine the relationship between ICT factors, digital competence indicators and economic development in the EU through statistical evidence.

A panel data analysis confirmed significant linkage between ICT factors (infrastructure, competence, investment and trade size) and economic growth in the EU countries. Taking into consideration the digitalization trends, could be stated that there is still a huge potential for progress and growth. 


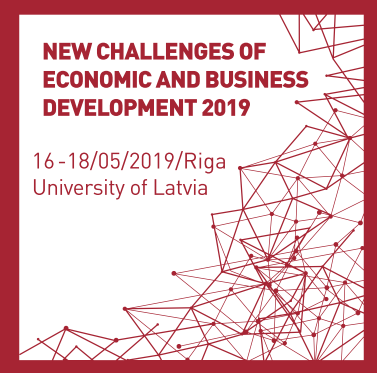

\section{Financial \\ Services, \\ Accounting and Finance}





\section{IS IT POSSIBLE TO ASSESS THE CORPORATE MARKET VALUE IN THE EMERGING MARKET?}

\section{Neli R. Abramishvili, Saint Petersburg State University \\ Nadezhda A. Lvova, Saint Petersburg State University \\ Natalia S. Voronova, Saint Petersburg State University}

Key words: investment assessment, investment value, market value, emerging market JEL code: $G 32$

Assessment of the corporate market value is required in many management decisions. In some cases, the need for such an assessment is predetermined by national legislation. Such cases may include the acquisition of shares by the company at the request of shareholders, the additional issue of shares, etc. However, in the emerging market, which is usually characterized by an increased level of information asymmetry, the ability to correctly estimate the market value is limited, even when it concerns public companies that implies the research problem.

Correspondingly, the research aim was to answer the question on the relevance of assessing the corporate market value in the emerging market. We also sought to show the unfoundedness of the traditional approach to assessing market value using computational models, which in the strict sense allow us to obtain the investment value. Since differences in assessment of market and investment value can be clearly shown with the example of publicly traded companies, the research methodology was as follows. The research was based on theoretic and applied methods including analysis, synthesis, analogy, and financial modelling. According to a business evaluation methodology, the investment value was determined by the method of discounted cash flows over a period of five years in retrospect (for a sample of Russian public companies, representing the largest industries in the stock market). For the same period, the market value of the companies was analysed, which was determined through the market capitalization. Main results and findings of the research concern the significant differences in the assessment of market and investment value. This showed the inconsistency of computational models for estimating market value in the emerging market.

Correspondingly, the main conclusions of the research are the following. In was proved that in assessing a business in the emerging market one should focus primarily on the standard of investment value. The corporate market value in the emerging market is a rather suppositive value, which should be used cautiously. At the same time, the investment value as a whole can be used in solving the same range of analytical tasks for which the market value is currently estimated. The revealed limitations in the assessment of the corporate market value should be suggested as one of the characteristic signs of the emerging market. The research contributes to the development of the theory and methodology for assessing the business value as well as partly to the current discussion about the content and defining features of the emerging market. The practical significance of the research, in our opinion, lies in the fact that the results obtained can be applied in the improvement of national standards for evaluation activities. 


\section{AUDIT PROCESS: PROFESSIONAL ETHICS AND INDEPENDENCE EFFECTIVE DESIGN - CASE STUDY IN LATVIA}

\section{Ieva Aizsila, University of Latvia}

Key words: audit; international auditing standards, audit process, auditor, international code of ethics for professional accountants

JEL code: M40, M42, M48

A significant part of audit process and overall strategy is the operation on the audit firms system of professional ethics and independence. The audit process in Latvia is regulated by national legislation (law On Audit Services) and international legislation (International auditing standards and International Code of Ethics for Professional Accountants). Currently the International Code of Ethics for Professional Accountants (the Code of Ethics) much attention has been paid to business ethics. No company manager can be protected from internal risks and external fraudsters, so it is useful to evaluate the importance of the Code of Ethics especial when the especially when auditors are required to consider the independence principle that is one of the five fundamental principles of the Code of Ethics.

The purpose of this paper is to analyse and understand how can auditor firm design and operate effectively with their commitment to apply the requirements set by the audit firm's ethics and quality control manual that are obligated by law On Audit Services and International auditing standards. When analyzing the information from financial statements the role of professional auditor has become especially important, as professionals in his profession, they are able to analyze and interpret both financial and non-financial data and can challenge suspicious information. It plays an important role in building an ethical organization culture and in risk prevention.

In this paper the following qualitative and quantitative methods of research are applied: the monographic method, descriptive statistics and graphical method. Are reviewed professional ethics and independence theories, each of them contains author comments and compartment with audit process and quality control manual.

Presents general considerations on the case study of commitment to apply the requirements set by the audit firm's ethics and quality control manual and allows to use in practice obtained results to increase the quality of implemented procedures. 


\section{DEVELOPING CORPORATE BOND MARKET IN BELARUS}

\section{Siarhei Baslaviak, Polotsk State University}

\section{Key words: corporate bond market, issuers of bonds, institutional investors, funding} JEL code: $G 23$, G24

Corporate bonds are fundamental financing instruments that are widely held by institutional investors, fund managers and households all over the world. Corporate bonds play an important role in capital markets. As the economy develops, firms try to borrow first in the form of indirect financing (bank loans). At the same time the bigger firms in good standing seek funding in the form of direct finance from the corporate debt and equity markets. Corporate bond market also offers access to longer-dated, unsecured financing for growth businesses. So, the importance of corporate bond market in the framework of direct debt finance can be hardly overemphasized.

The aim of the article is, while investigating the current state of Belarusian corporate bond market and revealing the problems concerning to this market, to find out more actual and preferable measures to improve it according to the best practice of developed markets. The research methods used in this article are scientific abstraction, reviewing the literature, the comparative method, methods of sample survey and data evaluation.

The article presents the results of analysis of volumes of corporate and government bonds trading at the platform of the Belarusian Currency and Stock Exchange. The author reveals the problems in Belarusian corporate bond market development as follows: the existing emphasize of household financial savings towards bank deposits; the significant reliance of the corporate sector on bank borrowing; the lack of institutional investors on the demand side; an illiquid secondary market; the lack of information for benchmarking; large borrowing costs for issuers.

The analysis shows that coupon rate is considered as the main factor determining the demand and return on Belarusian corporate bonds. By comparison, the main factors at developed bond markets are loan size and credit rating of the issuer. The coupon rate "corridors" have been examined in the article as well for bonds nominated in national currency (BYN) and for bonds nominated in free-convertible currency (EUR, USD). The article concludes that high-priority measures for developing Belarusian corporate bond market are the simplification of the trading procedure, the enhancement of the competition from demand side and the creation of observable benchmarks for issuers and bond investors. All these measures will encourage issuers and investors, both domestic and international, to participate in the Belarusian corporate bond market. 


\section{THIS TIME WILL BE DIFFERENT? BUILD-UP OF CYCLICAL SYSTEMIC RISKS AND ACTIVATION OF THE COUNTERCYCLICAL CAPITAL BUFFER IN CESEE BANKING SECTORS}

\section{Kristina Bojare, University of Latvia}

Key words: countercyclical capital buffer, CESEE, cyclical risks

JEL code: E32, E50, F43

While in Western countries the global financial crisis manifested itself as a culmination of a prolonged accumulation of both structural and cyclical systemic risk factors, in the CESEE region the cyclical aspects predominated. In this region countries policymakers, financial sector participants and financial consumers at that time still had relatively limited experience with free market principles and the low base allowed for rapid credit growth, which often resulted in pronounced economic and credit booms, especially in real estate sectors. This, in combination with inherent vulnerably of CESEE region countries due their size and openness, in many cases led to economic, financial and in some cases also political cataclysm when the global economy nosedived in the wake of global financial crisis.

To prevent credit booms of such magnitude end, ensure that financial sector participants are better prepared to absorb related losses and be able to continue to provide credit during the downturn in the financial cycle global policymakers agreed on countercyclical capital buffer (CCyB) - a macroprudential tool aimed at countering pro-cyclicality in the financial system. This paper seeks to answer the question whether there is a renewal in the build-up of cyclical systemic risks in the CESEE countries and how does it develop in conjunction with the presence of $\mathrm{CCyB}$ in the toolkit of national authorities in charge of financial stability. As the CCyB framework was originally developed and calibrated on a global basis, some of its aspects are not entirely suited to the specificities of CESEE financial systems and national authorities have taken various approaches to dealing with these issues. These and their potential effectiveness are also analysed in the paper.

The author finds that cyclical systemic risks are indeed on a rise in the CESEE region, nevertheless there is currently no reason to expect the repeat of the drastic boom-bust cycle of a decade ago. National authorities in the region analyse financial cycle trends using a wide spectre of indicators and in some cases, have already activated the CCyB. Furthermore, this is done even if the credit-to-GDP gap - the globally agreed benchmark for estimating the financial cycle and the size of the resultant $\mathrm{CCyB}$ - is still negative, as it is recognised that this region is especially vulnerable to volatility of the credit cycle and that specifics of its financial systems call for increased attention to indicators which are relevant in local context. 


\title{
LATEST TRENDS IN ASSESSING PENSION REFORMS
}

\author{
Larisa Bule, University of Latvia \\ Inna Romanova, University of Latvia \\ Ramona Rupeika-Apoga, University of Latvia
}

Key words: pension system, reform assessment

JEL code: $H 55, I 38$

Old age pension provision constantly creates an increasing financial pressure on most of the EU countries, therefore some of European countries are in a further stage or reforming pension system, others already completed transformation and became an object of analysis and surveillance for researchers and policymakers.

Over the years attitude towards the role of pension system in economy changed significantly from simple provision of retirement benefits and income distribution to indisputable contribution to a very wide range of economic, social and other processes. Nowadays pension system is supposed to be the instrument of impact and all reforms, even parametric, have a consequent effect on work and tax incentives, welfare, consumption, demographic indicators, etc. Some of the results are well studied, e.g. income distribution, other outcomes, for example society's radicalisation, only recently have become a subject of research.

The aim of this study is to provide an overview of latest scientific approaches to the estimation of various effects of pension system's reform including the influence of parametric corrections. Scientific papers of Latvian and foreign researchers have been considered, systemized and characterised according to the main idea of research. The study provides conclusions on the extent of research on different effects and points out the most actual and up-to-date directions of scientific activities. The results of this study can be implemented for identifying the most untapped area of research, for further investigation and for the assessment of reform from the perspective of the newest scientific achievements. 


\title{
ACCOUNTING POLICIES OF AGRO-INDUSTRIAL COMPLEX COMPANIES AS A KEY ELEMENT OF THE CONTROLLING SYSTEM IN THE CONDITIONS OF THE DIGITAL ECONOMY
}

\author{
Svetlana Bychkova, Saint-Petersburg State Agrarian University \\ Dmitry Eliashev, Saint-Petersburg State Agrarian University \\ Elena Zhidkova, Kemerovskii State University
}

Key words: accounting policy, agribusiness, digital economy, controlling

JEL code: $M 4, Q 14$

The relevance of the article is that the development of a controlling system in the context of the transition to a digital economy allows to increase production efficiency and enterprise management. The authors substantiated that accounting policy as a key element of the controlling system is a special system for managing all processes of an enterprise and has a wide range of modern tools to improve the quality of management.

The main objective of a research is the theoretical justification and development of methodological and organizational bases for the formation of accounting policies in order to build an effective controlling system of an enterprises of the agro-industrial complex based on integration into the financial accounting system of automated systems and their digital transformation to ensuring adoption of reasonable administrative decisions are made based on providing access to an array of current forecast and analytical data.

The methodological basis of the research is economics and its fundamental provisions, the basic concepts of various types of accounting and reporting, economic informatics. General scientific and special methods of scientific research, abstract logical methods of research are used: methods of analysis and synthesis, classification and generalization, induction and deduction, statistical methods of analysis of economic phenomena, SWOT method of analysis, tabular and graphical methods of data interpretation.

The theoretical significance of the research lies in the development of the concept of formation the accounting policies of the organizations of the agro-industrial complex with to increasing its effectiveness for making strategic management decisions based on modern digital technologies. The practical significance of the study is substantiated by the development of an algorithm for forming accounting policies as a key element of the enterprise controlling system, focused on the introduction of modern digital automated information accounting systems. The results obtained allow the organizations of the agro-industrial complex to increase the effectiveness of applying accounting policies as a tool to use primary accounting data for making sound management decisions at the tactical and strategic levels.

The study was carried out with the financial support of the Russian Foundation for Basic Research within the framework of the scientific project 18-010-01096 «Neo-system approach as a factor of scientific justification of transformation of the fundamentals of controlling of agribusiness organizations» 


\title{
FORMATION OF INNOVATION AND INVESTMENT STRATEGY OF DEVELOPMENT OF AGRIBUSINESS BUSINESS STRUCTURES IN THE CONDITIONS OF ECONOMIC TRANSFORMATION
}

\author{
Svetlana Bychkova, Saint Petersburg State Agrarian University \\ Dmitry Eliashev, Saint-Petersburg State Agrarian University \\ Elena Zhidkova, Kemerovo State University
}

\begin{abstract}
Key words: innovation and investment strategy, business structures of the agro-industrial complex, controlling, economic transformation, development
\end{abstract}

JEL code: 012

In the conditions of transformation of the economy, decision-makers in organizations of the agroindustrial complex require an innovative view of the management decision-making process, the effectiveness of which is directly related to the share of systemic innovations in the structure of economic growth factors. The use of a modern controlling system in an enterprise contributes to the qualitative solution of this problem. At the same time, organizations of the agro-industrial complex in modern conditions need to take a step from the initial stages of introducing such a system to its transformation based on the transition from the state of effectiveness to the state of flexibility, in order to remain competitive. The aim of the study is to identify the controlling of innovations in the system of controlling agricultural enterprises and to characterize innovative activity in Russian agribusiness. As part of this study, it is proposed to characterize the conditions for controlling innovation in terms of economic transformation, determine the place of controlling innovation projects subsystem from the standpoint of tetrad theory, consider the regulatory regulation of innovation processes in the Russian Federation and the main directions of innovation activity in agriculture, and Russian agribusiness. As sources of information for research purposes are studies of Russian and foreign scientists in the considered area, regulatory documents and state statistics. The methodological basis of the study is economics and its main provisions; general scientific and special methods of scientific research, abstract logical methods of research are used: methods of analysis and synthesis, classification and generalization, induction and deduction, statistical methods of analysis of economic phenomena, tabular and graphical methods of data interpretation.

The study was carried out with the financial support of the Russian Foundation for Basic Research within the framework of the scientific project 18-010-01096 «Neo-system approach as a factor of scientific justification of transformation of the fundamentals of controlling of agribusiness organizations» 
BITCOIN AND STOCK MARKET INDICES: ANALYSIS OF VOLATILITY'S CLUSTERS DURING THE BITCOIN BUBBLE BASED ON THE DYNAMIC CONDITIONAL CORRELATION MODEL

\author{
Andrejs Cekuls, University of Latvia
}

\title{
Maximilian-Benedikt Koehn, University of Latvia
}

Key words: bitcoin, financial contagion, dynamic conditional correlation model, volatility JEL code: G13, G41, F39

The market of virtual currencies, called cryptocurrency, has gown immensely since 2008 in terms of market capitalisation and the numbers of new currencies. Bitcoin is one of the most famous cryptocurrency with an estimated market capitalisation of nearly \$ 112 billion. The fact that Bitcoin prices have fallen about $70 \%$ from their peak value and most indices were down double-digit year to date (2018) with a high daily volatility create the appearance that there has to be a correlation.

The purpose of this paper is to investigate the contagion effect between bitcoin prices and the main American, European and Asian equity markets using the dynamic conditional correlation (DCC) model proposed by Engle and Sheppard (2001).

Contagion is defined in this context as the statistical break in the computed DCCs as measured by the shifts in their means and medians. Even it is astonishing, that the contagion is lower during price bubbles, the main finding indicates the presence of contagion in the different indices among the three continents and proves the presence of structural changes during the bitcoin bubble. Moreover, the analysis shows that specific market indices are more correlated with the bitcoin price than others. 


\section{VULTURE INVESTING IN ITALY}

\section{Alessandro Danovi, University of Bergamo \\ Jessica Tanghetti, University of Bergamo}

Key words: vulture funds, corporate restructuring, distress financing

JEL code: $G 24$

In mature capital markets high segmentation and specialization are normal. Every phase in the life cycle of companies corresponds to specific investors. So, even for companies in decline or in crisis, it should be somehow easy to find investors willing to buy out their shares, in order to verify the possibility of a turnaround or relevant portions of corporate debts in order to carry out arbitrages of value.

As it is not an easy job ("Turnarounds seldom turn" Slatter) great economic returns are expected and this probably explains the great attention paid by professionals and the press and, why these funds have never been popular. In the US since the " 80 s they have been called "vulture" like large birds eating flesh of dead animals. While economic literature about venture capital is very articulated, this is not the case with vulture funds, only few academic papers have been dedicated to the topic.

The purpose of this paper is to provide an updated overview of turnaround financing in Italy, meaning operations regarding distressed or troubled companies, carried out by professional private equity investors. This analysis springs from and is compared to similar studies carried out a few years ago trying to investigate whether there has been an improvement.

From a methodological point of view, the analysis was carried out by submitting a questionnaire to the operators and with one to one interviews. The results, even if not always statistically significant because of the size of the sample, represent an important part of the universe of Italian vulture funds and offer interesting qualitative points of view regarding the operational aspects. Despite a more developed private equity market, the development of a big NPLs market involving international funds and the reform of the bankruptcy law the Italian market still shows only few dedicated operators and a general lack of interest for this private equity niche. 


\section{BRIDGING SUSTAINABILITY GOALS AND CORPORATE PERFORMANCE: INSIGHTS FROM EMPIRICAL STUDY ON SCANDINAVIAN AND BALTIC LISTED COMPANIES}

\section{Valdone Darskuviene, ISM University of Management and Economics}

Key words: sustainability, $S D G$, performance, $R \& D$, cash flows

JEL code: Q56, L25, G32, O32

This paper explores the relationship between sustainability and company performance through the lens of proposals for curbing sustainability from institutional perspective (e.g. OECD Agenda for sustainable development, Sustainable Development Goals (SDG) promoted by UN). In spite of importance of sustainability issues raised by global/ international institutions and national governments, empirical studies relating sustainability and corporate performance are inconclusive. The current paper focuses on examining the drivers of performance and role of sustainability as measured by ESG indicators for Scandinavian vs Baltic listed companies. The empirical study is performed, based on regression analysis, to assess the relationship between ESG indicators and company performance indicators. The empirical study concludes that sustainability may have positive relationship with performance in case of larger cash flows and investments into $R \& D$, with stronger positive effect for larger companies. This may have considerable implications for development of national policies to support sustainability goals. 
THE VALUE-ADDED INTERNAL AUDIT IN PUBLIC ADMINISTRATION IN LATVIA

\section{Ivita Faitusa, University of Latvia}

Key words: internal audit, public administration

JEL code: $M 42$

The quality of internal audit and the added value of internal audit are unanswered questions in many public institutions in Latvia and around the world.

This research was aimed at determining the evaluation approach of internal audit in the public sector of Latvia and developing a list of added value or benefits of the internal audit in a local government. The monographic method and the survey method, an expert survey, were used in the paper.

The author has developed a valuation approach of internal audit in local governments. The author offers applying the approach developed when carrying out external evaluations to the commission of the responsible ministry in the sector, the representatives of the audit committee, the management of the local government, and to the auditees by inviting independent experts in the field of internal audit when evaluating the efficiency of the compliance of local internal audit unit with the legal enactments regulating internal audit, standards of professional practice, and best practices in auditing.

Research results showed that the greatest added value of internal audit is the benefits associated with improving management, budget planning and execution control, ensuring the uniform work of the office and circulation of documents, improved coordination of organisational and technical aspects of the council and the local government, as well as improving procurement processes and providing more efficient procurement plans. In their turn, the experts have given the least valuation to raising awareness among employees about the improvement of the municipal work and facilitating the process of legal support and cooperation with the State Treasury. 


\section{CHANGES IN THE INSURANCE ENVIRONMENT: A REVIEW OF THE OPERATIONAL IMPLICATIONS ON UNDERWRITING}

\section{Andre Farrugia, University of Malta}

Key words: underwriting, client interaction, validation, new technologies

JEL code: $G 22$

Traditionally, insurance is based on trust and utmost good faith, relying on the proposer to disclose the truth when proposing an insurance (or making a claim). If collecting and validating data was always an issue, today this is being perfected mainly through various electronic mechanisms.

Although the traditional questions and answers via a proposal form are still in place, insurers are no longer completely at the mercy of the century old principle of utmost good faith to obtain material facts. New technologies such as artificial intelligence (AI), machine leaning, genomics and other verification/validation processes are increasing in demand.

We are also experiencing a different form of insurer-insured relationship, which sees a different form of interface as a means of interaction. The traditional proposal interview by technical members of staff and other front liners is being replaced by information technology (IT) systems and other AI equipment.

To this effect, we aim to describe the effectiveness of current underwriting operations in the light of the changing consumer and technological environments, by understanding the profile of the customer in today's world through a review of literature and the use of a survey and interviews.

The survey will consist of themes/proposition, on the implication on underwriting due to a changing insurance environment, gatherer from literature, using the thematic approach proposed by Braun and statements under each theme, to which participants need to mark their agreement according to a Likert scale from 1 to 10. (1) being the least agreement and (10) being the most agreement.

Findings and insights on the impacts and implications that the changing insurance field is facing, are important for the insurance Industry market players since it provides them with information that enables them to respond proactively to the changing environment within which they operate and hence perform more effectively. 


\title{
TAX INCENTIVES TO PARTICIPATE IN OCCUPATIONAL PENSION SCHEMES: THE PERSPECTIVE OF AN INDIVIDUAL
}

\author{
Anna Gierusz, University of Gdansk \\ Agnieszka Pobtocka, University of Gdansk
}

Key words: tax incentives, tax systems, occupational pension schemes JEL code: $G 22, H 24, J 32$

Tax incentives can be an important tool in encouraging private pension provision. Many possible pension tax regimes can be applied in occupational pension schemes. They differ depending on whether contributions into the scheme, investment returns earned and benefits paid out of the scheme are taxed or exempt from tax. Many OECD countries apply an EET system, where contributions and investment returns are exempt from income tax and benefits are taxed. This can be considered attractive from the member's point of view, as the tax relief is received immediately, whereas the tax is applied to benefits which will be paid in a distant future. However, other tax regimes are also in use. Currently in Poland the system in use is TEE (contributions are taxed whereas investment returns and benefits are exempt), and this is likely to be used in the new occupational schemes which are due to be introduced in Poland in 2019.

Aim of this paper is to compare the different tax regimes which can serve as an incentive to save in the new pension schemes in Poland from the member's point of view. Model of a pension scheme under different tax regimes was constructed. This allows to calculate benefits and replacement rates that could be achieved, as well as post tax income throughout the scheme membership. Different categories of workers based on their salaries were considered. It can be shown that for chosen assumptions TEE and TTE regimes result in higher replacement rates for high earners in comparison to low earners, whereas for EET and ETT the opposite is true. In addition, there is almost no difference in replacement rates under different tax regimes for low earners, as only the taxation of investment returns has impact. In contrary, for the high earners different tax regimes can result in higher or lower replacement rates. The practical implication of the paper is that there is no single tax regime that would provide highest replacement rates for all workers. Different aims can be achieved by using different regimes, depending on particular country's income tax rules. 


\section{HISTORICAL BACKGROUND OF BALTIC CREDIT INSTITUTIONS}

\section{Colin Glinkwoski, University of Greifswald \\ Jorn von Elsenau, University of Greifswald}

Key words: contemporary events, central banks, commercial banks, credit unions JEL code: B25, G21, N24

In order to shape the future, it is necessary to comprehend the past. History has formed banking systems and determined banks' behaviour. The Baltic banking systems of today are a result of economic and political turmoil which has been occurring since the 19th century. By the first independence of Estonia, Latvia and Lithuania in the beginning of the 20th century, central banks were established. Although they operated on various financial fields - different to our modern understanding of a sincere central bank - they formed banking systems which laid a foundation for banks still working nowadays. Banks are regarded as cornerstones and pillars of modern money economies. The well-being of entire economies often depends on them. The present study examines the period of the first Baltic independence between the two world wars. The methodological basis for the comparative analysis is provided by the New Institutional Economy. The goal of the study is to compare the first Baltic credit institutions and their different establishment approaches in the three countries. The comparative analysis shows to what extend and why those developments differed in this period of time. The study's results constitute that the differences were mainly due to the states' and central banks' strategies. For example, the Estonian and Latvian central banks combined two functions in this period, namely the monetary authority and commercial banking, which had an impact on the banking systems' diversification. The study elaborates general strategic aspects of implementing credit institutions. The conclusion can point other countries to the challenges of building a diversified and strong banking system. 


\title{
FINANCIAL INCENTIVES OF ECONOMIC GROWTH IN EMERGING MARKETS: EVIDENCE FROM RUSSIA
}

\author{
Viktor V. Ivanov, Saint Petersburg State University \\ Nadezhda A. Lvova, Saint Petersburg State University \\ Natalia V. Pokrovskaia, Saint Petersburg State University
}

Key words: emerging markets, financial system, economic growth, financial incentives, Russia JEL code: $E 63$

The impact of the financial system on economic growth is mixed. As a rule, the financial system is considered to be able to create preconditions for stable economic growth. And, thus, it is advisable to financially stimulate the economy. However, the relationship between financial development and economic growth is non-linear as can be seen in emerging markets. On the one hand, emerging markets have not reached the limit of financial saturation. On the other hand, the imperfect institutions of these countries hinder effective financial stimulation of the economy. In this regard, the aim of the study was to substantiate the instruments of financial stimulation of economic growth in the emerging market (on the example of the Russian Federation).

When justifying financial incentive instruments, general scientific methods are used, as well as methods of statistical analysis of aggregated data on the functioning of the financial sector of the Russian Federation. The main results and conclusions of the study include the following.

Emerging markets are characterized by significant institutional weaknesses, including weak protection of property rights, which limits the use of financial instruments in developed markets. In these conditions, the fiscal and monetary mechanisms of financial stimulation of economic growth have the highest potential, which is clearly seen in the example of neocontinental financial systems.

According to the authors, the instruments of financial stimulation of economic growth in the emerging market should be based on the principles of transparency and efficiency. For Russia, this means, first of all, the use of such financial incentive instruments that would contribute to the growth of the efficiency of public institutions ' expenditures, the reduction of the share of shadow business; the use of monetary policy instruments that stimulate, first of all, economic growth; creation of new institutions of economic development.

The study makes a certain contribution to the system of scientific ideas about the applicability of certain instruments of financial stimulation of economic growth in emerging markets. The applied value of the research results is that they can be used in the practice of management and regulatory decisions made in emerging markets. 


\section{MAIN FACTORS OF EMOTIONALLY ATTACHED CUSTOMER IN RETAIL BANKING OF LATVIA}

\section{Irina Japparova, University of Latvia Ramona Rupeika-Apoga, University of Latvia}

Key words: emotional attachment, branding, customer loyalty

JEL code: $G 21,016$

How the banking strategy in Latvia is changing? How can banks increase the number of active clients? Are banks in Latvia focusing to attract new clients or prefer to work with the existing client portfolio? How can the retail banking sector in Latvia impact the customer loyalty?

The regulation developed by the Basel Committee impacted the number of banks in Latvia and the number of active clients in retail banking. Latvian banks are getting more flexible in customer services and actively working to increase customer loyalty. If previously banks actively attracted the new clients to increase the number of customers, now banks are working to increase the number of active loyal clients. Only a totally complacent customer will be a loyal customer.

The purpose of this study is to examine the effects of customer emotional attachment on customer loyalty to the provided goods and services in the retail banking sector in Latvia by the analyses of banking products and services in Latvia. The profitability of each Bank directly depends on customer loyalty and how many customers return for goods and services. The main object of loyalty is customer emotional attachment, which is the determining factor in decision making in retail banking. The customer's emotions and feelings drive his/her chose.

When banks connect with customers' emotions, the income could be considerable. That is why it is significant to research customer emotions to create long term partnership in retail banking. Research methods used are clients' survey in the retail banking sector in Latvia.

The banks branding, the personality of produced goods and services, the customer experience and trust, the digitalization and innovation tendency are the factors that can emotionally attach the customer. All these factors, from the new product and services development till the daily provided, affect the customers' value to the bank. As the main result, the strategic goal is to have emotional attached customers in retail banking of Latvia. 


\title{
EVALUATION OF TANGIBLE ASSETS ACCOUNTING INFORMATION DISCLOSURE QUALITY IN THE PUBLIC SECTOR: THE CASE OF LITHUANIA
}

\author{
Rasa Kanapickiene, Vilnius University \\ Ieva Stankeviciute, Vilnius University \\ Almute Grebliune, Vilnius University
}

Key words: accounting quality, disclosure quality, financial reporting, municipality

JEL code: $H 83, M 41, M 48$

Accounting information is significant to internal and external information users in order to make reasonable decisions. However, the disclosure of information in the private and public sectors is insufficient. The issue of accounting information disclosure quality is encountered. This issue is also enhanced by the fact that in order to analyse and evaluate accounting information disclosure quality, it needs to be separated from phenomena that are referred to by other concepts of quality and to identify their interrelations. In the meantime different concepts are employed in the scientific literature: information, accounting and accounting information disclosure quality. In addition, it is essential to evaluate the requirements which the accounting information has to meet in order to be viewed as qualitative. The question of accounting information disclosure quality in the Lithuanian public sector is also relevant, as since 2010, after the Accounting and Financial Reporting Reform in the Public Sector, the accounting system has been changed from the cash basis to the accrual basis. The Public Sector Accounting and Financial Reporting Standards have been introduced which are employed to improve the presentation quality of the financial statements of the public sector entities. The financial statements prepared according to these standards would help the users of financial information to make more reasonable economic decisions that deal with the distribution of resources; the transparency indicators of the financial statements would increase. This aim can be reached only if the information of the financial statements meets all of the requirements in the standards. Generally the questions of accounting information disclosure quality get quite some attention in the private sector; nevertheless, the research on this issue is insufficient in the public sector. The research of accounting information disclosure quality in Lithuania is scarce in both theoretical and empirical fields. The aim of the research: to examine and evaluate the accounting information disclosure quality of the tangible assets in the financial statements of the municipalities of Lithuania. In order to achieve this aim, the following objectives have been identified. The concepts of information quality, accounting quality, disclosure quality have been analysed. After the analysis of the performed research of information disclosure in financial statements, the theoretical model of accounting information disclosure quality has been designed. In accordance with the designed disclosure index, the disclosure quality in the financial statements of the tangible assets of the municipalities of Lithuania have been evaluated and compared. With the help of this index, the municipal administration and other stakeholders will be able to identify problematic areas of financial information disclosure. 


\section{THE PRINCIPAL-AGENT PROBLEM WITHIN SUSTAINABLE INVESTING}

\section{Hendrik Kimmerle, University of Liechtenstein}

Key words: theories of the firm, sustainable finance, principal-agent problem JEL code: $G 1$

Recent studies show the positive impact of sustainability factors within the investment process. Mostly these studies concentrate on performance effects while disregarding existing agency problems. In this paper we deal with the principal-agent problem within sustainable investing, as corporate executives (agents) try to maximize their personal utility at the cost of investors (principals). We examine how adverse selection and moral hazard can be mitigated by signalling and monitoring mechanisms and how effective these are. The results indicate that sustainability reportings and ESG ratings can visualize company's sustainability efforts and reduce ex ante information asymmetries. However, we find evidence that reports and ratings are not standardized and not easily accessible. To reduce ex post asymmetries, we propose specific incentive-type contracts for corporate executives to participate in a sustainable development, albeit lacking standardized performance measures. 


\section{A BEHAVIOURAL FINANCE EXPLANATION OF SPECULATIVE BUBBLES: EVIDENCE FROM THE BITCOIN PRICE DEVELOPMENT}

\section{Maximilian-Benedikt Koehn, University of Latvia Andrejs Cekuls, University of Latvia}

Key words: bitcoin, cryptocurrencies, speculative bubbles, behavioural finance, volatility JEL code: $G 41, E 31$, G12

In 2008 a group of programmers, alias Satoshi Nakamoto, introduced bitcoin. Bitcoin is a cryptocurrency or virtual money derived from mathematical cryptography and is conceived as an alternative to government authorised currency. The founder anticipated, through bitcoin's construction and his digital mining processes, that bitcoin prices would be relatively stable. However, the recent bitcoin price decline proves that bitcoin is extraordinarily volatile and is not that stable as hoped. Although some scientists have already shown that the fundamental value of bitcoin is zero, the price of bitcoin has reached over $19.000 \$$ in December 2018. Since then, bitcoin prices dropped nearly 70\% from their peak value and showed in addition to that the typical trends of a speculative bubble.

Hyman Minsky and Charles Kindleberger discussed three different patterns of speculative bubbles. One is when price rises in an accelerating way and then crashes very sharply after reaching its peak. Another is when the price rises and is followed by a more similar decline after reaching its peak. The third is when the price rises to a peak, which is then followed by a period of gradual decline known as the period of financial distress, to be followed by a much sharper crash at some later time. One of the key findings of this study is that all these three patterns occurred during 2017-18 for the bitcoin price.

Therefore, the purpose of this paper is to analyse the historical bitcoin prices in context with the typical five-step characteristics of a speculative bubble. Furthermore, each phase of a speculative bubble is explained by a behavioural finance approach and answer the price development of this cryptocurrency. The result is frightening, bitcoin can be seen as a perfect textbook example of a speculative bubble. 


\section{NON-FINANCIAL REPORTING IN THE MICRO ENTERPRISES \\ IN SELECTED EUROPEAN COUNTRIES}

\section{Beata Kotowska, University of Gdansk}

Key words: financial statement, micro enterprise, non-financial reporting, stakeholders, sustainable development

JEL code: $L 25$, M13, M41

The micro entities are important element of European economies. They constitute average $93 \%$ of all registered companies and employ nearly $30 \%$ of all workers. For recent years, European Union countries have been seeking solutions and tools to help micro undertakings collecting and presenting information. The European Directive 2013/34/EU is a first huge step for taking care of the micro entities, which finally can prepare financial statement in simpler form. This Directive introduces among others: limitation the scope of regulations, improving competitiveness and internationalization of information, providing necessary but not excessive financial information for competing with other micro units. Suggestions for presenting non-financial information are included in the Directive 2014/95/EU, but only for large entities, not micro. It should be highlighted that not only stakeholders of large companies but also of medium, small and even micro are interested in collecting and getting information about their sustainable development. Nowadays, when the European market is a global market the accountability, sustainability and reporting back become extremely important.

The main aim of this research paper is to carry out a comparative analysis of the non-financial reporting obligations of micro enterprises which keep account books in selected European countries.

At the beginning of this paper, criteria for classification of micro undertakings will be presented and compared. The analysis of the legal regulations will allow on identification and comparison of the registration requirements arising from the accounting law regarding these units. Next will be presented place and scope of non-financial data in the financial statement for micro in the researched countries.

The main conclusion of the analysis is: micro entities do not have to obligatory present non-financial information. It means that in each country the scope of disclosures of this information is not homogenous.

This paper is a basis for seeking the best solutions and practices of presenting non-financial information, which will be adequate to ensure the needs all groups of the stakeholders. 


\section{IMPLICATIONS OF FUZZY DELPHI METHOD IN ASSESSING THE EFFICIENCY OF FINANCIAL LITERACY PROMOTION}

\section{Kaspars Kravinskis, University of Latvia}

\section{Key words: financial literacy, Fuzzy Delphi method}

JEL code: $A 20$, F69

Evaluation of the efficiency of financial literacy promotion efforts has always been an interesting and challenging problem for both the researchers in the field as well as practitioners. Although there are several sources of measurement tools for the actual levels of financial literacy available and tested in an international setting, the overall evaluation of efficiency of actions, programmes, strategies and approaches targeted towards improving financial literacy among the general population are difficult to construct. Therefore an approach based on multi-faceted international expert panel judgment can be introduced as a source of more uniform point of view.

The paper discusses the implications, possibilities and limitations of Fuzzy Delphi Method (FDM) when applied to conceptualization, inception and formation of a questionnaire-based evaluation tool targeted towards evaluating the efficiency of a multitude of financial literacy promotion efforts. Using this method a set of key efficiency appraisal instruments can be constructed and established on multiple dimensions - time, population, topics and fields. The paper demonstrates the process of initiating and forming the research structure, selecting the experts, providing feedback and collecting responses in multiple rounds. As the error level is reduced, using fuzzy sets allows for the quantification of expert opinions and variables to be more related and consistent with human socio-linguistic behaviour on an international level. The paper concludes that FDM is a valuable tool in expert opinion-gathering when the topic of interest is prone to bias, vaguely defined and may not be easily quantifiable. 


\section{SOURCES OF FINANCE IN THE IGAMING INDUSTRY: THE CASE OF MALTA}

\section{Marshia Mamo, University of Malta \\ Sharon Seychell, University of Malta \\ Simon Grima, University of Malta}

Key words: remote gaming companies; credit institutions; sources of finance; regulatory requirements, Malta

JEL code: $G 30,016$

The Malta Gaming Authority (MGA), Interim financial report for January to June 2016, indicates that the direct gross value added generated by this Industry amounted to $12 \%$ Gross Domestic Product. Generating $€ 700$ million and employing 9,000 people. As at June 2017, 275 Remote Gaming Companies (RG) companies, including giants Betsson, Tipico, Betfair, now call Malta home. A growth rate of $11.9 \%$ over the activity registered during the same period in 2015 .

Notwithstanding this growth rate and the importance of this activity for Malta, the industry has limited sources of finance. Most local based banks do not grant loans to this industry and this has made it difficult for them to raise funds. Therefore, in this paper we analyse and discuss the lack of appetite by local Banks for this exposure. In doing this, we analyse and discuss the risk perception of local Banks on RGs and seek to determine the current and possible sources of finance available to RG companies residing locally. We will also, evaluate and recommend any changes in the RG company structure, processes or other to promote more comfort for local banks. This by analysing data collected through self-administered semi-structured interviews with 32 personnel working in RG companies 28 personnel working in 27 locally licenced credit institutions.

Finding show that (1) RG companies are cash rich, due to their operations and therefore additional support of financing in the form of bank borrowings is only required for aggressive growth. Also, (2) the lack of appetite is due to reputation with corresponding banks, who do not have an appetite for transacting with Banks associated with RG companies. Moreover, (3) there is a lack of communication between the two industries. 


\section{IMPACT INVESTING - AN ACCEPTABLE NICHE EXISTENCE?}

\section{Marco J. Menichetti, University of Liechtenstein}

Key words: sustainability, socially responsible investing, sustainable investing, ESG investing, negativel exclusionary screening

JEL code: $G 11, D 82, D 64$

Sustainable and socially responsible investment (SRI) strategies face high growth rates worldwide. Although SRI strategies gained high amounts of assets under management over the last years, we do not recognize a significant shift towards sustainable business practices. The research aim of this paper is to give an answer to the question, why the high amount of assets managed sustainably does not lead to a significant transformation in business practices and how we could change the existing framework in order to achieve significant changes. Our methodological approach first leads us to a comparison of the existing seven sustainable investment strategies and a description of financial instruments, connected with those strategies. Second, we collect decision criteria and goals for supply side and demand side market participants. Finally, we use this preparatory work for the construction of a decision matrix, which allows us to interpret differences in goal fulfilments.

This analysis delivers insights into the connection between sustainable investment strategies, preferences of supply side and demand side institutions, and the low speed of transformation. Up to now, no research on the connection between sustainable investment strategies and the speed of transformation towards sustainability has been done. Our results focus cost disadvantages of impact investing compared to other sustainable investment strategies. A stronger standardisation of impact investing's private debt and private equity structures is needed. The legislator could favour impact investing to other investment strategies, as current law is based on less efficient investment strategies. A blockchain application could additionally drive down the costs and increase the flexibility of impact investing. 


\section{THE IMPACT OF PERSONNEL REDUCTIONS \\ ON THE SUCCESS OF GERMAN SAVINGS BANKS}

\section{Matthias Paschke, University of Latvia}

Key words: financial institution, financial service, development bank

JEL code: $G 210,0160$

Earnings of regional credit institutions have been declining for several years. Subsequently, the German savings banks as regional banks must explore new earnings potential and, at the same time reduce costs. The assumption of managers that customers are increasingly using digital access paths is leading to a significant reduction in the number of employees in banks. Digitalisation allows services to be processed more efficiently. However, it seems that measures taken in the local banking market to reduce labour costs are partly based on managers instinct because necessity of cost reduction is often mentioned at management events in practice. However, there is no scientifically sound justification for this. The current relationship between personnel reduction and the success of German local banks is unexplored.

The purpose of the research is to investigate the effect of personnel reduction in German savings banks on the company's success and to show how significant it is, because there is a high cause effect between personnel costs and the success of the company. The novelety is shown in the impact of personnel changes on earnings and independence of banks. In addition to its scientific relevance it is an important factor for the management of local banks because the pressure on earnings and the requirements of European regulation on equity capital are increasing.

First, the literature review will give an overview of the German banking system, the savings bank group and current trends. Secondly, success factors of the business are highlighted. Further, an analysis of quantitative data of approximately fifty examined savings banks follow and graphical illustrations are added. The research method is quantitative and is carried out by evaluating the annual financial statement data of the savings banks, from which the independent variable (personnel costs) and the dependent variables (earnings ratios and equity ratios) are extracted and analysed with a regression analysis.

As a result the variables show that the personnel reduction has no negative impact on customer business and bank stability. Nonetheless, the main result is that the focus on personnel reduction has a highly significant and positive impact on the success of the bank. The conclusion can be drawn that it makes full sense to reduce the number of employees instead of investing in personnel capacities. 


\section{BLOCKCHAIN IN FINANCIAL INDUSTRY: BETWEEN INFLATED EXPECTATIONS AND DISILLUSIONMENT}

\section{Dancho Petrov, University of Economics - Varna}

Key words: blockchain, distributed ledger, smart contract, financial industry, financial services JEL code: 031, G10, G20

"Blockchain", "distributed ledger" and "smart contract" are terms that were anonymous only a decade ago, but today they are increasingly aggressively present in our daily lives. The financial industry is one of the areas in which the implementation of blockchain technology is reasonably expected to lead to dramatic changes. The time of the initial euphoria is gone, giving way to realism and "sobering" of the illusions about the possibilities and limitations to the feasibility of the new technology. The main research goal of the present study is systematization and testing using selected criteria, to arrive at a differentiated assessment of the degree of applicability of blockchain in different segments of the financial services industry. The methodological tools used are based on literature review and secondary data, through which the expected positioning of blockchain in the financial industry in line with the Gartner Hype Cycle of Emerging Technologies is explored. Based on the analysis of the specificities of the selected segments of the financial industry and the comparative analysis of the benefits and limitations in the development and application of the technology, the criteria for assessing the degree of applicability and the expected impact of blockchain technology on the analyzed segments are systematized. The results of the study testify to the uneven level of impact and penetration of blockchain in various spheres of the financial industry. The main challenges and barriers to the application of the technology and the possible solutions for overcoming them are outlined. 


\section{NOVEL USAGE OF NETWORK MODELLING. SYSTEMIC RISK IN BANKING}

\section{Kristine Petrovska, University of Latvia}

Key words: systemic risk, network modelling, banks

JEL code: $G 21$, G28, L14

One of the reasons for the Global financial crisis, European sovereign crisis and other minor market crisis descends from the systemic risk. In this paper one of the channels of systemic risk is analysed and determined in the Latvian banking sector, namely, interconnectedness of banks. Recent developments in regulation and research still do not fully cope with the interconnectedness problem of banks, especially in markets where any type of bank liabilities or equity is not publicly traded. Therefore, this research shows a novel method in determining interconnectedness of banks to form distinct networks, using bank performance indicators from publicly available data. The research covers Latvian banking system between 2006 and 2018.

The results suggest that banks present in Latvian market form distinct networks that are subject to change over time. It is possible to determine the changes in networks before crisis, during crisis and after crisis. In each period leaders within a group can be diagnosed. This novel method of network modelling scientifically reaffirms the duality of the market while identifying herd behaviour. It is also found that due to stricter panEuropean regulation and recent structural developments banks tend to become more homogeneous. 


\title{
GREEN AND INFRASTRUCTURE INVESTMENT - AN IMPORTANT AREA OF PENSION REFORMS FOR TRANSITIONAL ECONOMIES
}

\author{
Zhanna Pisarenko, Saint-Petersburg University \\ Natalia Kuznetsova, Saint-Petersburg University
}

\begin{abstract}
Key words: institutional investors, green investments, infrastructure investments, pension reform JEL code: F21, F43, H55
\end{abstract}

Problem statement. The development of green and infrastructure investment is an important area of structural reforms for emerging markets transitional economies. So far as the concepts of "green" and "infrastructure" investment is still not enough developed no one transitional economies have proposed an effective model for green growth financing. These economies' goal is to ensure a shift towards more sustainable production and consumption models incorporating environmental issues into decision-making process in accordance with global sustainable development priorities. These tools have great potential for new, knowledge-based continuous economic growth provision but to use them one need a mechanism for such investments financing. The aim of the study concerns theory and methodology of green and infrastructure investment made by institutional investors in the context of transitional economies' pension systems reforming.

The study's objectives are: transitional economies' comparative analysis of structural shifts to sustainable economic development and knowledge-based economic growth; processing of new type of socially-oriented green and infrastructure investments that become financial mechanism for intensive growth and sustainable development provision; assessment of the state pension schemes transformation via redistribution of risks from public to individual level demanded by state and households.

The scientific results lie in the: formation of theory and methodology for green and infrastructure investment in the context of the transitional economies' transformation into sustainable economic development and growth model; disclosing the essence and content of this methodology, as well as specific features caused by the current reform of the pension systems in countries under consideration; evaluation of ways to create a favorable institutional environment for green and infrastructure investment; construction of scenarios for new concept of the welfare state and programs for a culture of collective investment development.

The practical significance lies in a chance of achieved results implementation for: improving the models of state and interstate regulation of the activities of individual institutional investors and financial conglomerates; conducting a comparative analysis and developing tactical and strategic decisions to ensure the competitiveness of national insurance companies and non-state pension funds; improvement of financial literacy, competence and activity of the population and legal entities in matters related to pension benefits; involvement of public funds into the long-run process of responsible green and infrastructure investment and the formation of transitional economies' internal investment potential, as well as a scenario of self-sustainable economic growth conducive to increase these countries' population welfare. 


\title{
BAYESIAN MODEL OF PROVISION FOR EMPLOYEE RETIREMENT BENEFITS
}

\author{
Agnieszka Poblocka, University of Gdansk \\ Ewa Spigarska, University of Gdansk \\ Grzegorz, Krzykowski, University in Gdansk
}

Key words: accountancy, valuation of retirement benefits, Bayesian model of provision JEL code: $C 11$, M40

Retirement benefits are an additional security for an employee that impacts present and future lives of both - an employer and an employee. The employer tries to expand the job offer and looks for additional forms of remuneration for their employees. An employee satisfied with work, encouraged by additional employee benefits (retirement benefits, jubilee awards, etc.) decides to retire after reaching the required seniority.

The article presents a Bayesian approach to the valuation of a provision for employee benefits. The main goal of the article is description of current legal requirements and actuarial methods for estimating provisions for employee retirement benefits and to create a Bayesian model of provision for an employee benefits. To achieve the goal, non-classical statistical methods were used to estimate the provision for an employee in accordance with current legal standards in Poland (i.e. the Accountancy Act, labour law, international accounting standards). In the Bayesian approach, the provision for retirement is the posterior distribution, which can be used to estimate selected characteristics, such as measurement position or dispersion.

The survey showed that the level of the estimated provision for employee benefits in the enterprise depends on the probability distributions of age, gender, and seniority of employees. The proposed Bayesian model of provision for employee benefits can be used in large and medium-sized enterprises. 


\title{
INNOVATIVE ASSETS: IMPROVING THE METHODOLOGY OF ACCOUNTING, ANALYTICAL AND ESTIMATION PROCEDURES
}

\author{
Galina Reshina, Baltic International Academy
}

Nataliya S. Plaskova, Plekhanov Russian University of Economics

Natalya A. Prodanova, Plekhanov Russian University of Economics

\begin{abstract}
Keywords: innovative assets, accounting and analysis of innovative assets, valuation of innovative assets
\end{abstract}

JEL code: $M 41$

Important factors and tools of improving the competitiveness of business and its efficiency is innovation, the management of which should be provided with scientifically based information and tools for assessing the achieved level of its development and forecasting the social and economic effect in the future. Estimation of the existing methodological support of accounting, analysis, assessment and forecasting of innovation activities has revealed a number of methodological problems in this area; these problems have negative impact on the quality of financial statements of innovative companies, while this statement serves as a basis for investment decisions contributing to the intensification of the innovation process.

The goal of the study is to improve the methodological approaches in the field of accounting and valuation of innovative assets, clarification of their economic, financial and legal characteristics for the formation of objective financial reporting information on the basis of which owners, investors, and creditors estimate the investment attractiveness of innovative companies.

The research is based on scientific and practical developments; these developments allow forming the methodology for estimating the value of innovative assets for their correct representation in the accounting system and financial statements of companies in accordance with international standards. They also permit employing the proposed methodology for assessing and forecasting the effectiveness of innovative assets in the commercial activities of innovative companies. The economic and statistical methods of systematization of accounting data, as well as multivariate simulation of aggregated indicators demonstrating the efficiency of innovative assets employment have been used for formation of a representative empirical base of this research.

The main results of the study are the specification of theoretical and methodological provisions and methods of valuation base, accounting and analysis of innovative assets capable of improving the quality of financial statements of innovative companies, as well as the justification of the system of indicators for assessing and forecasting the effectiveness of innovative activities. The proposed methodological and methodical approaches contribute to the creation of a system of high-quality financial and analytical information, and form the conditions for the development of optimal managerial decisions aimed at enhancing the innovation process and strengthening the investment attractiveness of innovative companies. 


\title{
EVALUATION OF INTERNAL AUDIT ACTIVITY EFFECTIVENESS IN RISK ASSESSMENT OF ANTI-MONEY LAUNDERING AREA: \\ A CASE OF LATVIAN BANK "N"
}

\section{Svetlana Saksonova, University of Latvia \\ Arina Matvejeva, "Deloitte"}

\begin{abstract}
Key words: risk assessment, anti-money-laundering, internal audit activity effectiveness JEL code: $G 32$, G21
\end{abstract}

Due to recent AML violation cases occurred in financial institutions within Baltic States (Estonian Danske Bank, ABLV Bank AS and Versobank AS) and expressed concerns on Banks' Internal Audit activity within AML area, the author sees the necessity for assessment of Internal Audit activity within AML area in order to determine the level of adequacy of AML regulatory changes within the risk assessment and potential gaps in risk assessment of AML area. The research focuses on AML compliance with the constantly evolving and increasingly more complicated regulatory requirements and evaluation of organizational part of IA activity using an example of a Latvian Bank N.

The aim of this research is to investigate completeness of Internal Audit risk assessment in accordance with recent AML regulatory changes. This research also compares the IA organizational process that affects all banking areas between a Latvian Bank $\mathrm{N}$ and an Estonian practice.

This research relies on qualitative methods. Qualitative methods include face-to-face interviews with Board Members of Latvian Bank N, AML Internal Auditor of Latvian Bank N and telephone interviews with Estonian IA Experts. Also, involves documentary analysis of Latvian Bank N internal audit risk assessment conducted in 2017 for the implementation in 2018.

The conducted investigation showed that IA activity has certain deficiencies and shortcomings in relation to AML regulatory changes reflection in IA risk assessment for AML area, and for overall IA organizational process organization that is crucial for audits organization and conduction not only in AML area, but for all Latvian Bank $\mathrm{N}$ and other Latvian Banks' activities areas. Elimination of these deficiencies will help to achieve full reflection of AML regulatory changes and thereby mitigate the risks that bank processes which are affected by these regulation changes are not sufficiently assessed within the Internal Audit Risk Assessment. In addition, elimination of the deficiencies identified in relation to IA organizational processes will lead to increase of conformance in accordance with International Standards for the Professional Practice of Internal Auditing (pub. the Institute of Internal Auditors, 2017) and, as a result, will strengthen and improve the IA activity effectiveness that is within Internal Audit department and Bank's interest.

Many of these results are likely to apply not only in the particular bank on which the research is focused, but also to other banks in Latvia. Thus, the research has practical implications in formulating common risk management tactics and methods that could be applied across the banking sector. 


\section{PIE STATUTORY AUDIT MARKET CONCENTRATION: EVIDENCE FROM LATVIA}

\section{Svetlana Saksonova, University of Latvia \\ Ludmila Rozgina, IRIS-ALKONA}

Key words: audit market, audit market concentration, concentration ratios, audit firms, public-interest entities

JEL code: $M 42$

The reform of EU audit legislation was adopted by the Council of the EU in April 2014. The legislation consists of an audit Directive and an audit Regulation. The Directive applies to all statutory audits; the Regulation contains specific requirements for the statutory audits of public-interest entities (PIEs). The Regulation aims both at enhancing audit quality and at promoting competition in the audit market. Mandatory rotation, together with the incentives for joint audit and tendering, as well as the prohibition of certain nonaudit services to audit clients - requiring de facto that another audit firm provides these services - are examples of measures that should make the market more dynamic and ultimately less concentrated. The purpose of this research is to assess the concentration levels and developments prospects in the market for statutory audits of PIEs in Latvia (within the EU audit reform context). The methods of the research are systematic, logical and comparative analysis, analysis of secondary data, as well as expert method. Data on market shares is analyzed using the four firm concentration indicators. The principle results of the study provide evidences about the high level of Latvia's audit firms/networks market concentration, the dominant share of non-audit revenue in total revenue for the 4 biggest market players, the auditing oligopoly in the PIE market, the impact of the EU audit reform on the auditor-client relationships in the banking sector. Based on the findings and results of the study, the author proposes a set of recommendations aimed to make the Latvian audit market more transparent and less concentrated. 


\title{
THE CHALLENGES FOR THE PROFESSION OF ACCOUNTANT IN THE CHANGING GLOBAL ECONOMIC ENVIRONMENT
}

\author{
Ruta Sneidere, University of Latvia \\ Inga Bumane, University of Latvia
}

Key words: accountant, profession, education, competence, ethic

JEL code: M41, M49

Nowadays we observe dynamic growth in the global economic environment and rapid changes in information and communication technologies. These factors have a strong impact, they cause changes in the expectations of parties involved and greatly impact the conditions and competencies of any profession. Technological progress and the importance of behavior competencies, both ethically and legally, exercising professional judgment and emotional intelligence will bring many challenges and opportunities for those who have chosen the profession of an accountant. The professional organizations of accountants are organizing different workshops and open discussions where participants exchange their experiences, share examples of best practice and the vision for the future.

The purpose of the article is to explore the latest tendencies of development of the profession of accountant in the context of the changing global economic environment and to make recommendations for improving professional skills and competencies of accountants.

The study is based on theoretical aspects of scientific researches that were carried out in different countries and the guidelines developed by the major professional organizations for education of the accountants, as well as on empirical research results.

The conclusions made at the end of this research and the results of the study underline the main key points regarding the skills and competencies of professional accountants - knowledge of information technologies in combination with expertise regarding accounting standards, economics, tax laws, as well as respect for professional ethics and maintaining professional competence. The challenge for professional accountants will be finding new ways to add value for their clients.

During this research widely accepted quantitative and qualitative methods of economic science were applied including synthesis and logical constructive methods.

The article has theoretical and practical significance, it provides recommendations which will allow to identify the directions for improvement in the education system of professional accountants. 


\title{
ASSESSMENT OF BANK FINANCIAL HEALTH IN LATVIA
}

\author{
Irina Solovjova, University of Latvia \\ Inna Romanova, University of Latvia \\ Ramona Rupeika-Apoga, University of Latvia \\ Svetlana Saksonova, University of Latvia \\ Marina Kudinska, University of Latvia \\ Aina Joppe, University of Latvia
}

Keywords: bank, financial health, financial strength, rating

JEL code: $G 21, G 24$

Financially strong, trustful and reliable banks form the basis of each economy and are a vital precondition for the stable economic development of every country. The financial health of banks is important for different stakeholders, including bank clients, corresponding banks, state and others. Therefore, lack of appropriate measures for bank financial health can cause a number of risks for the bank stakeholders. Traditionally the assessment of bank financial health and reliability is done by the international rating agencies as Standard\&Poor's, Moody's and Fitch. These ratings are widely recognized worldwide; however, due to different reasons ratings assigned by the international rating agencies historically are not available for the majority of European banks. Besides, after the global financial crisis of 2008 the number of banks with a rating of an international rating agency has substantially decreased. Therefore, the aim of the paper is to design a model allowing to assess bank financial health using publicly available information. The proposed model is based on the analysis of financial statements data of Latvian commercial banks in the period from 2003 till 2017, key macroeconomic indicators, and aggregate statistical data of Latvian commercial banks managed by the Financial and Capital Market Commission (FCMC). The methodology is based on the design of multiple choice model ordered logit using eViews 7.0. The paper determines the main factors affecting the bank financial health based on the Moody `s Investors Service Long Term Bank Deposit Ratings. According to the developed model, the main factors involve bank assets structure, level of credit risk, profitability, bank capitalization, stability of resource base as well as macroeconomic factors, including investment and unemployment. 


\section{HISTORY OF CASH FLOW STATEMENT AND PRACTICES IN LATVIA AND OTHER STATES}

\section{Dzeina Steinberga, University of Latvia \\ Ruta Sneidere, University of Latvia}

Key words: cash flow, financial statements, financial analysis, accounting

JEL code: $M 41$, M49

The development of any country is based on a successful company that creates such added value, which brings not only its own worth but also contributes to the development of the state. The company's long-term development is unthinkable without its own resources control, which is most convenient to control by using its financial statement data.

Based on data of the report of the Ministry of Economics of the Republic of Latvia, the small and medium-sized enterprises in Latvia are $98 \%$ of all economically active enterprises. The preparation of financial statements in Latvia is determined by the Annual Account and Consolidated Annual Account Law, according to which the cash flow statement should be prepared for medium and large companies, however according to authors view, cash flow statement contains information that other financial statements do not provide so clearly and therefore could also be used by small enterprises both for planning financial resources and insolvency prediction.

The authors have set the objectives of the study: to study and assess the preparation of the cash flow statement and the availability of information on the practice of preparing a cash flow statement in different countries and to develop recommendations for extending the meaning of the cash flow statement among the preparers and users of financial statements in Latvia.

The authors used economic analysis and synthesis methods - studying theoretical aspects and official informative sites, statistical methods - performing data processing and analysis, as well as a logical constructive method, interpreting research results, formulating conclusions and proposals. Based on the results of study the conclusions have been defined, formulated proposals for increasing the significance of the cash flow statement in Latvia and made a comparison of the practice of different countries in preparing the cash flow statement.

The article has theoretical and practical significance for expanding the meaning of preparation of the cash flow statement among financial report preparers and its information users. 


\section{EVALUATION OF THE IMPACT OF STATE SUPPORT AND CORPORATE INCOME TAX EXEMPTIONS ON THE FINANCIAL CONDITION OF SOCIAL ENTERPRISES}

\section{Rasa Subaciene, Vilnius University}

Key words: social enterprises, financial condition of social enterprises, state support and corporate income tax exemptions for social enterprises, Lithuania

JEL code: $M 20$, M48

Social enterprises take rather small part of all legal entities, although they play an important role of social economy of any country. The enterprises involve in different activities and active social life the most vulnerable part of the society, make opportunities for the disadvantaged to be involved in the process of the creation of the economic value. According to their status social enterprises have corporate income tax exemptions and may apply for the state support in Lithuania. These tools help to reduce the operating ineffectiveness and improvement of financial condition of social enterprises. The latest political discussions initiated several governmental decisions, which reduced the level of state support and exemptions of corporate income tax for social enterprises under opinion, that such enterprises may misuse the status of social enterprises and accordingly the other tools of state incentives. Therefore, such changes may change the position of social enterprises and raise the need to evaluate their impact on the financial condition of social enterprises.

The purpose of the research is to evaluate the impact of state support and corporate income exemptions for social enterprises on the financial condition of social enterprises. The object of the research involves data of balances sheets and income statements of social enterprises, the information on the state support for the period of 2013 - 2017. The legislation analysis, the inductive and deductive, the methods of systematisation, comparison and summary of information were used for the research.

The research results show, that the reduction of corporate income tax exemptions would not make a significant impact on the financial condition for most social enterprises, as they would be able to apply corporate tax exemptions for small enterprises. Although the reduction of the state support may limit opportunities to develop business of social enterprises and to reduce the employment of disadvantaged population. 


\title{
EVALUATION OF THE POSITION OF THE SUBJECT OF CONTROLLING IN MEDIUM-SIZED COMPANIES
}

\author{
Daiva Tamuleviciene, Vilnius University
}

Key words: the subject of controlling, institutionalisation of controlling, controlling in medium-sized companies

JEL code: $M 49$

Introduction of the controlling system helps to improve the functionality of companies and the process of decision making as well as to increase the company's value. However, this system is more necessary for medium-sized and large companies rather that the small ones because the difficulties of management decisions usually increase as the company and its organizational and production structures grow. For the system of controlling to fully implement its functions, the subject of controlling must be defined; i.e. determine who is responsible for the introduction and functioning of the system and the implementation of strategic and operational tasks in the company. Many authors have studied the issues of the subject of controlling in large companies. Meanwhile, the issue of the subject of controlling in medium-sized companies has been studied only in a narrow and ambiguous way. The issues of the need for a controlling institution in medium-sized companies, identification of the position of a controlling institution in medium-sized companies' organizational structure and choosing between active and passive controlling are especially widely debated. The aim of the study is to analyse and evaluate the position of the subject of controlling in medium-sized companies based on the features of activity and level of institutionalization.

The article studies the subject of controlling in medium-sized companies based on two features characterizing the subject of controlling: the level of activity of the subject and the level of institutionalization. When the subject of controlling based on the first feature was studied, the aim was to examine when might medium-sized companies apply the passive controlling and when the active controlling. Based on the second feature the possibilities of application of self-controlling, institutional controlling and outsourcing/co-sourcing in medium-sized companies were evaluated. The position of the subject of controlling in medium-sized companies was defined after carrying out an analysis of scientific sources, an expert evaluation and a survey of medium-sized companies. The results of the study revealed that taking the number of employees in a medium-sized company and its scope of activity into account, the subject of controlling can be considered as: 1) active controlling which has to be realized through institutional controlling by developing controlling services inside finances department; 2) passive controlling which has to be realized through self-controlling by allocating some or all the functions to managers.

The research methods: analysis of scientific literature, methods of information classification, comparison, elaboration and generalization, expert evaluation method, a survey of medium-sized companies. 


\title{
TURNOVER RATIOS AND PROFITABILITY RATIOS CALCULATION METHODS: THE BOOK OR AVERAGE VALUE
}

\author{
Maria Tissen, University of Latvia \\ Ruta Sneidere, University of Latvia
}

Key words: ratios, analysis, book or average value

JEL code: M41, M49

Problem statement: The scientific literature of the turnover ratios and profitability ratios calculation offers to use book or average value of balance sheet calculation methods. Different schools of financial analysis nowadays offer many variations of the ratio calculations and even though the components of ratio formulas change, the meaning stays the same.

The aim of this research is to analyze the ratios calculation methods and to study the differences of the turnover ratios and the profitability ratios, based on how those are used by different schools of financial analysis and empirical research results.

Research methods used: The authors of this paper are using the international scientific literature, articles and research papers that help to study the measures of turnover and profitability ratios. For the empirical research, to compare the results using the book or average value of balance sheet calculations the authors have used the data from the annual statements of Latvian companies from different industries over a five-year period. In the research the authors have applied quantitative and qualitative research methods of economics such as the mathematical and the statistical methods, the ratio analysis, the graphical method, logically constructive methods.

Main results and findings of the study: The result of done research shows that differences exist between using the book and average value calculation for turnover ratios and profitability ratios, but quantitative research during five-years period shows that results are uniform and parallel.

Theoretical and practical implications: after having analyzed fifteen scientific sources of the different financial analysis schools, the authors of this research offer the most widespread turnover and profitability ratios interpretations and the use of ratios abbreviation for more convenient calculations.

As for the conclusions, turnover and profitability ratios calculation can be used as the book or average value, as based on the authors research the results are the same, but the authors offer to use the book value because it is the same exact as average value, but less time and data expensive. 


\section{FIRM AND COUNTRY-LEVEL DETERMINANTS OF GREEN INVESTMENTS: AN EMPIRICAL} ANALYSIS

\section{Wangchao Yuan, Concordia University \\ Thomas Walker, Concordia University \\ Stefan Wendt, Reykjavik University}

Key words: green investments, sustainability, environment

JEL code: G11, M14, O13

Green investments (GI) are investments necessary to reduce greenhouse gas and air pollutant emissions, such as investments in renewable energy technologies, without significantly reducing the production of nonenergy goods. Although GI has been growing rapidly, the drivers of GI have been scarcely researched. The purpose of this paper is to examine the determinants of corporate GI. We use environmental expenditures as a proxy for green investments on a firm level. We run a series of univariate and regression analyses to determine the impact of both firm- and country-level factors. We find that bigger firms tend to invest more in green projects, whereas firms that are more profitable are less likely to go green. In terms of country-level determinants, we find that GDP per capita and surface area are negatively related with GI, while population is positively associated with GI. Firms in English common-law countries and English-speaking countries invest less in GI than firms in other countries. To verify the results of our country-level determinants, we also perform a country-level test that employs a country's ecological footprint as the proxy for GI. The results of the latter analysis are mostly in line with the results of the firm-level analysis. The results provide implications for a broad range of stakeholders and can help policy makers to design environmental policies based on a better understanding of determinants of green investments. 


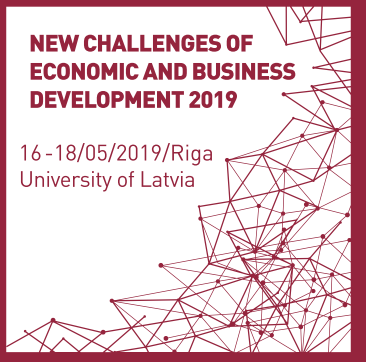

\section{Human}

\section{Development \\ and Efficiency}





\section{WORK AND LIFE BALANCE - THE NEW AGE MANAGEMENT MATTER}

\section{Annija Apsite, University of Latvia}

Key words: work-life balance, job satisfaction, stress

JEL code: J28, M54

In the past 25 years the topicality of work-life balance issues has been prominent. Even apart from the dramatic statistical data about sicknesses caused by imbalance and burnout, surveys make it clear that individuals are struggling to enjoy living because of the growing workload and the persistent presence of technologies around us. A high imbalance is not only harmful for the employees, but also threatens the functionality and efficiency of the companies. It was 1987, when scientists detected that stress related issues are making a 300 billion loss every year in USA alone, now the situation is even more dramatic. Work-life imbalance causes loss because for several reasons - intentional or unintentional absence at work, high employee turnover, low productivity, insurance costs and other reasons.

One of the main indicators connected with work-life balance is job satisfaction. Job satisfaction is a pleasurable or positive emotional state resulting from the appraisal of one's job or job experiences. Job satisfaction is created by many factors, which can all be adjusted and changed for the organization to do better. Thus, if an employee is not satisfied with job, it will be a great challenge to sustain work-life balance.

The aim of this research is to evaluate the importance of this topic in Latvia and to detect the major steps to even the balance out between work and private life. Author gathered the available statistical and research data to assess the current situation among employees in Latvia. The research shows that unemployed people in Latvia tend to feel less stressed than those who are employed, which shows that although unemployment itself may cause stress, workplace and employment creates even a greater room for stress related factors. Also, $66 \%$ of employed people state that they feel too tired after coming back from work to do their other duties. Further author is determined to conduct a research to later provide a model, which could be practically used by managers to help them with managing the work-life balance for their employees. The practical meaning of the research is to help managers and to provide a better environment for the society to live in by balancing their work and private life needs. 


\title{
THE ROLE AND TENDENCIES OF DEVELOPMENT OF THE SOCIAL MEDIA IN HUMAN RESOURCES MANAGEMENT
}

\author{
Ilze Boitmane, University of Latvia \\ Inesa Voroncuka, University of Latvia
}

Key words: human resources management, social media, social networks JEL code: $015, M 31$, J24

Social media as a topicality in human resources management has gained significance during the recent years. The goal of the article is to determine the role and priorities of using social media and to examine the types of social media currently used by organisations.

The theoretical frame of the research is based on the structure of social media, characterised by two directions: personnel development that includes the inner environment of an organisation and the brand management of the employer that includes the outer environment. The main topicality and problem of the research is that employers are unable to provide companies with labour force, and employers' activities in the social media environment are insufficient and not organized professionally in the context of human resources management.

The quantitative and qualitative research methods were used in the research. The purpose of the article is to study the habits of using social media in small and medium-sized enterprises. It is based on a pilot study with non-representable sampling, where 79 small and medium enterprises both from the private and public sectors were surveyed.

The results of the research showed that, currently, organisations use the social media at a low level in their operations, and maintain and develop their social media profiles. The employees of the organisations are involved in maintaining the social network profiles. The data collected in the research reflect that organisations associate the use of the social media with human resources selection, attraction, publishing of the vacancies, and developing content in their social media profiles.

The data provided in the conclusions show that small and medium-sized enterprises use social media in human resources insufficiently. The proposals are to increase the intensity and competence of corporate social media use. 


\section{IMPACT OF DECISION- MAKING IN NON-PROFIT ENTERPRISES OF DISABLED LIVING STATIONS}

\section{Martin Josef ten Bosch, University of Latvia}

Key words: decision- making; non-profit organization

JEL code: $L 31$

With the introduction of the Federal Participation Act (BTHG) on 1 January 2017, the basis for the provision of integration assistance by cost and service providers for people with disabilities has been restructured. In the future, the existing provision of the entire housing needs of disabled people will be broken down into the provision of living costs, such as rental costs and meals, as well as into specialist hours and care services.

The service providers of these previous housing services will have to reposition themselves within the framework of their decision to introduce these services until the law is fully integrated in 2020 .

The positioning of the service providers by the legislator is predetermined. The decision of the service providers for new housing offers thus depends on the legal requirements and also on the will of the affected persons themselves.

The splitting up of the provision of services means that decisions are no longer subject of the pure will of the recipients. The providers will analyses the factors influencing decision-making and this will depend on the knowledge of the decision-makers and also on the internal management behavior of the system as well as on communication.

The parameters are highlighted in the research:

- Description of the organization

- Parameters for decision- making

- Impact factors of decision- making

- Acceptance for and by the clients

- Changing of the relationships between the actors

- A first expert survey differs in wide range.

The expectation is that impact of the decision- making of the enterprises leaders in the non- profit sector will have a significant impact on the clients in the future.

Which exact effects can be observed of the analysis of customer behavior will be lead to a conclusion. 


\title{
ENCOURAGING EMPLOYERS' INVOLVEMENT IN THE TRAINING OF FUTURE LABOUR FORCE
}

\author{
Ilze Buligina, University of Latvia \\ Biruta Sloka, University of Latvia
}

Key words: employers, labour force, vocational education and training, motivation

JEL code: $125, I 28, O 15$, L38

Links to the labour market developments determine the quality of vocational education and training and the future labour force it prepares. Even though employers suffer from the lack of competent labour force, they are not always motivated to get involved in the development of such labour force. In Latvia a relatively recent development is work-based learning leading to students' early involvement in the actual labour processes and environment. At the same time evidence shows that employers are often reluctant to became participants of work-based learning, and there is an urgent need to study the motivating factors to take more employers on board regarding work-based learning.

The current paper analyses results of scientific research in this field by using the empirical results of a survey implemented among employers who are already familiar with the work-based learning concept and principles but show a varying degree of commitment. The aim of the research was to identify the factors that increase the attractiveness of work-based learning in the eyes of employers and that might potentially lead to the employers' more active involvement in work-based learning.

The methods used: employers' survey results analysis in scale of 1-10. For analysis of data indicators of descriptive statistics (means and indicators of dispersion) as well as cross tabulations and multivariate analysis - factor analysis were applied. The results have indicated the priorities of motivating factors in the implementation of work based learning allowing for better decision making for public administrations in the field of education. The conclusions can be drawn that employers' awareness of the possibilities offered by work-based learning still needs to be improved, since a certain part of the desired motivating factors are already existing in practice. At the same time the existing legislation needs to be reviewed to test its compliance with actual labour market developments and conditions of stakeholder involvement. 


\section{THE IMPACT OF THE LATVIAN LOCAL GOVERNMENT REFORM ON ECONOMIC DEVELOPMENT}

\section{Lauris Gruntmanis, University of Latvia Andrejs Cekuls, University of Latvia}

Key words: local governments, business, reform

JEL code: $R 11, H 11$

In order for the current Latvian administrative-territorial division to become economically sustainable, an administrative reform is needed. This need stems from the fact that $90 \%$ of local governments are not selfsufficient and rely heavily on grants from the Fund for the Equalisation of Local Government Finances. However, this means that taxpayer money is being misused. The administrative centres of some municipalities have no economic reason to exist, other than being the main employer in the region. The reform, which was finalised in 2009, has left much to be desired, because about a half of the 119 local governments do not meet the legal criteria. The incomplete nature of the reform has created unfavourable conditions for a part of the Latvian population. Some local governments are even unable to fulfil their functions. Furthermore, at times, they fail to show initiative for developing the business environment within their territory.

This research aims to define the factors of the local government reform that encourage economic development at Latvian local governments. It examines the existing model of local governments and evaluates the potential impact of the next reform on regional economic development. The study investigates the possible directions and types of the reform.

Static research, legal framework and general scientific research methods were used in the development of this study. The Latvian local government system was evaluated in comparison with local governments of other European countries.

Conclusions: after the reform, local governments should be able to fulfil their statutory functions and provide citizens with services of adequate quality. At the same time, we should introduce mechanisms (such as tax policy, etc.) that will encourage local governments to develop business-friendly environments, as well as make their budget more dependent on their own socioeconomic activities. 


\title{
THE MODERATING ROLE OF SENSE OF COHERENCE BETWEEN PERCEIVED SUPERVISORY SUPPORT AND JOB BURNOUT SYMPTOMS
}

\author{
Frank W. Hager, University of Latvia
}

Key words: supervisory support, burnout, mental exhaustion, sense of coherence, SoC JEL code: $M 12$, J24, J28

Managers not only bias the working climate and the culture of their organization, but through their ability to provide social supervisory support, they also have a considerable influence on job satisfaction and well-being of employees. Conversely, the consequences of poor supervisory support vary from heightened perception of stress, an intention to leave, absenteeism to serious psychological consequences like Burnout. However, as several researches show, the risk of developing a Burnout is not every employees concern. In this research it is understood, that perception of and the response to leadership behavior as well as supervisory support is a function of personal traits. One of these individual characters is the Sense of Coherence (SoC). This research unravels the moderating effect of the $\mathrm{SoC}$ on the relationship between perceived supervisory support and Burnout symptoms. Sense of Coherence describes the extent, to which the individual has a pervasive, enduring and dynamic feeling of confidence that his/her environment is predictable and that things will work out as well as can reasonably be expected. Understanding the relationships of individual characteristics as well as supervisory support as a job characteristic in connection with burnout is necessary for in order to be able to initiate appropriate preventive measures. The sample comprises of managers $(\mathrm{N}=82)$ from different German industries. In the examination, the Survey of perceived Supervisory Support (SPSS), the Maslach Burnout Inventory (MBI-D) and the Sense of Coherence Scale (SoC-29) were used. It was hypothesized that employees' Sense of Coherence moderates the relationship between perceived supervisory support and burnout symptoms among managers. In the line with the predictions, a significant correlation between supervisory support and Burnout the Burnout Dimensions "emotional exhaustion" and "professional fulfilment" among the interviewees was found. Also a significant moderating effect of Sense of Coherence on the relationship between perceived supervisory support and Burnout symptoms was determined - an indicator for the responsibility of own spiritual views to interpret and valuate potential stress situations either as problems and intimidations or as challenges and growth opportunities. The findings are valuable in the framework of human resources management, organizational development and leadership research. 


\section{ECONOMIC ACTIVITY CHANGES DUE TO SOCIO-DEMOGRAPHIC FACTORS}

\section{Kristine Lece, University of Latvia}

Key words: children, economic activity, education, marital status

JEL code: $O 15$

Background: Due to the preparation for the Population Census of 2021, the Central Statistical Bureau of Latvia is publishing economic activity status statistics annually, dividing the population into two categories - economically active or inactive individuals. When comparing the economic activity status on the individual level from the Population Census in 2011 and the beginning of 2017, it was observed that economic activity status changes are not distributed evenly within the population. Due to socio-demographic factors, some groups of the population are more vulnerable to economic inactivity.

The aim of the study was to determine the relevance of socio-demographic factors for economic activity on the individual level and identify the groups that are more vulnerable to economic inactivity. The following socio-demographic factors are analysed in the study: age, education level, profession, marital status, birth of children and place of residence.

Data and methodology: The study uses data from the Population Register of the Office of Citizenship and Migration Affairs, Population Census 2011, Ministry of Education and Science, and others on the individual level. The study analyses economic activity changes between the Population Census 2011 and January 1st, 2017, of individuals who were 15 to 59 years old at the time of the Population Census 2011 reference date.

Results: It is concluded that economic activity status changes vary among different age groups. Individuals who were 15 to 24 years old at the Census 2011 are completing their studies and some of them are beginning to work, while part of people who were 55-59 years old at the Population Census are retired. Therefore, the age group 25 - 54 years old, as a group less affected by age, has been studied in more detail. The study shows that most vulnerable to economic inactivity are people with a primary education and individuals who lived in rural areas during the census. Regarding the profession during the census, more vulnerable groups are agricultural, forestry, fishery workers, craftsmen as well as simple labourers. Regarding the marital status, the most vulnerable group is single men. However, a birth of a child during the period of observation (2011-2017) is related to an active status of economic activity at the beginning and end of the reference period. 


\section{ANTHROPOLOGICAL FAMILY TYPE AND ITS IMPACT ON SUCCESSION PLANNING IN FAMILY BUSINESSES - RESEARCH REPORT}

\section{Wojciech Popczyk, University of Lodz}

Key words: family business, anthropological family structures, socialization, succession planning, entrepreneurial behaviours

JEL code: F23, F20, F00, F61, L26, M16, M21, O19, O32, O30

Generational succession in family businesses determines their longevity, development, long-term success and allows such entities to maintain and enlarge family social capital a source of competitive advantage over their non-family counterparts. Empirical research results on succession show that this process is extremely difficult and in majority of cases ends unsuccessfully. The purpose of this paper is presenting the anthropological approach to socialization processes of young generation within different types of families, which can help explain the source of succession failures in family businesses. There are four types of families described by two variables: liberty/authority, equality/inequality characterizing the relations between generations and within the younger generation itself.

The research problem is the question if and how the family socialization pattern influences:

a) the entrepreneurial orientation of the young, and

b) their readiness to take over the family business in the case of entrepreneurial families.

The Author refers to own quantitative, questionnaire research carried out in 2018 year on the sample of 261 management students at the Lodz University, which prove that the socialization within entrepreneurial families has a more positive influence on the entrepreneurial behaviours of the young than it takes place in the rest of families and what's more that female representatives of younger generation in families running businesses are even more entrepreneurial but at the same time less sure as for succession than their male siblings. Finally, the Author identified the dominating type of families in the Lodz region and verified potential problems with succession in businesses controlled by the nuclear egalitarian families on the base of the anthropological concept. 


\section{EVALUATION OF LABOR SKILLS IN LATVIA}

\section{Karlis Purmalis, University of Latvia \\ Sandra Jekabsone, University of Latvia \\ Edgars Kassalis, University of Latvia}

Key words: skills, skill set, skill demand, skill demand forecast

JEL code: J01, J08, J24

Skills are a decisive factor for the country's economic development and social well-being. The OECD emphasizes that skills can help countries integrate into global markets and specialize in technologically advanced industries, and countries need to invest in skills not only to help people enter the labor market and protect them from the risk of job loss and low quality of work, but also to increase international competitiveness and economic progress in an interconnected world. The development of the global economy and the dynamic changes in the labor market raises a number of problems related to the balancing of labor supply and demand not only in general, but also in certain groups of professions. This leads to the need to complexly address issues related to the quantitative forecasting of labor demand by individual occupational groups, along with the establishment of appropriate changes in the demand for skills. The aim of the research is to evaluate the most demanded labor skills in Latvia within the framework of certain groups of professions, as well as trends in the demand changes according to the skills of employees in order to better identify the specialists and their skills required for the national economy in accordance with the needs of the national economy. A matrix of skill sets was developed within the framework of the study, which summarizes the skills characteristic of each occupation group according to their importance, as well as the list of the most demanded skills sets in the Latvian labor market (Top 10). By analyzing the skills groups corresponding to the occupational groups, it was concluded that in all major occupational groups among the most important skills were mentioned to comply with the requirements of the regulatory enactments and other regulatory documents, to plan and organize the work to be done, to work in the team / group, to communicate and cooperate, and to self-educate, to acquire new knowledge and skills. These skill sets are common to many occupational groups, which is also reflected in the most demanding skills forecasts. 


\title{
PROCESS MODELING ELEMENTS, PATTERNS AND SCOPE
}

\author{
Uldis Rozevskis, University of Latvia \\ Rita Freimane, University of Latvia \\ Juris Krasts, University of Latvia \\ Rita Zuka, University of Latvia
}

Key words: business, process, qualitative models

JEL code: $M 12$, M15

Problem is insufficient use of qualitative research methods in business management research. Goal of qualitative research in business and economics is to build an understanding of phenomenon (processes in business, management, economic), essential elements, their relationships, possible links and causation. Quantitative research measure, appraise, test and prove elements dependencies and causation. Both methods (qualitative and quantitative researches) use forceful tools for reflecting findings - different types of models: logical, mathematical. Both type of models (logical and mathematical) must correspond to each other for effective research organization and realization. Transformation form qualitative model to quantitative model should be simple and appropriate.

Research aim is to find essential elements and patterns for process modelling in the first, qualitative phase of scientific research. Qualitative process model idea lets choose the right locus for process measuring, suitable indicators and appropriate tools for quantitative analyses.

Qualitative research methods where used. In accordance with research theme, consonant focus groups and respondents (students, scientists, staff) were observed while building, discussing process models, modelling goals and tasks. Multiple models building cases were studied. In-depth interviews where applied when necessary to understand process modelling goals and tasks.

Study findings allow identify certain types of process elements and patters, which are proposed to use for qualitative process modelling for the purpose of further quantitative research.

Implications and conclusions. In beginning steps of process innovation and reengineering is important to recognize the situation, communicate in common language and logical models can help on it. Next steps include solutions testing, proving by mathematical models, simulation. Main concepts understanding in model building and presentation may provide faster and cost-effective changes in business and management development. 


\title{
THE ASPECTS OF COMPETENCY IN THE CONTEXT OF EDUCATION SITUATION IN LATVIA
}

\author{
Aija Staskevica, University of Latvia \\ Margarita Dunska, University of Latvia
}

Key words: competency, higher education, competency-based approach, core competencies, skills JEL code: 123, J24

Competency models are a useful tool for various organisations and, in particular, academic institutions in order to develop a quality education programme based on the up-to-date skills and behaviours that are currently required from employees. The importance of competency model development is emphasised at the EU level. In 2018, the European Council issued recommendations on key competencies for lifelong learning identifying key competencies that allow individuals to fully participate in public life and successfully change jobs in the labour market as well as would improve the chances of their employment or self-employment.

The aim of the research is to identify the main aspects of competencies in the field of higher education in Latvia as a result of which it would be possible to determine the possibilities for competency development in Latvia. The research methods used to achieve the goal are as follows: literary review, textual analysis, document analysis, methods of data processing, statistical analysis and case study.

The results of the analysis showed that competency-based approaches evolve in academic environment, the development of competency approach influenced significantly the form of study programmes and courses descriptions at the University of Latvia, Faculty of Business, Management and Economics. Over the last 10 years, the number of educational institutions and students in Latvia has decreased significantly which has a negative impact on this sector. On average, people in Latvia speak more foreign languages than people in the European Union; their problem solving, communication and information skills are at an appropriate level while digital and software skills are averagely lower than average in the European Union. The results of the research can be theoretically and practically applied in the academic field by developing and implementing educational programmes that would be based on today's crucial key competencies.

It was concluded that regardless of current difficulties in the field of education, knowledge of foreign languages is a competitive advantage of Latvia's people in the international market. Support should be provided to the digital and software skills that are less developed than the average in the European Union. As well it is essential that institutions of higher education understand the aspects of competency, because they have to adapt their documentation and study process implementation according to new legislation related to competency approach. 
100. 


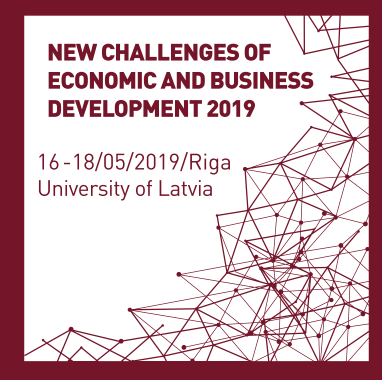

\section{Industries and \\ Productivity}





\section{TRENDS AND DRIVERS OF PRODUCTIVITY GROWTH IN LATVIA}

\section{Daira Baranova, University of Latvia}

Key words: sustaining productivity growth, labour productivity, productivity, productivity measures JEL code: D24, E24

Work on productivity will continue to be a key theme for researchers and policy makers. Productivity growth has generally slowed over past decade. Designing policies to rise in productivity and understanding global challenges affecting the growth is an important current issue. OECD, IMF, World Bank, the European Commission deal with different aspects of productivity. The research aims are to analyse fondations of productivity measurement and causes of actual trends, policies fostering productivity growth and promoting sustained economic growth.

The research consists of two parts. In the first part, review of OECD papers on productivity have been done. OECD methodology of productivity measurement and relations between structural reforms and productivity growth is the focus of this part. Second part of the research deals with trends and causes of the current situation. The problem of productivity growth in Latvia and in the EU is analysed based on empirical data and calculations. This part of the research is also dedicated to economic policy fostering productivity growth.

Results of the paper find different factors with negative impact on productivity, and factors with positive impact on productivity. Effects on productivity depends on the purpose of productivity measurement as well as on impact on productivity in the short-run or in the long-run. 


\title{
APPROACH FOR A PRODUCTION PLANNING AND CONTROL SYSTEM ARCHITECTURE WITH INTEGRATION INTO AN ENTERPRISE RESOURCE PLANNING SYSTEM FOR THE USE OF ADDITIVE MANUFACTURING
}

\author{
Wjatscheslav Baumung, Reutlingen University \\ Herbert Gloeckle, Reutlingen University \\ Vladislav V. Fomin, Vytautas Magnus University
}

Key words: $P P C, E R P$, additive manufacturing, $3 D$ printing, architecture JEL code: 014, L16, M11

Additive manufacturing (AM), also referred as 3D printing, is a disruptive innovation and is already indispensable in the field of prototype development. In the course of the constant development of the technology, it finds increasingly into the industrial area. The use of this technology offers the production of parts without component-specific tools, which leads to a higher geometric design freedom in the construction area and to a novelty of flexibility in production processes. This enables dynamic use of production resources until the start of production. In the Production Planning and Control (PPC) module, this allows agile reactions to changes in the areas of detailed scheduling and process planning, and a high level of efficiency of the production facilities by combining different orders with each other. In order to use these advantages, a PPC system is required that can handle these new possibilities, especially when using multiple facilities in a company or partner network. For the development of the architecture we have examined different scopes of the traditional PPC systems and derived those scopes which have to be adapted, are needlessly or should newly added. Based on these requirements, a conceptual design for a PPC overall system for AM technology will be presented and integrated into an Enterprise Resource Planning (ERP) system. The interaction and task areas of the individual system sections are pointed out. The technical applicability will be demonstrated by individual implemented partial areas. For further research, sections for which no technical solution exists so far have been identified. The presented solution approach promises for the customer a price reduction of the use of the AM technology by a more efficient utilization of the manufacturing facilities and a shortening of the reaction time during the processing. For the manufacturer, machine failures can be directly taken into account by distributing components to other internal and external company facilities. 


\title{
STRUCTURAL CHANGE PATH AND ECONOMIC GROWTH PERFORMANCE OF POLISH ECONOMY
}

\section{Pawel Dobrzanski, Wroclaw University of Economics Leon Olszewski, University of Wroclaw}

\begin{abstract}
Key words: transition economies, structural changes, economic growth, competitiveness JEL code: D24, G34, L33
\end{abstract}

In 1990, Poland and later other Eastern European countries moved away from the centrally planned economy system by implementing a package of stabilization and structural reforms IMF and WB (SAPs). Poland with strong political support from the Solidarity Movement has decided for a radical break with the old system. The first half of the 90's was marked by economic stabilization policies. High inflation, inefficient public enterprises sector, external debt threatened social explosion and chaos difficult to control. The political determination of the Solidarity movement and the strong desire of the society to break communism have contributed to the application of shock therapy to change the system.

In our paper we present a comparative analysis of systemic changes in the first period of implementation of the principles of the Washington Consensus. We focus on structural policy aimed at modernizing the economic structure and creating competitive capacity on international markets in the ongoing globalization process. We consider changes taking place in the structures of economies in the period 1992-2008. Transition period can be divided into three periods. This first period till 1995 was stabilization phase. In the second period form 1996 till 2003 the elements of aqui communautaire set in the EU accession were consistently implemented. The third period contains years after accession 2004-2008.

The aim of our analysis is to partially answer the question: what effects resulted from the implementation of a shock therapy in the sphere of productivity. The paper presents changes in labor productivity caused by structural changes and those that were the result of modernization of production technology. Authors used Shift-Share Analysis. Decomposition equation for labor productivity growth was used. Labor productivity growth in an economy can be achieved by technological change, improvement of production process etc. (pure labor productivity growth) or by moving labor from low-productivity sectors to high-productivity sectors (structural labor productivity growth).

The analysis shows that Poland improved both pure labor and structural productivity growth thanks to the changes and modernization of economic structures. In analysed period productivity increased in all sectors, however the most significant rise was noted in financial intermediation; real estate, renting and business activities. Simultaneously employment decreased the most in agriculture, hunting and forestry; fishing - the sector with the lowest productivity. In all analysed years pure productivity indicator was positive. However, structural productivity indicator was negative after first years after transition, that obtain the highest value after accession to EU. The research can be used by the Government agencies for industrial development policies. The project is financed by the Ministry of Science and Higher Education in Poland under the programme "Regional Initiative of Excellence" 2019 - 2022 project number 015/RID/2018/19 total funding amount 10721 040,00 PLN. 


\title{
DYNAMICS OF REAL LABOUR PRODUCTIVITY AND REAL COMPENSATION IN LATVIA
}

\author{
Rita Freimane, University of Latvia \\ Janis Priede, University of Latvia \\ Roberts Skapars, University of Latvia
}

Key words: labour productivity, wages, panel data models, employee compensation JEL code: J24, J30, C23

Relationship of labour productivity and wages is an important issue not only for economists, but also for policy makers, and trade unions as it represents how fair is distribution between labour and capital. In the last decades, we have witnessed that in the EU wage growth has been lagging productivity growth. At the same time in Latvia, also in some other central Eastern European member states, wages increased more than productivity, rising concerns about disbalance in the economy. However, comparison of wage level and productivity level in Latvia and respective levels in the EU15 shows that wage level in Latvia is much below the EU15 average value in absolute terms, but also in relation to productivity level. To understand whether dissimilarities in wage and productivity development are dangerous for Latvia's economy, it is worth looking at the situation in different economic sectors, as well as make comparisons with other EU countries.

The aim of the paper is to investigate the dynamics of real labour productivity and real compensation in Latvia in different economic sectors and compare with the other EU member states. The empirical analysis was conducted with comparative analysis and panel data regressions for the time period from 2004 till 2017. For robustness checks, different alternative specifications were compared.

Our results confirm significant linkage between real labour productivity and real compensation. The gap between these two variables depends on cyclical conditions, the different economic sector with their specifics, the Russian sanctions and labour market structure. The findings of the study is a necessary input for the further microanalysis of the industry with would lead to better policy-making regarding productivity improvements in Latvia. 


\title{
ENTERPRISE RESOURCE PLANNING SYSTEMS: A CONCEPT CONCERNING THE SPECIAL OPPORTUNITIES AND REQUIREMENTS OF ADDITIVE MANUFACTURING
}

\author{
Herbert Gloeckle, Reutlingen University \\ Wjatscheslav Baumung, Reutlingen University \\ Vladislav V. Fomin, Vilnius University
}

Key words: ERP, PPC, additive manufacturing, $3 D$ printing, architecture

JEL code: 014, L16, M11

Enterprise Resource Planning Systems (ERP) cover all logistical and financial activities, which are necessary to control an enterprise. From the point of view of end-to-end processes, such as from sales to delivery, one important component is always included: Production Planning and Control (PPC). Additive manufacturing (AM) allows the production of finished goods in a single step on general purpose machine. With this technology, the production is no longer bond on a shop floor with available fixtures and a specific set of tools. As a result, a network of points of production $(\mathrm{PoP})$ can be established more or less worldwide and always in the immediate vicinity of the customer location. For this purpose, an already researched area must be considered in the PPC, the solutions for combining different parts into one print job. For this purpose, parameters are identified and highlighted from a technical point of view as well as during the scheduling of production orders. This paper expands these approaches and focuses on the issue of cost-optimized production within a logistics network of PoPs, in terms of transport time, transport cost and production cost at different locations. In order to meet these new requirements, extensions and connections to ERP systems are described and the effects of such a business models with a widely distributed production network are discussed. An important extension of the ERP system is the network management of AM facilities with all necessary master data and interfaces. Another major extension is the module for cost-optimized order placement, for which we also consider and discuss the push and pull approaches. The ability to combine sales orders into one print job leads to the logistical requirement to separate them for production and assign each part to the associated sales order for delivery. For the necessary re-assignments to the respective customer orders different approaches for the identification of parts are presented and discussed. 


\section{PRODUCTIVITY DYNAMICS AND THE PRODUCTIVITY TRAP: PROBLEMS AND SOLUTIONS IN LATVIA}

\section{Sandra Jekabsone, University of Latvia \\ Irina Skribane, University of Latvia}

\section{Key words: productivity trap, labour cost, economic growth, structural changes} JEL code: $E 61,011,047$

By analysing changes in productivity and labour costs in Latvia from 2013 till 2017, we can see that growth of labour costs exceeds the growth of productivity by more than 2 times in both, tradable sector and total economy. Slow growth in productivity compared with the labour and other production expenses lead to an increase in the price of final goods and services, which negatively corresponds with producers' competitiveness in both internal and external market. Furthermore, this leads to a drop in consumption of domestic production and inefficient production facility usage, resulting in declining economic growth rates. The rapid growth in labour costs is mainly associated with the tight situation in the labour market. Even though the unemployment rate is still quite high, especially in the region of Latgale, the absence of working hands is perceptible more and more around Latvia, which also maintains the pressure on the salaries. The upward trend for salaries is also influenced by the convergence process, which is inescapable in EU opened labour markets. Comparatively, high labour emigration reflects Latvia's weak competitiveness in those markets, especially due to the low wage, which in turn is related to the low productivity of internal producers. Therefore, increasing the productivity level and slowing down the gap of productivity with highly developed countries is the most important precondition for Latvia's competitiveness to strengthen and economy to grow. The goal of the research is to appreciate the dynamics of labour productivity and the level of productivity between Latvia and EU average, as well as, to find the main factors which influence the productivity convergence rates to drop, making productivity trap. The research tasks, to determine possible solutions for labour productivity increases, are to detect the factors which have influenced the labour productivity in last 10 years in Latvia, to compare the productivity in Latvia with EU, as well as, to detect the factors which influenced the productivity convergence rates to decrease.

In the analysis, there are used different high quality and quantity research methods, for example, analysis of scientific literature, calculation of average and relative sizes, grouping, comparison, decomposition etc.

The results of research conclude, that in the last years productivity growth rates in Latvia before the crisis were one of the sharpest in EU, which contributed with convergence process, decreasing gap with EU average level. However, in after crisis period (from 2013) growth rates of productivity have significantly dropped and, according to Eurostat data, are only 0.2 percent points at average a year, which shows that Latvia is close to or already is into productivity trap. To avoid the trap, it is important to detect separate industry problems (the study of barriers at individual company and sector level) and to promote the structural changes in the national economy (moving towards high technology industries). 


\section{THE ROLE OF PROCESS IMPROVEMENT TOOLS AS CRITERIA OF EVALUATATION OF SUPPLIERS IN PRODUCTION SECTOR}

\section{Maciej Urbaniak, Lodz University}

Key words: improvement tools, supplier evaluation, production sector, supply chain management JEL code: $M 11, M 21$

The purpose of this paper is to present the role of organisational improvement tools as criteria for periodical evaluation of suppliers in production companies operating in the Polish market. The identification of these criteria of evaluation of suppliers was based on an analysis of the literature, as well as on the results of empirical research conducted by the CATI technique and covered 300 producers from the chemical, metal and automotive industry sectors operating in Poland. The results of the conducted research indicate that the main supplier requirements relating to technical quality of products, shortening cycles of process implementation and willingness of the supplier to reduce costs. One could also observe that for many industrial clients, their relationships with suppliers are not just confined to fulfilling rigorous requirements connected with the implementation of process improvement tools. Increasingly, they recognize that building their competitive advantage also requires building partnerships with suppliers that are manifested in joint projects or support programs in the field of effective application of the requirements of tool (like quality, environmental and safety management systems, Toyota Production System or Lean Management concept), which have an impact on the improvement of the products and processes in the supply chain. The main reason for the transfer of these tools is the requirements of the production companies towards their suppliers which focus on ensuring technical quality, improvement of environmental performance, reducing costs (through an increase in the efficiency of processes) and shortening operational processes cycles. 
100. 


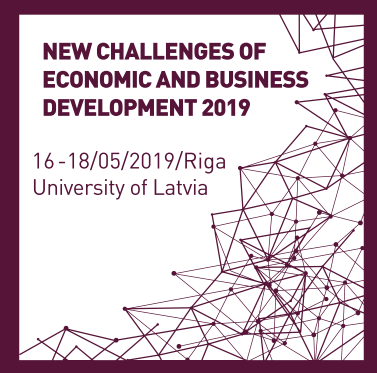

\section{International \\ Economics and Globalization}





\title{
EU'S ASSISTANCE PROGRAMMES IN SUPPORT TO SUSTAINABLE ECONOMIC GROWTH IN CENTRAL ASIA
}

\section{Liga Andersone, Riga Stradins University}

\author{
Key words: EU, Assistance programmes, Central Asia
}

JEL code: $F 35$

The aim of a paper is provide an analysis EU's regional assistance programmes for Central Asia aimed at facilitating region's sustainable economic growth. Sustainable and inclusive growth remain a challenge for most of Central Asian countries. For this research, the author used quantitative research method by applying the hypothesis testing approach.

Currently EU's assistance programmes for Central Asia are implemented mostly through the Development and Cooperation Instrument. A big proportion of regional allocations are channeled through a blending mechanism, the Investment Facility for Central Asia by fusing EU's development assistance with loans from European financial institutions. There are ongoing EU's internal discussions regarding a new MultiAnnual Financial Framework. Commission's current budget proposal suggests simplifying the funding architecture for the EU's external actions by creating a new financing instrument in support for external relations. The new Neighbourhood, Development and International Cooperation Instrument would integrate existing financial instruments and would have and overarching geographical scope.

Simultaneously, the EU is working on a revised strategy for Central Asia to be finalised by December 2019. In June 2007, the European Union adopted its strategy for Central Asia by enhancing its partnership with Central Asian countries and facilitating regional cooperation in the region. To this end the EU should send an encouraging message to all countries in the region by inviting them to work closer in facilitating political contacts and creating economic and trade links in the region and with neighbouring countries. It will provide political guidance for programming new assistance programmes for Central Asia, thus complementing EU's political messaging by practical support. Against this background, the paper provides recommendations for a next programming period for EU's assistance to Central Asia to continue regional support programmes aimed at sustainable economic growth, putting an emphasis on blending mechanisms. 


\section{TOURISM ASSOCIATION DEVELOPMENT TENDENCIES IN LATVIA}

\section{Kristine Berzina, University of Latvia}

\section{Key words: tourism, tourism associations, cooperation}

JEL code: $M 10$

Tourism as one of the leading industries has gained attention from scholars, researching different aspects tourism destination development influence factors that boost further progress as well as those that create obstacles. One of challenges that tourism destinations need to overcome is heterogeneous nature of tourism industry that is solved by professional and regional tourism association creation. Current tourism technology from one side creates additional potential for tourism enterprises and destination, from other side could decrease need for traditional tourism associations.

The Investment and Development Agency of Latvia (LIAA) is indicating eighteen active tourism associations in Latvia. These tourism associations have been going though different development stages in Latvia, first ones started their activities already straight in time of struggle for independence and are actively functioning even now after 28 years of intensive involvement in industry development. On the other hand some of tourism associations have hardly surviving and are forced to bootstrap. Research aims to analyse different stages of tourism association development and draw conclusions on development strategies applied by tourism association in Latvia. Research method will comprise in-depth interviews with tourism association management during the year of 2018. Research findings show variety of development strategies applied both by professional tourism associations as well as regional associations. Conclusions indicate most successful tourism association management model, evaluation of current development stage of tourism associations in Latvia as well as evaluation of future development potential. 


\section{THE IMPACT OF ECONOMIC GROWTH ON QUALITY MANAGEMENT SYSTEMS IN PHARMACEUTICAL INDUSTRY}

\section{Johannes Bramboeck, University of Latvia}

Key words: quality, economic growth, pharmaceutical industry, globalization, pharma JEL code: 040, L65, F60

Quality management systems are becoming increasingly important for economic success in pharmaceutical industry. Health authorities worldwide have been set more and more focus on product quality and services. Global stakeholders such as patients, clients and government agencies require the highest possible quality standards, manufacturing and documentation practices. A functioning quality management systems concept is indispensable to prove the safety, quality and effectiveness of the products. Quality is next to costs, availability of products and services one of the main success factors. To ensure this, companies transform their organizations evermore globally, influenced by the economic growth of this industry. The number of mergers and acquisitions in the pharmaceutical industry are a sign of progressive globalization and changing focus area. The aim is often the focus on their core competencies and strengths. Core issues are site and transnational systems, productivity, costs, production strategies and availability. The quality assurance departments should have adequate knowledge and system access across the whole pharmaceutical production chain to ensure ongoing compliance in the company worldwide. The local company organizations should fulfill all these requirements, hence to increase competitive advantages on the international market. The central research question is if a reliable quality management system has significant impact on the economic success of pharmaceutical companies. The current requirements on quality management systems, which are influenced to a certain degree by economic growth, are huge needs for the daily pharmaceutical production business. The reputation of a company is one of the most important assets of a globally successful business organization and often a huge effort is needed to restore the trust after incidents in quality and compliance. The thesis approach is to conduct research through semi-structured expert interviews and field study. The case study shows many and deep information and creates a holistic view. The combination of interviews and case study provides a broad spectrum and representative data. The expected outcome is to support pharmaceutical companies in their decision-making processes. 


\section{THE IMPACT OF INTERNATIONAL TRADE ON EU MEMBER STATES PERFORMANCE}

Vida Davidaviciene, Vilnius Gediminas Technical University Alma Maciulyte-Sniukiene, Vilnius Gediminas Technical University

Key words: economic openness, export, import, productivity, growth JEL code: $011,047, P 45$

One of European Commission priority is to achieve balanced and progressive trade policy that ensures boosting EU economic growth. However, growing international trade flows do not necessarily guarantee economic growth. The impact of international trade on the growth of countries is a rather widely discussed issue. Previous empirical investigations have shown heterogonous results. Some of the previous studies examining effect of international trade have revealed that export and/or import had a positive impact on EU member states economic performance. However, the results of other studies indicate that international trade impact on countries growth is insignificant or even negative. In this study, we create the hypothesis that the effect may vary according to the level of productivity achieved by the countries and that it may occur after a certain period of time. The aim of this investigation is to evaluate impact of international trade on EU countries performance depending on the level of productivity achieved by the countries and taking into account longterm effects. Moreover, in the last decade two different paradigms of the impact of foreign trade on growth have emerged: export led growth (ELG) and import led growth (ILG). The study made it possible to test these theories empirically. We used: i) the cluster analysis for divide countries into groups by productivity level; ii) Ordinary lest square (OSL) and fixed effect (FE) estimator, in regressions model including counties dummies and times lags, for investigation international trade impact. Investigation results reveal that both import and export positively influenced performance of EU member states and there is no significant difference on impact depending on level productivity of the country. Moreover, statistically significant effect was found to occur in the first year and lasts for two years. 


\section{DECENT WORK AND ECONOMIC GROWTH IN THE TIMES OF FOURTH INDUSTRIAL REVOLUTION}

\section{Marcis Dzelme, University of Latvia}

Key words: tripartite dialog, economic growth, industrial revolution, globalisation, sustainable development

JEL code: F69, Q01, 000

Global economy is integrating, but global political system is becoming more fragmented because of a backlash against the disrupitve effects of globalization. While globalization continues to strengthen the world economy, two-thirds of all households in advanced economy countries are seeing their incomes stagnate or decline. This allow politicians to exploit economic resentment resulting in protective policies such as imposing higher tariffs on imported goods, restricting the flow of cross-border data, clamping down on immigration, and calling for a return to traditional values, which is often code for social and economic protectionism. In September 2015, world leaders agreed to seventeen Global Goals for Sustainable Development (GGSD). In this paper, I am to focus on GGSD "Decent work and economic growth" (GGSD 8) in the context of fourth industrial revolution (4IR). The core of reaching GGSD 8 is sound Tripartite and Social Dialog that covers: negotiation, consultation and information exchange between and among the different actors; collective bargaining; dispute prevention and resolution; other instruments of social dialogue, including corporate social responsibility and international framework agreements. Preconditions for sound social dialogue is strong, independent workers' and employers' organizations with the technical capacity and access to relevant information to participate in social dialogue; political will and commitment to engage in social dialogue on the part of all the parties; respect for the fundamental rights of freedom of association and collective bargaining; an enabling legal and institutional framework. Opportunities and forces unleashed by technology and globalization have accelerated, ushering in the 4IR. Innovation has created new business models, disruptive incumbents. On the workers' side, the challenge is of organising the collective voice of informal workers, as well as those outside of established employment relationships, and the need to build broad-based coalitions with organizations that have similar interests, such as cooperatives, user groups, traders' associations and other civil society membership-based organizations. On the employers' side, the challenge of effectively representing the interests of SMEs and strengthening the relationship between MNEs and national employer organizations. Effective social dialogue depends on achieving such representation. The strategic challenge of the next decade is navigating a world that is simultaneously integrating and fragmenting. 


\title{
DIGITALIZATION AS A CHALLENGE FOR THE MULTILATERAL TRADING SYSTEM
}

\section{Tatiana Isachenko, Moscow State Institute of International Relations Natalia Navrotskaia, St. Petersburg State University}

\author{
Key words: globalization, digitalization, international trade, multilateral trading system \\ JEL code: F13, F20, F51
}

The modern multilateral trading system has come a long way of formation and has undergone significant changes due to the emergence of new areas of competition, new types of partners and new forms of business. In the past two decades, transformations in the global economy have reached a new level and have become increasingly noticeable. At the same time, the global regulatory system has lost its ability to react flexibly and in fast to changes and challenges due to increased competition and sharpening contradictions between the main players and between developed and developing countries.

A serious test for the multilateral trading system was the expansion of the number of regional trade agreements, under which many issues that were not reflected in the WTO rules were regulated. Another important aspect that had a serious impact on the state of world trade was the proliferation of global added value chains. One of the most important issues of the modern stage of development of the multilateral trading system and to a large extent its successful operation in the future is the interrelation of trade and investment. It is clear that trade facilitation is directly related to investment facilitation and promotion. In addition to all the issues outlined above, the "fourth industrial revolution" has become a new challenge for international cooperation, which has seriously changed the way we produce and trade goods and services.

The main consequence of the fourth industrial revolution and the formation of a fundamentally new technological order became the digitalization of the world economy and all forms of international economic cooperation. The aim of the presented paper is to analyze the crucial impact of the digitalization on the global trade regulation, its main principles and practical implications for national trade policy formation. The paper is based on the empirical research methods. The main conclusions drawn from the study are the following: there is an evident need of the change in many basic WTO principles, the WTO agreements need the serious update of the content and many new regulatory instruments should be adopted at national, regional and multilateral level. 


\section{CLUSTER POLICY INSTRUMENTS FOR DEVELOPMENT - A COMPARATIVE STUDY OF VARIOUS CLUSTER POLICIES}

\section{Anna H. Jankowiak, Wroclaw University of Economics}

Key words: clusters, cluster policy, instruments of cluster policy

JEL code: $L 14$, O25

Cluster policy is widely used in many countries of the world, both in developed and developing economies. Its task is to support the development of cluster initiatives and already functioning clusters that ensure economic growth and improve the level of innovation of the regions in which they are located. Cluster policy has many support instruments that depend on the specificity of the country and the available outlays, and are not unified and standardised. Each policy uses different methods leading to similar assumptions.

The article aim is to present currently used cluster policy instruments and to create a set of universal development support tools that cluster policy offers to its beneficiaries. There are following research questions in the paper: (1) What kind of instruments can the cluster policy use? (2) Are the instruments similar to or different in various national economies? (3) Is there a universal set of instruments that can be implemented in every cluster policy? The article will present the experience of the most advanced and comprehensive cluster policies from selected European and non-European countries (US, Canada, Japan), and then an attempt will be made to build a universal model of cluster policy instruments. A research method used in the paper was a comparative study of various cluster policies, and the paper adopts a deductive-analytical approach. The article is based on a critical review of the literature on the subject and international reports and analysis. The main findings of the paper is that cluster policy is shaped not only by national and local authorities but mainly by economic conditions existing in a given economy. The assumptions of cluster policy are similar throughout the world, but the tools of this policy are diverse and specific. The paper has a practical implication on the cluster policy and effective instruments for cluster and regional development. In conclusion, authors emphasised that the main challenge for cluster policy and the government is to elaborate an effective method of evaluating inputs and instruments of cluster policy cause a wide stream of support is directed to clusters but there is no complex method of measuring the effectiveness of cluster policy instruments. 


\title{
APPLICATION OF THE LOGIC MODEL IN MEASURING THE EFFECTIVENESS OF CLUSTER POLICY
}

\author{
Anna H. Jankowiak, Wroclaw University of Economics
}

Szymon Mazurek, Wroclaw University of Economics

Winand Dittrich, Wroclaw University of Economics

Key words: logic model, clusters, cluster policy, the effectiveness of cluster policy

JEL code: $L 14,025$

Many countries in the world conduct cluster policy as an element affecting economic growth, the level of innovation and the development of cluster connections in particular regions. Cluster policy is variously defined in the literature on the subject. The objectives, instruments and the possibilities of its implementation vary in the diversified conditions of individual national economies. Generally, it can be assumed that cluster policy is all activities directed towards clusters, which in some economies have a formal nature, while in some they are an element of another policy, e.g. innovation. The biggest challenge cluster policy is currently facing are the methods of measuring its effectiveness. In each country, the vast expenditures are spent on strengthening clusters, their innovative potential and their internationalisation, but the impact of these expenditures on the effects of cluster policy is difficult to measure. The paper aims to examine the utility of a logical model in measuring the effectiveness of cluster policy. In the first part, a model of cluster policy will be presented, with particular attention paid to the expenditure of this policy. In the second part of the paper, a logical model used for evaluation will be explained. and in the third part, the authors will analyse the possibilities of implementing this model to study the effectiveness of cluster policy. The paper is based on a critical review of the literature on the subject and international reports and analysis both about cluster policy and logic model. In conclusion, the authors emphasised that the logic model can be implemented in measuring the cluster policy effects and effectiveness and it is possible to build a universal procedure of cluster policy evaluation. This research can be used by policymakers to create more purposeful cluster policy where the inputs and outputs are visible. 


\section{GREEN BONDS MARKET - MAIN TRENDS AND DEVELOPMENT PERSPECTIVES}

\section{Anetta Kuna-Marszalek, University of Lodz}

Key words: green bonds, eco-investments, global market, climate change, ecology

JEL codes: F21, G15, O13

The purpose of the article is to identify main trends, changes, and development perspectives on the green bond market. The existing literature devoted to these instruments focuses on their essence, market development and projects that are implemented with their support. However, it is little known about the structure of the bonds offered, as their characteristics or differences to non-green bonds. In the article, the statistical analysis (using correlation measures, and basic descriptive statistics) of green bonds market in time series will be carried out on a sample of bonds registered in the Thomson Reuters Eikon database.

The study indicates an increasing share of corporate issuers, an increase in the diversification of the purpose of issuance, and the currencies in which the bonds are denominated. This proves the growing competition between issuers. Compared to similar non-green bonds, they are issued for a shorter time, allowing for more flexible management of the investor's portfolio. It can be noticed that the diversification of the purpose of the issue occurs primarily in issues carried out by corporations. Public issuers define the purpose of the issue more generally. High activity of international financial institutions is related to issues made to developing countries. Issues carried out by corporations are strongly associated with local currencies, which may indicate aversion to the foreign interest rate risk.

Green bonds seem to be a more attractive instrument than the traditional non-green corporate bond. They carry an additional emotional charge - they support activities that protect the environment. That is why green label can be the main factor supporting the development of this segment of the financial market and related advanced pro-ecological technologies. 


\section{FEATURES OF THE NETWORK MARKETS LEADING TO CROSS-INDUSTRY COOPERATION}

\section{Szymon Mazurek, Wroclaw University of Economics}

Key words: networks, network market, cooperation, consortium, strategic alliance

JEL code: L14, L22, M21

Network market can be defined as a market where network structures and network effects are observed, and competition takes place mostly between networks and not individual actors. The success of a company on the network market is often not the result of the value of supplied goods and services, but the dynamics of the growth of a network created or used by this enterprise. The possibility of achieving this goal is determined by the ownership of critical network assets, like intellectual property rights, manufacturing abilities, the presence of complementary products or brand name and reputation. Collecting them all in one organisation is hard moreover, the pursuit of maximising the value of the market forces to share knowledge and profits with others. In many cases, market leaders look for a compromise: smaller market share but compensated by the overall size of the market. Ultimately, all this leads to the formation of cross-industry cooperation structures.

This research paper aims to explain the concept of network goods and network markets and to point out specific features of those markets which force their participants to cooperate and to look for partners in different industries. It is the synthesis study based on a qualitative systematic review (qualitative evidence synthesis), a method for integrating or comparing the findings from individual studies. However, the goal of the study is not aggregative as with a meta-analysis. On the contrary, it is interpretative in broadening understanding of network markets and cross-industry cooperation phenomena.

The results from this study suggest that the explanation of increased cooperation on network markets lies in the redefinition of the competitive fight on those markets. If the popularity (size) of a network is the primary goal and critical assets are scattered, striving for openness is an expected consequence. Those findings may be significant for the economic theory and business practice, justifying cooperation as a part of network feeding strategy, which is a form of competitive struggle. 


\section{THE ROLE OF CONFIDENCE IN AN EFFICIENT HUMAN LEADERSHIP}

\section{Oliver Menk, University of Latvia}

\section{Key words: confidence, leadership, trust, trust scale}

JEL code: M12, M54

The aim of this qualitative pre-research is to get a clear understanding about the importance of the factor confidence in a modern human leadership. It has been researched, if confidence is just some kind of an addon, which supervisors should use to get a better behaviour to their subordinates or if it's much more important, so that it can be used as a power of leadership.

In structured expert interviews, each with a duration of 60 minutes, 12 international leaders spoke about their own impression and relation between leadership and confidence. It has to be remarked, that leadership and confidence is researched between a supervisor and a subordinate. It is not researched between a supervisor and a whole company or organization. The result itself is the objective basis for the next planned quantitative research with questionnaires.

Overall it can be said, that in the modern leadership of today, leadership and confidence can be announced as one. It seems to be, that due to the different needs of a complex environment, confidence is no more only one of different factors or possibilities of leadership, it is one independent power of leadership.

$100 \%$ of the experts answered in a total open question that confidence and leadership belong to each other and/or that a leader is not able to lead without confidence.

To understand more of the daily behaviour of the leaders, the use of the different powers according French and Raven had been analysed. The leaders had been asked, what kind of powers they use to convince the employee, to do a special work (which the worker normally doesn't do voluntary). E.g. that the employee shall work on a special weekend or something else. Result was, that there are good and bad powers, which is in line with a confidence leadership model based on another pre-research of 19 employees.

Also $100 \%$ of the experts came to the result, that a specific use of the five categories of power could influence the confidence level of the subordinates.

The experts stated clearly, that respect without reserve and just hierarchy are leadership advantages from the past. Today leaders must win the subordinate. This can be done only with confidence. 


\section{ASSESSMENT OF INVESTMENT FOR SUSTAINABLE DEVELOPMENT: CHALLENGES AND PROSPECTS}

\section{Natalia A. Navrotskaia, St. Petersburg State University \\ Svetlana G. Gorbushina, St. Petersburg State University \\ Natalya Y. Sopilko, RUDN University}

Key words: sustainable development, investment, human and intellectual capital JEL code: $Q 56, E 22$

In the modern conditions of the dynamic transformations and a high degree of uncertainty, the construction of a concept of development based on the sustainability paradigm acquires special significance. This is reflected in the complex of documents that were developed by the international community under the auspices of the UN and supported by all countries.

The concept of sustainable development is based on the unity of the economic, social and natural systems, which has necessitated the development of a special structured system of goals and development indicators. It is especially important to develop approaches for the investment support of this concept. The study is based on the analysis of the world practice of assessing the effectiveness of sustainable development, relevant methodologies, indicators and their modifications in modern conditions.

The purpose of this paper is to study the real investments, which are connected with the ensuring of sustainable development, to substantiation of their structural changes, theoretical, methodological and practical approaches to their accounting and evaluation. The research is based on official database, open statistical reporting, international comparisons, methods of statistical processing of information (analytical grouping, analysis of dynamic series, correlation analysis, etc.).

This paper examines the following issues: the investment in real projects, human and intellectual capital, problems of their accounting and evaluation in the context of investment support of sustainable development. Special attention is paid to the issues related to the increase of the share of investment resources, which are forced into unproductive spheres. This, in particular, is associated with the need for more frequent renewal of the fixed capital, due to modern scientific and technical transformations, utilization and processing, etc. The increasing complexity of production processes also leads to man-made disasters, which require considerable financial resources to create mechanisms of their prevention or elimination of possible consequences. 


\section{CHINA'S ROLE IN EAST ASIAN ECONOMIC INTEGRATION SINCE AFC - EVOLUTION AND PROSPECTS}

\section{Pawel Pasierbiak, Maria Curie-Sklodowska University}

Key words: China, East Asia, regional economic integration

JEL code: F14, F15, F21

The Asian financial crisis (AFC) of the late 1990s contributed to the intensification of regional economic cooperation in East Asia. However, the initial optimism resulting from the greater interest in integration processes among the most important countries of the region weakened over time. It turned out that the economic interests of states are not convergent in many areas. This resulted in a slowing down of the integration dynamics.

One of the most important countries with real and growing influence on partners in East Asia is China. Its rising economic position not only in the region but also in the world makes its approach and activity in the area of regional integration crucial for the development of this process. These issues are the subject of this study.

The main purpose of the paper is to present and evaluate the role of the People's Republic of China in the development of regional economic integration in East Asia in the period from the outbreak of the Asian financial crisis (1997-8) to the present. Two most important components of the regional economic integration will be analysed, i.e., regionalism (de jure integration) and regionalization (de facto integration).

Various research methods will be used to achieve the goal of the study, i.e., a method of critical analysis of literature, a method of inference and a method of statistical data analysis. The basic conclusion is the statement that as a result of China's economic and political strength, its role in the development of East Asian economic integration has definitely increased. This takes place in the sphere of institutional cooperation, but above all in the development of economic ties in the region. China has become the main economic centre of East Asia and therefore can act as the most influential promoter of regional economic integration in East Asia. However, this role depends on the predominance of regional aspirations over global ones in Chinese strategy. 


\title{
LATVIA'S ECONOMIC PERSPECTIVES: EXPLOITING GLOBALIZATION THROUGH EU MEMBERSHIP
}

\author{
Inna Steinbuka, University of Latvia \\ Martins Zemitis, University of Latvia
}

\begin{abstract}
Key words: globalization, competitiveness, investment, innovation, trend analysis JEL codes: O10, O19, O32
\end{abstract}

This paper analyses the future growth potential of Latvia against such trends as globalization, digitalization and "green revolution". The main challenge for small and open economies, such as Latvia, posed by globalization is the lack of respect for national boundaries. While single-state economies can mitigate the consequences of globalization and improve their resilience, they are not self-sufficient to thrive in the global environment. Instead, supra-national challenges require supra-national solutions. This paper argues that the membership of the EU provides Latvia with the necessary financial tools and access to economies of scale to adequately face globalization.

The aim of the paper is to extrapolate the future growth vector of Latvia in various domains, such as competitiveness, investment, innovation, digitization, de-carbonization, and human capital. The main research method used is trend analysis. In each of the domains, the paper, first, looks at the status quo, second, extrapolates the impact of globalization trends, third, examines the benefits of EU financing and access to Single Market and, finally, compares the "in" with the counter-factual "out of the EU" scenario.

The main finding is that, on balance, the "in" scenario offers more benefits and less costs than the "out" scenario. Latvia as a small and open economy does not have the option of autarchy. It must turn globalization into a positive force for change. In order to remain competitive, Latvia needs to pursue investment in people, innovation and infrastructure. Contrasted to third countries, the membership of the EU allows Latvia to benefit from various EU investments and the Single Market.

The theoretical implication of the paper is that such research methods as trend analysis and counterfactual scenarios can be used effectively to justify economic policy choices. The practical implication is that the membership of the EU and its Single Market can be proved to serve as protection against globalization. The main conclusion is that Latvia is a net beneficiary of EU's policies, as they help Latvia to exploit opportunities which would otherwise be beyond reach. 


\section{HOW DO THE POLICY MIX DETERMINANTS AFFECT CREDIT RATINGS OF SELECTED EU COUNTRIES?}

\section{Joanna Stawska, University of Lodz Ewa Stawasz-Grabowska, University of Lodz}

Key words: credit ratings, sovereign ratings, policy mix, economy

JEL code: $G 24, E 52$, E62

The aim of the article is to identify and investigate the impact of quantitative and qualitative factors on the level of long-term sovereign ratings for ten countries that joined the European Union in 2004 (Czech Republic, Cyprus, Estonia, Lithuania, Latvia, Malta, Poland, Slovakia, Slovenia, Hungary). Among this group, we distinguish two subgroups - countries that are in the euro area and countries outside the euro area. We use the panel quantile framework that quantifies the relative importance of quantitative and qualitative factors across the conditional distribution of sovereign credit ratings in selected countries. The study uses long-term issuer credit ratings given by Standard\&Poors, Moody`s and Fitch. The survey covers the period of 2004-2011 - 2018q3. Selected quantitative and qualitative factors are divided into determinants in the field of policy mix (monetary and fiscal policy) and the so-called other factors. We try to answer the question which of the two groups of factors have a stronger influence on ratings: those dependent to a large extent on economic authorities' decisions (factors in the field of policy mix) or determinants outside the sphere of economic policy. In addition, we analyze the impact of determinants in the field of policy mix and others on countries in the euro area as well as outside it within ten selected EU countries. 


\title{
THE IMPACT OF DIGITALIZATION ON THE SUCCESS OF BUSINESS INTERNATIONALIZATION \\ RELATING TO GERMAN SMALL AND MEDIUM SIZED FINTECHS
}

\author{
Ann-Kathrin Teltz, University of Latvia
}

Key words: digitalization, business internationalization, small and medium sized enterprises, fintechs JEL code: $F 23$, O30

The increasing globalization compared with the increasing change of business processes through digitalization have changed the economic environment for small and medium sized enterprises. Awareness of market chances, rising competitive constraints as well as the need to follow industrial customers to foreign markets, stimulates the interest of enterprises becoming international. But most of them lack the internal resources needed therefore and the adaptation to new processes due to the digitalization. Consequently, the degree of small and medium sized enterprises acting in foreign markets is significant small. Structural problems, specifically related to small and medium sized enterprises make it more complicated for them to successfully master the challenges of globalization. To have a successful internationalization process the framework conditions of the corporation, regarding to different aspects like available recourse and the degree of digitalization seems to be crucial. Small and medium sized enterprises from the FinTech branch looks on the surface fully adapted to the digital processes and with these, best condition for an international market entry. But have a look in detail, beside the origin digital product and service they offer, the internal processes often lack due to the requirements digitalization needs.

The purpose of this research is, to figure out the impact of digitalization on the success of business internationalization relating to German small and medium sized FinTechs. For the theoretical background, a literature research of the classical market entry strategies as well as a conceptual delimitation of small and medium sized German FinTechs should give an overview. For the empirical part, an online survey with all German FinTechs was done. In a second step different experts on this field will be consulted to estimate the significance of the results from the survey. After this, expert interviews with participants from different fields will be conducted. Therewith a triangle of theory, quantitative primary research and qualitative study will be achieved. 


\section{PROSPECTIVE CONSEQUENCES OF THE TRADE WAR BETWEEN THE UNITED STATES AND CHINA}

\section{Monika Wojtas, Maria Curie-Sklodowska University in Lublin \\ Tomasz Bialowas, Maria Curie-Sklodowska University in Lublin}

Key words: trade policy, international trade, protectionism

JEL code: F13, F14, F51

First signs of a trade war between the United States and China appeared on March 8th, 2018 with the announcement by D. Trump administration of new additional tariffs on steel and aluminium imports to the US as a means of protection of domestic producers. In March USTR carried out a procedure based on Clause 301 of Trade Act of 1974 accusing China of unfair trade practices. In April a possibility to introduce tariffs on imports from China. Ultimately, on July 6th, new tariffs were implemented, and other are to be introduced in the future. Chinese government announced they would reply in kind to the changes in American trade policy and released a list of retaliatory measures they would be seeking towards the United States - thus both countries appear to have engaged in a trade war, that can affect their economies as well as the rest of the world.

Main goal of the paper is to evaluate potential effects of the US-China trade war. Analysis focuses on:

1) bilateral trade flows between the United States and China;

2) evaluation of the consequences of new tariffs and non-tariff barriers on the US and China;

3) assessment of the consequences of trade war on selected countries and the world economy.

The analysis carried out in the paper reveals that greater trade costs will pertain to China and negative effects in the US will stem from the introduction of non-tariff barriers. Additionally, trade war between the United States and China can result in a declining exports flows, lowering of the GDP dynamics and an increase in unemployment in many other economies. 


\title{
THE UNITED STATES' TRADE POLICY TOWARDS THE EUROPEAN UNION AND DEVELOPMENT OF BILATERAL TRADE FLOWS
}

\author{
Monika Wojtas, Maria Curie-Sklodowska University in Lublin \\ Tomasz Bialowas, Maria Curie-Sklodowska University in Lublin
}

Key words: trade policy, international trade, protectionism

JEL code: F13, F14, F51

The United States and the European Union remain key players in the international trade policy. Their positions during World Trade Organization Ministerials determine the issues, the course and results of negotiations and unilateral trade policy has a significant impact on global trade flows. They are also responsible for the bulk of the global trade. According to the WTO data in 2017 joint share of the US and the EU amounted to $43.3 \%$ of world merchandise exports and $47.2 \%$ of imports.

The change in American foreign trade policy towards a more protectionist approach announced during the presidential campaign of D. Trump has begun in 2018. New tariffs on steel and aluminium announced in March 2018 (in force since June) can be viewed as a start of a trade war. In response, European Commission introduced retaliatory tariffs on US products.

Main goal of the paper is to assess potential effects for the EU and selected member countries of the increased protectionism in the US trade with the European Union.

The analysis will focus on:

1) main tendencies in the development of trade and trade policy of the United States towards the European Union in 2010-2018;

2) evaluation of the consequences of new tariffs for the development of the EU trade;

3) assessment of the consequences of rising protectionism on foreign trade of selected EU members.

The results of the analysis allow to draw a conclusion that rising tariffs on steel and aluminium will have a limited impact on the total EU exports, however in the case of selected countries a small declines could occur. Moreover, there is a risk of trade conflict escalation that can bring about much more serious consequences. 


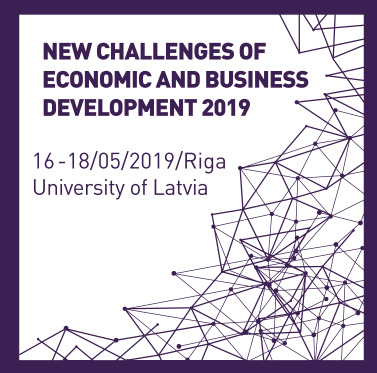

\section{Labour Markets \\ and Mobility of Labour}





\title{
CHINA'S FAMILY PLAN POLICY REFORM AND ITS POTENTIAL EFFECTS ON ITS GENERAL ECONOMIC DEVELOPMENT
}

\author{
Algimants Kontauts, $P w C$ \\ Jie Jiang, University of Latvia
}

Key words: China, two-child policy, labour market, demographic dividend, economic development JEL code: $J 11, J 18$

China has been one of the fastest-growing economies in the past decades with demographic dividend as its key driver of economic growth. However, this trend is changing. The fertility rate in China has dropped dramatically that raised concerns among Chinese policy makers and scholars. In 2016, a family plan policy reform was implanted to replace the existing wildly criticized one-child policy to two-child policy. The objective of this study is to analyse the potential effects of this family plan reform on China's general economic growth.

To achieve this aim, both qualitative and quantitative research methods have been applied. Literature research is conducted to check 1) the background of Chinese family plan policy reform (the intentions and consequences of one-child policy), and 2) the relations between demographic factors (population growth and life expectancy) and economic growth; A survey is conducted to analyse how family-plan policy may affect the demographic factors, by collecting data from general population on how their decision making on family birth plan has been/ can be affected by this family plan policy reform. The design of the survey is to reach on 500 survey recipients that are Chinese citizens within the age range of 20 to 40 years old. Regression analysis is used to analyze the data collected from the survey. Combining the results from the literature review and the survey, the research reaches the following key findings.

1. China's one-child policy results in changes in China's demographic factors, specifically, falling population growth rate, decreasing working age population to non-working population ratio, and unbalanced sexratio;

2. The demographic changes in recent China, during the period of one-child policy in force, have negative impacts on China's economic growth;

3. Due to the family-plan policy reform (replace one-child policy with two-child policy), there are changes in population's decision-making concerning family birth plan; however, the changes are not significant.

The research shows that in general, the China's family plan policy will lead to positive effects on China's long-term economic growth; however the short-term effect of China's family plan policy reform in population growth is very limited. Result from this research helps future researches in analysing trend of China's development. 


\title{
EMIGRATION AND REMITTANCES PATTERN ANALYSIS IN LAGGING BEHIND BALTIC REGIONS: CASE STUDIES OF NARVA, DAUGAVPILS AND VISAGINAS
}

\author{
Mihails Kozlovs, University of Latvia
}

Key words: economic migration, remittances, SWOT\&PEST, taxes, Baltic region JEL code: J11, J15

In this paper author is researching the economic effect of emigration in three lagging behind Baltic regions in last decade. During this time span emigration's influence on economy is analyzed in terms of migration flows size, quality of the labour market, levels of the unemployment and social benefit systems, which all affect local economies/communities.

The regional scope of this research is linked with distinctive lagging behind regions: Estonian Narva, Latvian Daugavpils and Lithuanian Visaginas. The objective of this research paper is (i) to measure the behaviour of the emigration in selected regions and regions with high density of minority population and (ii) compare emigration process and its patterns within Baltic countries.

The overall impact of emigration on the economies of Baltic countries is evaluated by weighting negative and positive factors. In order to have more realistic results - four quantitative approaches were developed in order to measure emigration's influence on the economies. Each of these scenarios contains different set of parameters and these combinations describe economic impact of the migration. Underlying formula of the undertaken approaches, with small modifications may be used for examination of similar issues in other regions and countries. As well author used a SWOT\&PEST multidimensional analysis, which combines SWOT and PEST methods in one grid, providing transparent representation of the results.

Emigration certainly has economic impact - it was proved, that negative effects of emigration increases, if the level of life/ salary grows in emigration-source country. Overall economies of Baltic countries receive fewer transfers from abroad, than taxes, which could have been paid by current emigrants. However, situation is different in lagging behind regions, where salaries are smaller and remittances have relatively higher value. That is why in some cases regional economies are gaining much more from remittances, than they could have earned from taxes of current emigrants. 


\section{MOBILITY OF LABOUR AND IMMIGRANTS' INTEGRATION: HOW TO DECLINE IMMIGRANTS-NATIVE WAGE}

\section{Tiiu Paas, University of Tartu \\ Maryna Tverdostup, University of Tartu; University of Innsbruck}

Key words: labour mobility, human capital, migration, European labour market, PIAAC JEL code: J61, O15, J31

International mobility of labour force is increasing globally generating new challenges for socioeconomic and political developments. National economic policies should create conditions that support integration of ethnically diversity societies and retaining a peaceful environment for economic activities. Among several aspects of immigrants' integration, a crucial role belongs to creating favourable conditions for declining the immigrants-native wage gap and better use of immigrants' labour.

Theoretical framework for studying immigrants-native wage gap relies on classical human capital theory stating that differences in individual's education and skills transmit into wage. Due to a lack of appropriate data, previous studies mostly approximated human capital with formal education to measure wage gap and occupation-qualification match. This paper aims to extend knowledge on how individual's skills and particularly their use in European labour markets are related to immigrants-native wage gap.

Empirical part of the study bases on the OECD Program of International Assessment of Adult Competencies (PIAAC) data on fifteen European countries implementing multivariate regression models based on pooled and country specific samples. We analyze individual human capital measured by the education, literacy and numeracy skills and explore to what extent immigrants employ their cognitive skills at work.

The analysis results are rather stable leading us to the conclusion that potential for development and utilization of immigrants' human capital in the European labour markets is underused. There are systematic and statistically significant differences in skill application at work across immigrants and natives. Only highly educated immigrants reveal skill improvement over immigration tenure. Additional country specific policy measures should be implemented for better integrating immigrants' labour force into working activities, e.g. to develop institutional framework improving qualified immigrants access to more challenging and highly rewarded jobs; to upgrade immigrants' qualifications considering hosts countries' needs; to improve information system for being better familiar with local labour markets. 


\title{
SHIFTING TAX BURDEN FROM LABOUR TO PROPERTY: THE CASE OF LATVIA
}

\author{
Anna Zasova, Baltic International Centre for Economic Policy Studies \\ Anna Pluta, Baltic International Centre for Economic Policy Studies
}

Key words: labour taxes, property taxes, shifting taxes, EUROMOD

JEL code: D31, C15, C63, R20, H20

The need to reduce high taxes on low wages and to raise more revenues from real estate taxes and environmentally related taxes has been repeatedly emphasized by the European Commission and OECD. In this paper we determine the scope to shift tax burden from labour to property in Latvia. There is no existing empirical evidence on who bears tax burden on immovable property in Latvia and no existing national models that can be used to model immovable property tax reforms. In our analysis, we use a unique dataset, which links EU-SILC 2012 database with administrative data on actual immovable property ownership, allowing for empirical analysis on the degree of progressivity of the property tax. The resulting database contains information on owned immovable property of EU-SILC 2012 respondents, i.e. the type of the property (individual house, apartment in an apartment block, garage, land, etc), area of the property in square meters, and cadastral value of the property. We consider the possibilities of ensuring more progressivity of the tax system while improving work incentives for low wage earners (by cutting the tax burden on low-paid workers in Latvia) and partly compensating foregone budget revenues with higher revenues from immovable property (by raising tax rates, especially tax rate on land, and lowering tax brackets, but providing the tax discounts to pensioner households). To estimate the effect of the tax reforms on disposable incomes, we use EUROMOD, the European Union tax-benefit microsimulation model, extended with immovable property tax modelling.

According to our results, in Latvia property tax is regressive, which is mainly due to taxation of land: land constitute the main source of revenues and poor households have large possessions of cheap land. Main beneficiaries of the proposed reforms are in middle deciles of income distribution. Though not strongly, the proposed reforms reduce income inequality and improve work incentives at the bottom end of income distribution, but further reforms of means-tested benefits are needed. The direct fiscal effect of the reforms is negative and most of the burden is on local governments' budgets. 


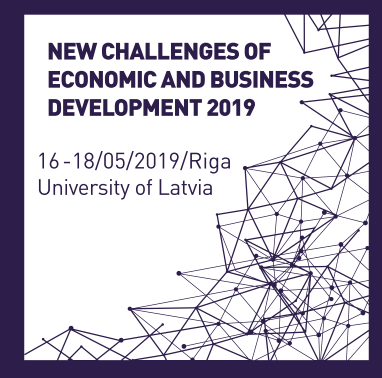

\section{Life Quality and Income Inequality}





\section{SOCIAL INEQUALITY AND CONVERGENCE PROBLEMS IN THE EU}

\section{Elena Dubra, University of Latvia}

Key words: social dimension, EU strategy, inequality, convergence

JEL code: A130, E130, I380, F630, E24

The purpose of this paper is to introduce EU social policy evaluation in the context of convergence policy application for reducing social differences between EU Member states.

The objective of this study is to assess social dimension and inequalities problems in the European states by applying theory of convergence for real estimations social situations in EU countries.

The research methodology based on the social economy and convergence theory foundations, on the EU strategies, European Commission legitimate documents application, on the growth theory calculations and socio-economic forecasts analysis of the welfare level in the EU states. This study analyze inequality gap between EU countries using various statistical methods.

This research contain objectives and general outlines of period 2014-2020 and present information about various socio-economic indicators and indexes. Study characterize changes of the key EU socio-economic concepts being influence on the EU convergence policy and living conditions development, but rapidity of convergence depends on the initial discrepancy of the development level in the EU states. The efficiency of European convergence policy can also be improve by significant economic growth and by clever choice of the country-specific social activities. This research investigate major information for social situations estimations in EU states as well as GDP growth, unemployment and population's welfare indicators.

The main results reflect the overall economic situation evaluation in the EU countries and present convergence policy impact on the social development in the European states. Additionally discussed development challenges, possibilities and new trends for socio-economic and well-being improvement in the EU states with target to avoid national disparities.

The main conclusions of this study contain the socio-economic situations appreciation in the context of social inequality problem clarification in the EU states, reflect the overall social convergence situation in the EU states and in Latvia, contain analysis and estimations of the national social development inequality problems decision in the future. 


\title{
CHANGES IN THE SUBJECTIVE ASSESSMENT OF QUALITY OF LIFE IN LATVIA AND THE EUROPEAN UNION: RESULTS EUROPEAN QUALITY OF LIFE SURVEY 2016
}

\author{
Silvija Kristapsone, University of Latvia \\ Silvija Bruna, University of Latvia
}

Key words: quality of life, subjective well-being, life satisfaction

JEL code: D69, J28, Q10

Assessment of quality of life, along with objective indicators, includes a series of subjective indicators. An important indicator of life quality measurement is subjective well-being (subjective well-being - SWB), which does not always coincide with the objective results of life quality measurement. Economic growth has been seen in the EU countries since 2011-2012, which is reflected in the country's macroeconomic indicators, indicating a general increase in quality of life. Does the subjective assessment of the quality of life of the population also show this? The European Quality of Life Survey (EQLS) 2016 has been tested for the fourth time the EU Quality of Life.

The purpose of the article is to assess the changes in the assessment of individual indicators of the subjective well-being of Latvian society in the context of the European Quality of Life Survey 2016 compared to the results of the 2011-2012 survey.

To achieve the objective the following objectives have been identified:

1) to provide an insight into the current concept of quality of life and subjective well-being,

2) analyse the data from the EQLS 2016 survey by countering EQLS 2011-2012 data in Latvia and EU countries as a whole.

As sources of information have been used descriptive and inferring methods of statistical analysis. The European Foundation for the Improvement of Living and Working Conditions 2011-2012 and 2016 survey databases, available in the UK Data Archive,

The statistical analysis showed the following. Comparing Latvia's indicators with the EU average, it is concluded that in the subjective well-being indicators assessed in the 10-point system, Latvia's residents value their welfare situation in 2016 and in 2011 less than the population of the EU as a whole. In EU countries, seven of the eight elective subjective well-being elements identified a maintenance rating at the 2011 level. In Latvia, a reduction in the assessment was found in six indicators. Only one indicator in the EU countries and in Latvia shows an increase, and this is Satisfaction with the current state of the economy in the country. Latvia ranked from 21st in Satisfaction with Education, Satisfaction with work and Satisfaction with the current state of the economy in the country to 28th Satisfaction with accommodation. EQLS survey data show that economic growth in the EU countries, socioeconomic reforms, and the effectiveness of social security in the post-crisis five-year period under study have not shown a significant increase in the perception of their personal quality in terms of population. 


\title{
HEALTHY AND ACTIVE PRE-RETIREMENT AND RETIREMENT AGES: ELDERLY INEQUALITY IN LATVIA
}

\author{
Juris Krumins, University of Latvia \\ Atis Berzins, University of Latvia \\ Aleksandrs Dahs, University of Latvia \\ Denize Ponomarjova, University of Latvia
}

Key words: active ageing, health expectancy, elderly inequality

JEL code: $J 11, J 18, I 38, R 11$

Distribution of income and inequality in working ages are principally explained through the labour market processes, influenced by the overall socio-economic conditions in particular country or region. Preretirement and senior population groups are more affected by activity limitations, unemployment and bad perceived health than population in active ages. Data for Latvia and many other EU countries demonstrate a warning situation - social and economic inequalities among elderly are not diminishing as fast as was expected. The aim of paper is to analyse inequalities in healthy and active life during pre-retirement and retirement ages to detect changes complying with active ageing and public health strategies.

Data and methodology for detecting absolute and relative inequalities and their determinants are used for several variables (e.g. income, self-assessed well-being, life quality etc.). Spatial analysis is used as well. We use Population Census, Household survey, Labour force survey and SILC data on the elderly population groups residing in statistical regions and in some occasions in smaller territorial units of Latvia. We employ a set of regression models in order to study the causal links and relations between the underlying social and economic circumstances and the selected measures of inequality. Ethnic and professional background are also considered as determinant factors. We attempt to identify homogenous and heterogeneous groups among senior population, and to find out main causes of divergence among them over the period of time since 2004 .

The existence of low-income groups and poor levels of self-assessed health and well-being among senior population in pre-retirement and retirement ages suggests that overall inequality among elderly poses a significant policy challenge in Latvia. Using the model estimation results, we propose a framework for the better understanding of elderly inequalities and their determinants, which includes not only traditional demographic and socio-economic factors, but also spatial determinants. Finally, using the accumulated data, we propose how targeted public policy and social activities aimed at promoting healthy and active ageing may help to overcome inequality risks associated with the transition from working life to retirement. 


\section{FACTORS INFLUENCING THE DECREASE IN INCOME INEQUALITY IN LATVIA}

\section{Indra Samite, University of Latvia \\ Maris Purgailis, University of Latvia}

Key words: income inequality, Gini index, education, statistical analysis

JEL code: $E 63,131, C 100$

Income inequality in Latvia, although among the highest in the EU, as measured by the Gini index, has been declining, while according to the OECD income inequality across the world is increasing.

According to the Gini index compiled by the OECD, Latvia is in $28^{\text {th }}$ place out of 38 countries surveyed. However, income inequality in Latvia has declined steadily from a high of 39.2 in 2005 to 34.5 in 2017. In addition, according to Eurostat, Latvia has registered the largest decrease in the income inequality ratio (the proportion of the total equivalised disposable income received by the $20 \%$ of the population with the highest income to that received by the $20 \%$ of the population with the lowest income) from 7.3 in 2008 to 6.3 in 2017 . Multiple studies indicate that income inequality has a negative impact on economic growth. Therefore, understanding the factors underlying decreasing inequality is an opportunity to raise the absolute living standards of the poorest segments of the country.

The objective of the research is to identify and analyze factors that can be established to have been statistically significant drivers of the decrease in income inequality in Latvia. The factors chosen for statistical cluster analysis are the changes by year by age, and income segments, per capita GDP, and spending on education. In contrast to other research on this topic, the authors will analyze the dynamic rather than the static impact of the factors. The research will draw conclusions on which age and/or income segments have had a role in reducing income inequality and whether a pattern may be assumed. In addition the research will look at whether per capita GDP and spending on education are correlated to income equality across the EU and what conclusions from and make policy suggestions based on the results. 


\section{THE RELATIONSHIP OF WAGE LABOR AND CAPITAL AND THEIR DEVELOPMENT IN THE FORMS OF SOCIAL PARTNERSHIP}

\section{Nataliia Spiridonova, Saint Petersburg State University}

\section{Key words: social partnership, wage labor, capital}

JEL code: $A 13$, D63, P47

Modern causes such as globalization, the increasing influence of transnational corporations and financial capital on the one hand, and the development of ICT, production automation and production robotization on the other lead to changes in the sectoral structure, employment structure, as well as the growth of social and economic inequality in the world.

The purpose of the study is to identify changes in the relationship between wage labor and capital and to characterize their regulation through the mechanism of social partnership. The objectives of the study are to identify the characteristics of the relationship between hired labor and capital in the XX - XXI centuries; determine the features of the social contract between the employee and the business in the new conditions of production; analyze the degree of exploitation of the employee by capital; and propose corrective methods through the ideology and practice of social partnership. A number of developed countries and the Russian Federation were chosen as objects of analysis. We used the open data of the International Labor Organization (ILO), the US Bureau of Labor Statistics, the American Economic Policy Institute (EPI), the OECD, the Rosstat Agency.

The study is based on a theoretical analysis of economic theory and a review of the scientific literature on this topic. Empirical data reflects the change in the relationship between labor and capital in the new conditions of post-industrialism and the crisis of the theory and practice of the state of social welfare. Statistical analysis shows that the level of exploitation in countries with a neoliberal (Anglo-Saxon) market economy model is higher than in European countries of general welfare, especially in the Nordic countries. A real negotiation process could maintain a balance between business efficiency and the protection of workers' rights.

The results of the study can be used for theoretical studies as well as for predicting socio-economic changes. State institutions can use the results to improve the effectiveness of their programs in the labor market. 
100.0 


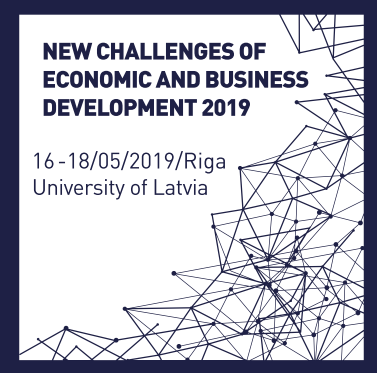

\section{Marketing and Brand}

Management 



\title{
INFLUENCE OF INTEGRATED MARKETING COMMUNICATION TOOLS UPON CONSUMERS' BUYING DECISIONS IN THE CONTEXT OF SUSTAINABILITY
}

\author{
Anda Batraga, University of Latvia \\ Daina Skiltere, University of Latvia \\ Jelena Salkovska, University of Latvia \\ Santa Bormane, University of Latvia \\ Aija Legzdina, University of Latvia
}

\begin{abstract}
Key words: sustainability; sustainable development; sustainable marketing; integrated marketing communications for sustainability, buyer survey
\end{abstract}

JEL code: $M 14 ;$ M31

Research background: A topical business subject of nowadays is the influence of integrated marketing communications (IMC) for sustainability upon various consumer audiences and their buying decisions. From the standpoint of businesses the use of integrated marketing communications in product promotion contributes to the consumption of sustainable, ecological products and, consequently, a healthy lifestyle, yet the factors influencing buyer's buying decisions still remain topical. In this research the authors surveyed buyers of Latvian food retail chains to find out the influence of promotion-related integrated marketing communication tools for sustainability upon buyers' buying decisions. The research brings conclusions regarding a customeroriented approach to the processes of integrated marketing communication for sustainability, incl. the making of integrated marketing communication for sustainability to increase consumer awareness of sustainability.

Purpose of the article: The purpose of the research was to study and assess the influence of promotionrelated integrated marketing communication tools for sustainability upon buyers' buying decisions. The object of the research is promotion-related IMC tools for sustainability. The subject of the research is the influence of product promotion tools for sustainability upon buyers' buying decisions.

Methodology/methods: The research makes use of the results of the studies of food retail chains conducted by the authors in 2017 and 2018. The authors surveyed randomly selected buyers of Latvian food retail chains with a sample of 1,003 respondents. In order to attain the goal and objectives, the following quantitative and qualitative methods of economic research were used: survey, comparison, grouping, evaluation, market investigation, comparative analysis. The study is based on scientific papers published by Latvian and foreign scholars, general and special literature, and periodicals. The survey data were processed and analysed using the SPSS 23 software.

Findings: The research confirmed the hypothesis that the use of integrated marketing communications for sustainability in product promotion enhances consumers' awareness of sustainability. The results of the research are of both theoretical and practical value. 


\section{ADDING A MORAL DIMENSION TO THE LUXURY BRAND VALUE}

\section{Liga Bitane, University of Latvia}

Key words: brand value, luxury, consumer sovereignty, morality, value co-creation JEL code: $M 14$, M21, M31

Luxury as a concept has generated extensive academic research, revealing its complex, ambiguous and fluctuating character. The extant research has agreed on the dimensions of consumers' luxury value perception, involving financial, functional, individual and social attributes. However, the conceptual framework is essentially built upon the assumption of luxury brand characteristics, as they are established by brand managers. Less academic attention has been paid to affluent consumers' individual understandings of luxury brands on both personalized and social levels. This study addresses the research question of whether luxury consumers' identity and ethical value base contribute to the luxury brand value.

The aim of the study is two-fold. First, the author provides systematic review of the literature in order to identify and evaluate the knowledge base about the luxury construct. Aiming to build theory based on secondary research, the method of meta-synthesis is applied to synthesize qualitative research in the field of luxury. Second, while addressing the identified research gap in knowledge about the moral motivations associated with luxury consumption practices, the study draws on theory of consumer moral leadership to offer an extended conceptual model of luxury value dimensions. By making contributions beyond those realised in the previous research, the purpose of the study is to deepen the luxury concept.

The main contribution of the research is a broadened conceptualization of luxury allowing a richer understanding of consumers' role in creating luxury value. The findings provide new insights for further luxury research and implications for luxury brand managers. By respecting consumers moral beliefs, businesses operating in the luxury segment can capitalize on socio-cultural changes in luxury markets and gain significant advantages in form of consumers' stronger identification with the brand and maximized positive buying behaviours. 


\title{
IMPROVED INNOVATIVE PRODUCT STRATEGY ASSESSMENT MODEL IN MARKET RESEARCH CONTEXT
}

\author{
Liga Braslina, University of Latvia \\ Anda Batraga, University of Latvia \\ Daina Skiltere, University of Latvia \\ Aija Legzdina, University of Latvia \\ Girts Braslins, University of Latvia \\ Eva Cildermane, University of Oxford
}

\section{Key words: growth strategies, innovations, market research} JEL code: $M 31$

In the innovation economy, companies are more often faced with the need to quickly and efficiently evaluate not only their existing portfolio of products and services in the context of the industries, but also the theoretical concepts of innovations. There are various systems for evaluating innovation concepts and already existing products and/or services for companies that are planning to expand their business in a new industry. The innovation economy is characterized by the convergence of the most demanded products on the market with constant market upgrades. A company that wants to grow in the new industry faces an assessment challenge between already existing, demanded products and the choice of innovative concepts in the context of the company's more perspective growth. As market examples show, a successful entry of a company into a new industry can be related to both- an innovative concept and an innovative business model of existing, demanded market products.

The aim of the study was to analyse the appropriateness of the current assessment systems of innovations concepts and market bestselling products from the perspective of an enterprise wishing to expand in the new industry.

The research was based on the analysis of the most approbated methods, based on available newest scientific and professional literature. Aside was conducted in-depth interviews with company leaders from the industries and scientists.

The results of the research highlighted the need for updated evaluation tools that combine both prospects - innovation concept assessment and industry bestselling products perspectives perspective. The results outline elements that are missing from existing models in one area or another, outlining the perspective of a new, improved assessment model.

The theoretical benefit of the study is to highlight a new, complementary dimension in the assessment of the company's growth strategy in the context of developing new industries. The practical contribution of the research is an improved, complex industry assessment tool for a company that plans to expand its operations by entering its new market sector.

The results in the broader context explain the potential for new market acquisition, combining innovation and the basic product demand on the market. 


\title{
THE EVALUATION OF MARKETING COMMUNICATIONS AND THE AWARENESS ABOUT HIV AMONG THE RESIDENTS OF LATVIA
}

\author{
Janis Duboviks, University of Latvia
}

Key words: health behaviour, HIV, marketing communications, social efficiency, social marketing JEL code: 112 , M31

In recent years, thanks to the work and the contribution of the global community to limiting the spread of HIV, not only the number of newly diagnosed HIV cases, but also the number of deaths from AIDS-related illnesses, has started to decrease globally. One of the most important tools that has made it possible to limit the spread of HIV is a well-targeted and socially effective marketing communications, developed by public and non-governmental healthcare organizations, which, in meeting its goals, encouraged society education about HIV infection.

Despite the approved action plan and its content, Latvia steadily takes the leading position among the European Union countries in the number of newly diagnosed HIV cases. The increasing trend of the number of newly diagnosed HIV cases indicates that the society lacks information and education possibilities about HIV and how to protect themselves from virus.

The aim of the study, which is based on evaluation of results of previous studies of implemented HIV spread control measures and marketing communications addressed to society, is to analyse the actual awareness about HIV and available educational opportunities about it among the residents of Latvia, as well as to find out the marketing communication sources of true and false information about HIV.

Such methods as survey, content analysis and correlation analysis are used in the study, and its results are based on the data obtained during the survey of the residents of Latvia.

The results of the study show the actual situation regarding the awareness of residents of Latvia about HIV and education opportunities about it. In spite of the fact that majority of respondents self-assess their knowledge about HIV as good, it must be emphasized that the results of the study show that the majority of respondents are not able to identify all possible ways of infection of HIV. The data correlation shows through what marketing communication channels respondents most often obtain true or false information about HIV. Thus, the findings of the study in the future will help to improve the content of marketing communications and use of an appropriate communication channel suitable for the certain target audience, in order to achieve its social efficiency. 


\section{THE IMPACT OF CUSTOMER SATISFACTION ON DEALER LOYALTY IN THE AUTOMOBILE RETAIL INDUSTRY: A LITERATURE REVIEW}

\section{Alfred Konrad, University of Latvia}

Key words: dealer loyalty, sales satisfaction, service satisfaction, product satisfaction JEL code: $M 30$, M31

The German automobile market has been characterized by stagnation for years. These circumstances leads to a strong competition between the different automotive brands and on the retail side between the different car dealerships. A key factor for sustainable growth and future security is not only to gain new customers rather to hold on existing customers. Loyal customers are significant for business success, as research has shown. Therefor it is not surprising, that one of the major task in the automobile retail industry should be to gain loyal customers. In the last years, the major focus has been on satisfying customers, to gain loyalty. Nonetheless some authors realized, that despite a high level of customer satisfaction customers are still move away to competitors. The purpose of this paper is to analyse the relationship between these two constructs customer satisfaction and dealer loyalty under the consideration of current research findings in the automobile retail industry. To fulfil this task an exhaustive literature analysis of scientific papers was carried out. Only those papers were included which have conducted an empirical verification. Scientific databases like EBSCO and ResearchGate as well as ScienceDirect has been used to search for papers with the following keywords: loyalty, re-purchase, automobile, automotive and car dealer. The literature research produced a total amount of 21 texts which were used for further investigation. The analysis of these texts revealed a general agreement for the loyalty-satisfaction link but also detected other moderating variables influencing the strength of this relationship. This article is of interest to researchers involved in the field of marketing and sales management and also for managers who want to understand how to improve their customer loyalty. 


\title{
THE IMPORTANCE OF BRAND FOR INFLUENCING CONSUMER BEHAVIOUR IN SOCIAL NETWORK PLATFORMS
}

\author{
Aija Legzdina, University of Latvia \\ Annemari Sperlina, Turiba University \\ Ilgvars Rukers, University of Latvia
}

\section{Keywords: brand, branding, consumer behaviour, social network, marketing JEL code: $M 31$}

Nowadays, many companies have understood the potential of social networks, thus more and more of these channels are being used as an essential part of communication platform for branding. Companies can increase their market share and profit through the brand, its values and ability to influence consumer behaviour. One must emphasize that this massive increase in the use of social media affects consumer behaviour, as there is a close interaction between these platforms and the wide availability of information. Social networks have changed the relationship between traditional branding and consumer, taking into account the availability of broad information, the way consumers share, evaluate and process information in comparison with traditional communication channels. Due to the huge accessibility and the high degree of instant feedback, businesses have the opportunity to communicate on a daily basis with their consumers and their potential audience, still it is not investigated how the brands affect consumer behaviour on social networks, and whether the brands play important role in order to facilitate sharing of information or product purchasing decisions through social networks. There are currently no similar studies in Latvia as well.

The goal of the research is to determine the brand's impact on consumer behaviour and decision making in the purchase process on social networks, compared to traditional communication and marketing channels, as well as to determine whether brand interaction in social networks facilitates the purchase of a product at different point of sales.

Latvian food producers have been selected as a research field, taking into account both: their representation at all major retail outlets and also carrying out communication in social networks. During the research structured interviews were used in order to evaluate the degree of influence of the brand in retail and in social networks.

The results of the research enable us to reveal the impact of the brand on consumer behaviour on social network platforms and determine the effectiveness of the communication channel by concluding that the brand has less influence in retail than on social networks, because in retail consumer behaviour is influenced also by other factors, such as price (the most important factor in purchasing process in food industry), decision time, availability, competitors placement and others; while in social networks, in most cases, the price is not known or available to consumers, and it is possible to develop a brand's reputation and loyalty, which allows to create phenomena where "price" is not playing such a significant role anymore. The results of the research lead to the conclusion that the brand has more significant role in social networks than in retail stores, and brand communication in social networks can facilitate the increase of sales volumes. 


\title{
TOURISM SERVICE ATTRIBUTE INFLUENCE ON OVERALL TOURIST SATISFACTION LEVEL IN RIGA
}

\author{
Ilze Medne, University of Latvia \\ Kristine Berzina, University of Latvia \\ Aija van der Steina, University of Latvia
}

Key words: tourist satisfaction, service attributes, penalty factors, reward factors

JEL code: $M 31, L 83$

The aim of the research was to study the satisfaction level of foreign tourists as consumers with various tourism product attributes in Riga and its influence on overall satisfaction and further consumer behaviour of tourists.

Tourist satisfaction is significant for successful destination marketing as it affects the choice of destination, consumption of tourism products and services as well as the decision on returning to the destination and intentions to recommend the destination to other potential tourists.

The mutual positive influence of customer satisfaction and loyalty is indisputably proven by empirical research studies carried out in different economic fields and industries including the tourism.

The method used in this research is the Penalty/ Reward factor analysis method, which was developed by Brandt and afterwards used by many researchers to investigate the influence of different service attributes on overall satisfaction level.

The research is based on data of tourist survey carried out in Riga in summer 2018. 996 valid questionnaires have been gathered. The questionnaire was designed to find out the aspects of the experience of foreign tourists in Riga. The data acquired in the survey allowed for conducting the Penalty/ Reward analysis which represents an important instrument for establishing the trip elements or factors the absence or poor performance of which (low quality) causes customer dissatisfaction (decreases the overall level of satisfaction) and the factors which cause increased customer satisfaction (raise the overall satisfaction level). MS Excel and SPSS software tools were used for analysing the data: descriptive statistics, crosstabulation, data correlation and regression analysis.

Main results and findings are intended for destination marketing organisation that is responsible for tourism development in Riga - Live Riga. The recommendations made by the authors will facilitate the improvement of the Riga's tourism product in accordance with the foreign tourist requirements, thus raising the satisfaction level of foreign tourists. 


\section{Elina Radionova-Girsa, University of Latvia}

Key words: $b 2 p$ marketing, relationship marketing, marketing communication, customer loyalty

JEL code: $M 31$

Being at a time when everything changes with the help of a single click, when marketing strategies are chosen almost personally for each individual client, companies begin to wonder and try to find out how they can create and build communication with their customers. And not just a communication, but a long-term and high-value relationship and interaction. It should be noted that nowadays the scheme such as B2B (businessis-business) or B2C (business-is-the consumer) does not always work in a such way as expected, and as every day an increasing emphasis is placed on individuality, then B2P (business-to-person) marketing occupies a certain niche.

The underlying problem is that this kind of marketing (business-to-person) will show results in the long run and it interacts very closely with relationship marketing. Therefore, initially for companies is the resource cost approach, however, it not only increases the life, which the company can carry out on the market, but also creates loyal customers.

The purpose of the paper is to show the relationship between B2P marketing and relationship marketing, and to make marketing communication with the consumer more efficient on the Internet.

Used methods - theoretical analysis of scientific literature, conducting consumer surveys and statistical analysis.

The results showed the strong influence of B2P communication and relationship marketing, this is explained by the fact that nowadays it is important to create long-term and based on trust relationship. The research results will help to provide an understanding on how the consumer reacts to different types of communication directly to the internet in order to be able to improve and adapt them to consumers' needs and expectations. The results have as theoretical as well as practical significance. 


\section{THE CALCULATION OF CROWDFUNDING CAMPAIGN SOCIAL MEDIA COSTS}

\section{Ronalds Skulme, University of Latvia}

Key words: crowdfunding, social media, costs, calculation two, three, etc

JEL code: $M 31$, G20

More companies than ever are using crowdfunding campaigns to raise funds and test their ideas. While one of the most important success factors of a crowdfunding campaign is the usage of social media during the campaign, yet there has not been proposed a formula that could help to calculate the estimated costs of social media activities needed to successfully launch a crowdfunding campaign.

The aim of this paper was to develop a formula that can help crowdfunding campaign creators calculate the estimated costs of social media activities during a crowdfunding campaign.

To achieve the aim of the paper several research methods were applied: (1) Theoretical analysis to determine what crowdfunding cost calculation methods are there; (2) Secondary data research method was applied to: a. Collect Kickstarter technology category campaign data; b. Collect data from Kickstarter campaign Facebook and Twitter accounts. Statistical package for the social sciences (SPSS) was used to conduct a correlation analysis and descriptive analysis of the collected data.

The result of the paper was that a formula was proposed that can help crowdfunding campaign developers calculate the estimated costs of social media activities during a crowdfunding campaign.

In practice, this paper can be used to calculate how much funds a crowdfunding campaign creator will have to invest in social media to increase the chance that their crowdfunding campaign will be successful. The theoretical contribution of this paper is that this paper can be used as a basis to develop a new crowdfunding cost calculation method. 


\title{
MAIN FACTORS INFLUENCING INTERNET SHOP SUCCESS
}

\author{
Biruta Sloka, University of Latvia \\ Sergejs Volvenkins, University of Latvia \\ Kate Cipane, University of Latvia
}

\begin{abstract}
Key words: internet shops, marketing, driving factors, survey
\end{abstract}
JEL code: M31, M37, M39

Recent business development increases competition among different actors in internet-shopping. New approaches related to digital marketing in sales organisation are applied and developed to attract customers and be competitive on international scale as internet shops more and more have no physical borders of countries. The research in this direction is conducted world-wide and Latvia is among the countries where share of internet-shopping is lacking behind other neighbouring counties.

Research aim - analyse main factors influencing internet-shop successful work and obstacles and brakes limiting the success of internet-shops.

Research methods used - scientific publication and previous conducted research analysis, internet shop customer's survey on aspects important for internet-shopping. Invitations to respondents to participate in the survey was organised together with Chamber of Trade and Commerce of Latvia. The survey was organised at the end of 2017 and beginning of 2018; 2530 respondents have participated in the survey. For analysis of survey results indicators of descriptive statistics (indicators of central tendency or location - arithmetic mean, median, mode; indicators of variability or dispersion - range, variance, standard deviation, standard error of mean), cross-tabulations, statistical hypothesis testing, multivariate statistical analysis methods - regression and correlation analysis, analysis of variance - ANOVA, factor analysis are applied. Research was carried out by company imarketing in co-operation with researchers from University of Latvia.

Main results and findings of the study - still challenges offered by recent technology development and advanced marketing tools are not taken into account for many internet-shops and this can cause reduction of internet-shop customers as they can choose internet-shops in other countries.

Theoretical and practical implications of the work - theoretical and practical findings have to be analysed deeper according identified breaking aspects identified in the survey and implemented in internetshop marketing for further successful work of internet-shops.

Conclusions drawn - technology development and new findings in advanced marketing tools developed in other countries requires new approaches in internet shop-work organisation also in Latvia; customer needs and preferences have to be studied deeper and respected as in Latvia there are some needs by internet-shop customers differing by customers in other countries with other cultural background in internet-shopping. 


\section{APPLICATION-BASED MARKETING - FROM REALITY TO THE FUTURE}

\section{Evgeniya Tonkova, University of Economics - Varna}

Key words: application-based marketing, marketing efficiency, technology and innovation JEL code: $M 31$

The use of new technologies and innovations in marketing and the effects of their application have been the focus of research over the past decade. Mobile marketing applications specifically designed to improve marketing efficiency and speed up business processes provoke particular scientific interest. One of the prerequisites for the boom in the development of a variety of marketing applications is the massive penetration of mobile devices into the daily routine of consumers. The steady growth trend in their sales on the market and the expansion of the range of features users use makes them attractive for the development of $\mathrm{B} 2 \mathrm{C}$ digital application-based marketing.

The paper examines the use of application-based marketing and the benefits for companies and end users.

The aim of the study is to systematize the benefits of $\mathrm{B} 2 \mathrm{C}$ application-based marketing under conditions of high technology and innovation.

The study is based on literature review and secondary data research methods for classifying business practices and published findings on the impact of using the application-based marketing covered by the research.

Research results indicate a variety of applications that are used for marketing purposes (location-based marketing, weather-based marketing, content-based marketing, event-based marketing, etc.) as well as communicated positive effects of their use in business. Enhancing marketing efficiency and speeding up processes as a result of their application are explained by more accurate targeting of customers, taking into account the specifics and circumstances of product and service offers. The results presented in the paper contain both a theoretical contribution to an application-based marketing study and practical implications for extending its scope to different areas. Taking into account the results of this study and the expectations for the change in the marketing environment over the next decade, future implications of application-based marketing are also presented. 


\title{
A COMPARISON OF BUSINESS EXCELLENCE MODELS
}

\section{Andzela Veselova, University of Latvia}

\begin{abstract}
Key words: comparative analysis, business excellence model, quality award
\end{abstract} JEL code: $L 15$, L26, M11

In today's competitive world, every organization strives for business excellence and mutual benefits of the stakeholders. There are several Business Excellence models applied throughout the world.

Business Excellence models help the organizations to identify eventual solutions to achieve business success by measuring the current position of the company is on the path to excellence; help understand the shortcomings; provide an approach for implementing the solutions.

Nowadays, there is a rising trend of implementing different Business Excellence frameworks also known as Quality Models for the improvement of organizational business performance. Models or Quality Award Model are used to recognize the best practice in the different areas. Many countries of the world adapt these models as their quality improvement tools for business assessment in comparison with the competitors. The research is focused on the review of the major Business Excellence Models such as Deming Prize, European Foundation for Quality Management (EFQM) and Malcolm Baldrige National Quality Award (MBNQA) and their influence.

The aim of research is to explore the common features and the differences of Business Excellence models based on their emphasis of the framework criteria. The tasks of the research consist of exploring basic Business excellence models, comparing different Business excellence models and making conclusions on best application of the respective model.

The research methods: scientific publications analysis, comparative analysis as a measurement tool to identify the emphasis of different Business Excellence models, survey of companies.

The results of the survey show that Business excellence models are tools that help the companies to improve the business performance and the general business performance increasing the efficiency of the country. In terms of application of the Business Excellence model criteria most companies show common features, meanwhile the differences stand out in the approach, namely, one part of the models relates to the satisfaction of the customers and the other - to business results. 

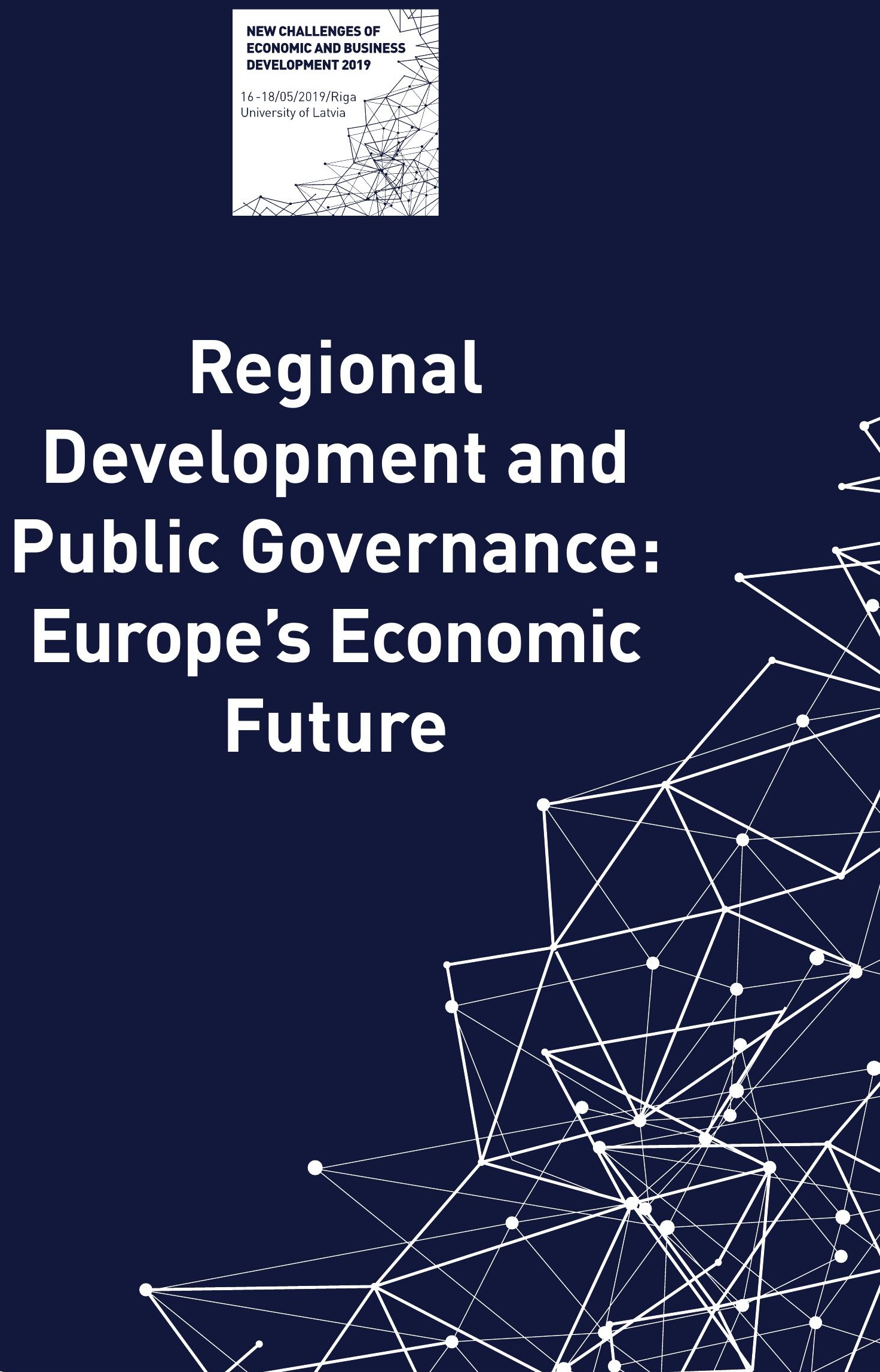



\title{
THE GOALS OF WASTE FRAMEWORK DIRECTIVE AS MECHANISM SECURING TRANSITION TO CIRCULAR ECONOMY
}

\author{
Natalija Cudecka-Purina, Liepaja University \\ Dzintra Atstaja, BA School of Business and Finance \\ Rudite Vesere, Riga Technical University
}

Key words: circular economy, sustainable development, waste management JEL code: $M 21, Q 57$

Circular economy is seen as economy's development direction expected to lead to a more sustainable development and a harmonious society. It covers at least five different business models, one of which is resource recovery, tackling in particular benefits of industrial symbiosis. in order to achieve a circular economy, there must be a greater understanding of the links between economic activity and waste generation. A consensus exists on the vital role of waste and resource management in achieving transition from a linear model to a circular one where the value of materials and resources are maintained in the supply chain. Waste systematically emerges throughout the supply chain as a result of economic activities and trade. Systemic and transformative change is also reflected in the growing number of case studies analysing innovative solutions based on new systemic thinking like "cradle to cradle" and "industrial symbiosis". The Authors have analysed one of circular economy priority fields - waste management and it's tendencies and have come to a conclusion that there is a range of divergences in waste treatment and their economic management mechanisms in the Baltic countries. If at the moment of inventory the Baltic States landfilled 95-100\% of municipal waste, then in 2015 Latvia landfilled $72 \%$, Lithuania $60 \%$ and Estonia only $8 \%$ of municipal waste, then while developing waste management policies the member states currently are situated in considerably different positions and their transition to circular economy has advanced significantly. Authors analyse a range of independent variables within the field in order to benchmark the situation in the three Baltic countries - Latvia, Estonia and Lithuania and to reveal the progress each of them has achieved in the transition to circular economy. The research is based on qualitative (system dynamics) and quantitative (benchmarking) research methods. As a result of the research, the authors identify best practices, strengths and weaknesses of each countries experience, allowing to identify further necessary steps for the abovementioned transition. 


\section{INCOME DISPROPORTION BETWEEN CENTRAL AND EASTERN EUROPE REGIONS}

\section{Pawel Dobrzanski, Wroclaw University of Economics}

Key words: inequality, income distribution, comparative studies, cohesion policy

JEL code: $D 31, D 63$, O15, R11

In 2004 the Czech Republic, Estonia, Hungary, Latvia, Lithuania, Poland and Slovakia joined EU. Those seven Central and Eastern Europe economies were far behind "old" EU countries in terms of economic development. Considerable differences were also inside countries, where the regions with capitals were significantly distinguished in terms of income and development over the remaining regions. In the same time idea of regional cohesion gain in importance in EU. Nowadays, one of the main EU's priorities is to reduce disparities between regions and improve economic well-being of delayed areas through actions under cohesion policy.

The purpose of the research is to analyse income disproportions between regions in Central and Eastern Europe. Such analysis will help to answer the question whether accession to EU helped to reduce income disproportions between CEE regions. In the first part of the article, Author will present literature review about income inequity issue at the regional level. In the second part, EU regional policy will be discussed and actions that aim to reduce disproportions between EU regions. Then paper highlights the key statistics about income from Eurostat by NUTS2. The research period covers years from 2004 to 2015. The main method is comparative analysis, which will be supplemented with descriptive statistics methods (in particular, time series analysis, including structure and dynamics analysis, distribution measures, including average measures). In the last part of the article, Author will analyse income gap between CEE regions.

Research confirmed that income inequity was changing with different speed and directions over CEE counties. Huge disproportions can be also noticed inside individual countries, where capital regions were always the most developed regions with the highest income. Gross Domestic Product by PPS compared to EU average increased in all regions in analysed period. Only four regions with capital cities achieved GDP exciding EU average: Praha, Közép-Magyarország, Mazowieckie and Bratislavský kraj. Moreover, hypothesis about spatial autocorrelation was not confirmed. Regions near strong capital regions did not achieve high level of GDP. The highest growth in disposable income was noticed in Slovakia, Latvia, Lithuania and Estonia, where income doubled in analysed period. However, all three Baltic countries are still behind EU average. Result of this research confirmed that cohesion policy actions are no fully effective in CEE regions. There are still huge income inequalities and this trend seems to continue. Policy makers should ensure proper policy is implemented to reduce income disproportions.

The project is financed by the Ministry of Science and Higher Education in Poland under the programme "Regional Initiative of Excellence" 2019 - 2022 project number 015/RID/2018/19 total funding amount 10721 040,00 PLN. 


\section{THEORETICAL BASES OF THE PUBLIC-PRIVATE PARTNERSHIP IN THE IMPLEMENTATION OF THE LOGISTIC INFRASTRUCTURE OF THE REPUBLIC OF BELARUS}

\section{Elena Dorina, Belarus State Economic University \\ Olga Meshcheryakova, Polotsk State University}

\section{Key words: public-private partnership (PPP), forms of PPP, concession, risk sharing JEL code: $H 41, H 54, L 32, L 33$}

In a modern market economy, the role of the development of favorable interaction between the government and private business is increasing. This is due to the need to solve social problems that require large capital investments. In the framework of projects using public-private partnership (PPP) mechanisms, instead of the state owning state assets and providing public services, comes a private partner. A private partner acquires assets, provides services to government organizations or end-users for a fee, depending on the quality of the services provided.

In the Republic of Belarus there are two main groups of forms of interaction in the implementation of infrastructure projects. This is due to budgetary funds and extra budgetary funds. When implementing infrastructure projects involving extra budgetary funds, there are also two groups of forms. These are forms of public-private partnerships and other forms with signs of public-private partnerships (quasi-PPP). Moreover, only the PPP agreement refers to the form of public-private partnership. Due to the fact that not a single PPP project has been implemented in the Republic of Belarus, it seems relevant to study the global experience of using concessions. And propose to consider the concession as a form of public-private partnership at the legislative level.

The purpose of the article is to develop recommendations on the formation and development of publicprivate partnership in the implementation of the logistics infrastructure of the Republic of Belarus. With publicprivate partnerships, you can increase your investment in infrastructure and increase its efficiency.

In order to achieve the target it's necessary to carry out the following tasks:

- to study the economic essence of the concepts "public-private partnership", "logistic infrastructure";

- to classify forms and models of public-private partnerships;

- describe measures to reduce risks in public-private partnership infrastructure projects.

As a result of the research, the author's definition of "public-private partnership" is presented, a new mechanism for implementing public-private partnership in the formation of the republic's logistics infrastructure is proposed, the risks between the state and private business that are used in the formation of the logistics infrastructure are distributed.

For the purpose of the achievement of the aim, the authors apply generally accepted economic research methods: economic analysis and synthesis, logically - constructive, qualitative methods including the methods of the analysis of normative acts.

The theoretical and methodological grounds of the paper are the normative acts regulating PPP, works produced as by Belarusian so foreign scientists and Internet sources. 


\section{IMPORTANCE OF INSTITUTIONS FOR LOCATION CHOICES MADE BY COMPANIES WITH FOREIGN CAPITAL}

\section{Tomasz Dorozynski, University of Lodz}

Keywords: institutions, investment incentives, location decision, FDI, Lodz province JEL code: F21, F23, R11

Multinational enterprises are looking at almost all countries and regions (which are politically and economically safe) in the world to find optimal investment locations. As foreign investors, they are mainly interested in finding a concrete site where their projects could be successfully developed. Bearing the above in mind, governments of countries or authorities at lower administrative levels may try to attract foreign investors by offering incentives financed from public funds.

Giving support to FDI under intentionally developed incentive schemes continues to be hotly debated by economists and the international business community (e.g., Aggarwal, 2012; Johnson, Toledano et al., 2013; Jensen, Winiarczyk, 2014; Tavares-Lehmann et al., eds., 2016; World Investment Report, 2018). Business environment institutions (BEIs), including public authorities at different levels (national, regional and local), may play a significant role in attracting (and retaining) foreign investors. They may use economic policy instruments (incentives) available to them based on their competence, regulations and resources.

The study discussed in the paper aims primarily to assess the role of the host country institutions in location decisions of enterprises with foreign capital. To accomplish the above goal, the author used results of his own questionnaire-based survey conducted in the Lodz Province (one of sixteen regions in Poland) as a case study. The study was carried out based on the quantitative PAPI (Pen and Paper Personal Interview) method. It covered 201 enterprises representing ca. 30\% of the total business population. To analyse the responses, their distributions as well as simple statistical measures and tests were used.

Apparently, cost factors were clearly central to location decisions made by enterprises with foreign capital and the majority of respondents claimed that the absence of State aid would not impact their location decision. The significance of individual groups of incentives varied. Relatively, in-kind support, i.e., accompanying infrastructure, was the most important to foreign investors in the Lodz Province. 


\section{THE DEMAND OF PUBLIC ADMINISTRATION MANAGEMENT'S STAFF COMPETENCES IN} THE FUTURE

\section{Ineta Lakstigala, University of Latvia \\ Signe Balina, University of Latvia}

Key words: competence, development, staff

JEL code: M59, O15, J24

The development of the competences of the staff of the Latvian Public Administration has been drawing more and more attention. The aim of the development of the human resources is a professional, motivated, advanced and honest staff of the Public Administration. It means that it is necessary to evaluate the competences of the staff in order to upgrade them and understand what is in demand nowadays.

The aim of the research is to understand, what kind of competences in the future are going to be in demand for Public Administration staff.

The methods used in the research work are going to be the analysis of the documents and data analysis.

The results of the research are going to be used in practice by evaluating and upgrading the competences of the Public Administration staff. 


\section{HOW TO IMPROVE THE FUNCTIONING OF THE EU SINGLE MARKET FOR SERVICES}

\section{Magdalena Myszkowska, Wroclaw University of Economics}

Key words: cross-border provision, services, single market, services directive JEL code: $L 84$, F15

The Single Market - including the services market - is one of the biggest accomplishments of the EU. However, the possibilities created by it are not always fully used. This results from the fact that regulations concerning the Single Market rules are not known, they haven't been implemented, or various (often unjustified and disproportionate) obstacles hinder their use. Further strengthening and advancement of the Single Market for services is one of the most important elements of the European Commission's new strategy aimed at removing remaining regulatory and non-regulatory barriers.

The purpose of this article is to provide systematized assessment of the effectiveness of actions aimed at better use of opportunities offered by the EU Single Market for services in the light of existing significant barriers. Such determined purpose encourages to ask the following research questions: 1) What are the actions undertaken in order to further liberalize the EU services market and what is their real significance? and 2) What additional actions (at EU level as well as member state level) could contribute to further strengthening and releasing the full potential of the EU single market for services?

A review will be conducted, as well as objective assessment of the legitimacy and effectiveness of the actions proposed by the European Commission (within the so-called "service package"), which are supposed to contribute to the reduction of regulatory barriers, improvement of access to the services market, as well as enabling the performance of regulated professions. Also, the analytical framework determined by the EC will be analysed, which should be used by the member states during the review of existing regulations or during the proposal of new regulations. Subsequently, on the basis of the ongoing process of mutual assessment, which is provided for in the Services Directive, as well as research, EC reports, reports submitted by the member states and updated database concerning regulated professions, the specific needs for actions and reforms aimed at improving the functioning of the single market for services will be indicated. The draft examination of strategic European legislative documents and analysis shows that the Commission's proposals address both administrative and regulatory barriers. However, it seems that these initiatives are not ambitious enough for the completion of the free movement of services within the EU.

Precise and diligent analysis of potential of the EU Single Market for services has key cognitive, as well as practical significance. The research results will allow to determine priority areas of action in the scope of the Single Market for services, the implementation of which could contribute to the establishment of more open and competitive market environment for services. Research on the Single Market for services is justified by significant gaps in theoretical and empirical knowledge, as well as significance and up-to-date aspect of the identified problem. This issue requires a diligent examination due to the increasing role of the services sector in the economies of individual member states, as well as the EU as a whole. One of the measures of this sector's significance is over $65 \%$ share of services in the GDP and EU employment. 


\title{
ELECTRONIC PROCUREMENT SYSTEM - INSTRUMENT FOR IMPLEMENTING GREEN PUBLIC PROCUREMENT: ANALYSIS OF THE LATVIA'S EXPERIENCE
}

\author{
Inese Pelsa, University of Latvia \\ Signe Balina, University of Latvia
}

Key words: electronic procurement, electronic procurement system, green public procurement JEL code: $Q 001, Q 58$

Green public procurement (GPP) is a mean of saving up finances for public institutions, especially taking into consideration not only procurement price but also total expenses of the contract lifecycle. In Latvia the first Electronic Procurement System (EPS) was established in 2005 and was the first such procurement system in the Baltic States. Initially, it only acted as an e-Procurement system in which public institutions can purchase standard goods and services.

This paper analyzes the success of the implementation methodology for evaluating e-Procurement in public procurement.

The aim of the paper is to explore the proportion of applied GPP of total procurement in EPS in Latvia in the period from 2015 to 2017, and to analyze how the aims of the proportion of GPP are achieved. In order to investigate the share of GPPs in the EPS, data on purchases made by EPS was collected and analyzed. An analysis was made of the percentage of GPP and the most important groups for which GPP was appropriate, and it was assessed whether the objectives set by the GPP have been achieved. GPP proportion in procurement made within the EPS in 2015 was 9\%, in 2016 - 8\%, but in $2017-19.10 \%$, which means that GPP a substantial increase. As the calculations made in the study prove a complete transition to e-Procurement will reduce both administrative costs and significant savings for the state budget in the Latvia.

At the same time, the winner will be a supplier, as it will have to participate in only a few procurement procedures during the year, and will be able to devote all its strength to providing EPS visitors with the best product at the best price.

The requirement to publish EPS contracts in Latvia is mandatory. At the same time, information on public procurement contracts and procurement contracts is not available in one place, but on the websites of institutions and corporations.

In Latvia often procurement decisions are still made on a basis of a purchase price, but costs that may arise in the upkeep and disposal of many products and work can also be very significant, such as energy consumption, aggregation, and the disposal of relevant materials. In order to improve performance in the field of GPP, involvement and motivation for all levels of management in the promotion of sustainable consumption and production of the public sector and society, as well as the development and development of EPS directories, are required.

Theoretical, empirical and statistical research methods as well as other qualitative and quantitative research methods have been used in this research. 


\title{
CHALLENGES IN PROPER FUNCTIONING OF INTERNAL MARKET - NON-FOOD PRODUCT MARKET PERSPECTIVE
}

\author{
Linda Rinkule, University of Latvia
}

Key words: public administration, internal market, market surveillance, enforcement, risk assessment JEL code: K42, L15, L51

Efficient market surveillance is important not only for the protection of public interests and safety or fair competition, but also for the proper functioning of EU Internal market - to ensure the free movement of compliant products, at the same time precisely identifying non-compliances and responsible parties.

The aim of the article is to analyse main challenges in market surveillance of non-food products and necessary improvements at EU level.

The following research methods are used in this work: secondary data are analysed from different sources: Rapid alert system for dangerour non-food products in EU (RAPEX), market surveillance reports from Member states, joint market surveillance campaigns in EU. System analyses method is used for studying the market surveillance system in EU at different enforcement levels (EU, Member state and authority levels). The best practice in enforcement is analyzed taking into account the theories of responsive regulation from I.Ayres and J.Braithwaite and smart regulation theory from N.Gunningham.

Enforcement results in non-food area show high non-compliance levels in EU from 27-77\% (depending on the product group). RAPEX statistics show that the most of the notified high risk products come from the third countries. The best practice in enforcement includes wide variety of instruments which can be used depending on the willingness and the ability of economic operators to cooperate with the market surveillance authority. This includes the detailed analyses of the behavior of the economic operator and the managment systems in place.

The study provides practical proposals for the improvements needed in EU market surveillance system, in order to ensure proper functioning of Internal market.

The main conclusions are - the market surveillance in EU is fragmented and existing coordination mechanisms are insufficient. Furthermore, the system is based on the producers, as the main responsible persons for the compliance of the product, but globalization processes dictate the increase of imports, where limited jurisdictions of EU Member states hamper the real surveillance of the market. The system approach is important for market surveillance, but there is no legal base in EU and there are several limitations of the method, e.g. for imports and on-line sales. 


\title{
IS IT POSSIBLE TO RISE THE POSITION OF HIGHER EDUCATION INSTITUTIONS IN RANKINGS
}

\author{
Evija Rusite, University of Latvia \\ Biruta Sloka, University of Latvia
}

Key words: University rankings, performance indicators, strategic planning, experts JEL code: $123,030,032$

It is impossible for higher education institutions (HEI) to ignore different national and international comparisons, since emergence of global rankings. This influences the way; how higher education institutions function and are planning their development. Involvement in rankings changes and in some aspects improves the performance of higher education institutions. Trying to rise their position in the rankings, higher education institutions are seeking ways, how to improve performance in those areas that are measured by the indicators used for rankings of higher education institutions. However, the question is, does devoting by HEI of too big attention to the highest ranking positions causes the definition of incorrect priorities of the higher education institutions development and restricts the ensuring of the main activities of the respective HEI.

Many international academic research and investigations have been performed in this field and the research results usually are used for management decision making on different levels: on university level, on higher education and science management level and for country management level.

Taking into account the above mentioned and that, how essential role ratings have in the forming of the reputation of higher education institutions, the purpose of this study is to search for some possible solutions for more effective research work organization at the universities and correct reflection of achieved results to raise their position in university rankings.

Research methods used: analysis of scientific publications on university rankings aspects related to different methodologies and indicators; expert survey on university organisation and used ranking indicators aspects supporting university rankings. For expert interviews were invited internationally recognized university management representatives and several administrators at universities in different countries. For different aspect evaluations there were used evaluation scale 1-10, where 1- do not agree and 10 - agree in full extent. Expert evaluations were analysed by descriptive statistics indicators and cross-tabulations.

Main results and findings of the study: Rankings have significant role in the development of higher education institutions. It is important to define the accessible rankings position in the strategy of higher education institution - in the scale of the world, in the regional scale and in the national scale. Higher education institutions must determine such goals and results of performance that favour the higher ranking position. For increase of international recognition HEI have to recognise that as well important aspects are the academic and employer reputation surveys in rankings. 


\section{SMALL BUSINESS IN A SMALL COUNTRY AND THE ROLE OF GOVERNMENT (THE CASE OF GEORGIA)}

\section{Svetlana Saksonova, University of Latvia Tatiana Papiashvili, International Black Sea University}

Key words: small and medium size enterprises, government policy, Georgia JEL code: $M 210$

The value of small and medium enterprises (SMEs) for a national economy is recognized all over the world. Georgia is not an exception. Georgian government has declared the importance of the creation of a strong private sector in strategic documents - "Socio-Economic Development Strategy of Georgia - Georgia 2020" (2014) and "For a Strong, Democratic and United Georgia" (2015), first of all. In line with country's general strategy - to achieve economic growth through private sector development - more proactive reforms to develop entrepreneurship, start-ups and build a competitive SME sector have been developed and special program -“SME Development Strategy 2016-2020”- was adopted. Nevertheless, some challenging tasks still remain.

The aims of the article are twofold. Firstly, to analyze Georgian SMEs contribution to the national economy in order to reveal the role of this sector, and following this reasoning, critically assess government policy towards SMEs after signing in 2014 the Association Agreement with the European Union.

Research methods applied in the paper are quantitative and qualitative based upon a bottom-up approach that combines desk research and statistical data analysis provided by the National Statistics Office of Georgia, national researches and international organizations. Desk research consists of analysis of academic literature related to the topic. Media reports and interviews are used as additional sources.

Main results/ Findings are as follows:

- nowadays Georgian SMEs contribution to the country's economy is difficult to be assessed due to the new classification methodology applied by the National Statistics Office of Georgia,

- Georgian government policy toward SME is changing,

- Georgia urgently needs the Action Plan to achieve the program's goals. Practical implication of the work: Recommendations for the policy decision-makers were developed. 


\section{PERSONALISATION - AN INNOVATIVE APPROACH TO HEALTHCARE SERVICE DELIVERY IN WELFARE ECONOMICS}

\section{Samanta Savickaite, Klaipeda University}

Key words: personalisation, healthcare, welfare state, personalised services JEL code: $P 46, I 18, I 15$

Applying the most advanced health service delivery approaches as well as the improvement of the health system organization and performance represent permanent matters of concern for every country. With the objective to reduce the costs of the health care services for people with long term conditions as well as to reduce the fragmentation of health and social services, personalisation agenda paved the way for a transformation in many welfare states, including UK. However, the promotion of personalization principles and values such as engagement, independence, choice and control of the individuals is a great challenge because of the different interpretation and application at practical level.

The paper aims to explore the personalisation idea and its appliance peculiarities in the UK health care system.

Research methods - document analysis.

Personalisation has its roots from the social care sector and started with a movement of disabled people that were asking for more choice and control over their lives. The provision of personalized services is based on intensive intersectoral cooperation (service recipient vs. representative of governmental institution vs. service provider) which highlights the importance of the negotiations among the stakeholders. Moreover, the role of community services and the third sector is crucial in the context of personalization as well. Directpayments, personal budgets are the main personalization instruments that build on and extend the use of contracting within both social and health care. Personalisation appliance in health sector has a great potential to improve health care outcomes for people with long term conditions and is seen to be the best approach to help target resources most efficiently. However, despite the advantages of person-centered services both at the micro and macro level, such change in service delivery is a great challenge to manage as it requires for a change in the policy, legislation, service management tradition and organizational capacity.

Personalisation as an innovation in transforming healthcare has become a high-profile approach in public reform agenda in UK. It has the power to shape the services around the individual, improve the service delivery outcomes and can be taken as the best way to combine fragmentary support into a structured and meaningful whole. However, person-centered care is a radical change in health sector which requires for a change both in a culture, policy and service management tradition. 


\title{
EFFECTS OF SPECIAL ECONOMIC ZONES POLICY IN POLAND - A SURVEY OF EMPIRICAL STUDIES
}

\section{Janusz Swierkocki, University of Lodz}

\author{
Key words: Special economic zones, Poland, investment incentives
}

JEL code: F21, L52, R11

In 2018 the Polish government announced the new law on investment incentives which will substitute for the present special economic zone (SEZ) regime. It has been in operation since 1994 and was intended to correct some failures of the market mechanism. This change may suggest that SEZ have not met the expectations of politicians or that the future investment policy will need different tools.

The aim of this paper is to evaluate whether SEZ were attractive for investors and what was their impact on the Polish economy. The effectiveness of SEZ policy will be assessed on the basis of comparative analysis of empirical studies which were conducted by Polish and foreign researchers. Most of such publications are available only in Polish. As a result of a language barrier, SEZ policy achievements and failures in Poland are much less known internationally than their records in China and other developing countries.

The empirical studies on Polish SEZs are not easy to compare. The scope and level of analysis differ together with methods, sources of data and periods covered. However we may say that only some goals of SEZ policy were considered by researchers due to the lack of data (e. g. on production, exports or technical progress). Most studies were devoted to the impact on jobs and investment, i. e. to the static effects. Majority of them were descriptive, not based on theoretical framework. Their results show that, generally speaking, SEZ effects were positive. However researchers who verified the findings formally, either with statistical or econometric methods, did not provide conclusive results. To large extent the methods used determined the answers which were obtained.

Further studies are important for better evaluation of investment incentives, especially of their indirect (external) effects. The estimates of costs of incentives are usually neglected by researchers, too. The results of such studies could help to shape more rational investment policy. 


\section{REGIONAL DEVELOPMENT WITH CONSIDERING ECOLOGICAL FACTORS}

\section{Kateryna Tiulkina, Odessa State Academy of Civil Engineering and Architecture}

Key words: regional development, sustainable development, ecological factors

JEL code: 018

In the decentralization framework held currently by local authorities of Ukraine, stimulate regional development should be carried out in order to meet the society' interests on the basis of the natural, demographic, historical and economic preconditions. It is also necessary to consider not only the limited natural resources but also the possibility of conservation and restoration of the environment.

The research aim is to reasoning the region's development directions on the basis of determining sustainable development index and its components. In the study, these indicators compare with average values also. The necessity to take into account ecological factors during the implementation of economic activity in a certain region and the opportunity of introducing environmentally-oriented measures in this activity is based on comparing of the regional index of the environmental dimension with the average value.

The paper presented an assessment of the sustainable development of the Ukrainian regions, which is based on determining the sustainable development index and its components (components of quality and safety of life, indices of social and institutional, ecological, economic dimensions). There are the results of monitoring socio-economic development of Ukrainian regions with their ranking by directions "Rational Environmental Use and Quality of the Environment" and "Renewable Energy and Energy Efficiency", which are based on data on emissions of pollutants into the air, the volume of consumed fuel and energy resources, the introduction of energy-saving light sources in external lighting and other indicators.

The article obtained a conclusion that the Odessa region is characterized by an extensive type of economic development now. But the achievement of sustainable development at the regional level is possible by ecologizing the economic activity in a region. 


\title{
INVESTMENT IN HIGH TECHNOLOGIES AND ITS ROLE FOR ENHANCING THE COMPETITIVENESS OF THE NATIONAL ECONOMY
}

\author{
Evgeniya Tonkova, University of Economics - Varna \\ Dancho Petrov, University of Economics - Varna \\ Sevdalina Hristova, University of Economics - Varna
}

Key words: investments, technology, innovation, competitiveness and national economy

JEL code: $R 58, O 1$

High technology investments today are becoming a crucial factor for the development of national economies. This logically leads to exacerbating competition in attracting high-tech investors to individual countries or economic regions. The results of the implementation of high-tech investments have an impact on public sector management, which is increasingly focusing on updating incentive policies to attract new investments of this type.

The purpose of the paper is to determine the impact of high technology investments on the competitiveness of the economy and, on this basis, to draw recommendations for improving the promotion policy toolkit to attract high-tech investments.

The research is based on a literature review of post-2000 publications and secondary data research methods applied to high-tech investments in Bulgaria, on the basis of which the results of the implementation of high technology investments at local and national level are identified and evaluated. Research results show that high technology investments lead to positive "direct" economic effects and "transfer" effects, which have a more pronounced social character. Direct effects include reducing operating costs, speeding up turnover through automation of core activities and the payment process, increasing profitability of production / logistics and return on investment, transfer of know-how, etc. The transfer effects concern predominantly the income levels, improve the environment, the image of the territorial unit, etc. The results of the analysis of investment practices in Bulgaria show a favorable impact of investments in high technologies on the competitiveness of the local and national economy. The theoretical dimensions and practical benefits of this study are complemented by recommendations for updating programs/measures to stimulate high-tech investment and improving policies to attract high-tech investors. 


\section{SUITABILITY OF THE EXPENDITURE BENCHMARK: THE CASE OF LATVIA}

\section{Karlis Vilerts, University of Latvia}

Key words: EU fiscal framework, expenditure benchmark, fiscal policy, fiscal rules JEL code: E61, E62, H60

Supranational fiscal rules in the euro area (laid out in the Stability and Growth Pact) are often criticized of being ineffective, opaque and too complex. Therefore, overhaul of the current framework is one of the key items on the reform agenda for the European Economic and Monetary Union. Among numerous proposals for a new fiscal framework, a common feature seem to stand out: increased reliance on the restricting the expenditure growth. For example, European Fiscal Board has proposed to impose a constant ceiling on expenditure growth to anchor the fiscal policy around $60 \%$ reference value for government debt. Although such framework seems to be more effective in highly indebted countries in Southern Europe, it is not clear how it would impact fiscal outcomes in less-indebted countries such as Latvia.

Therefore, this research aims at estimating the impact of expenditure rule on fiscal policy in Latvia. We use fiscal aggregates for Latvia for period 1995-2017 and model fiscal outcomes e.g. headline balance, cyclically adjusted balance, debt level under different fiscal rules. On the one hand, our results suggest that under expenditure rule fiscal policy would be less procyclical and lead to lower accumulation of public debt. On the other hand, expenditure rule would limit the flexibility that is prevalent in the current framework hence reducing governments ability to react to urgent needs. 
100.0 


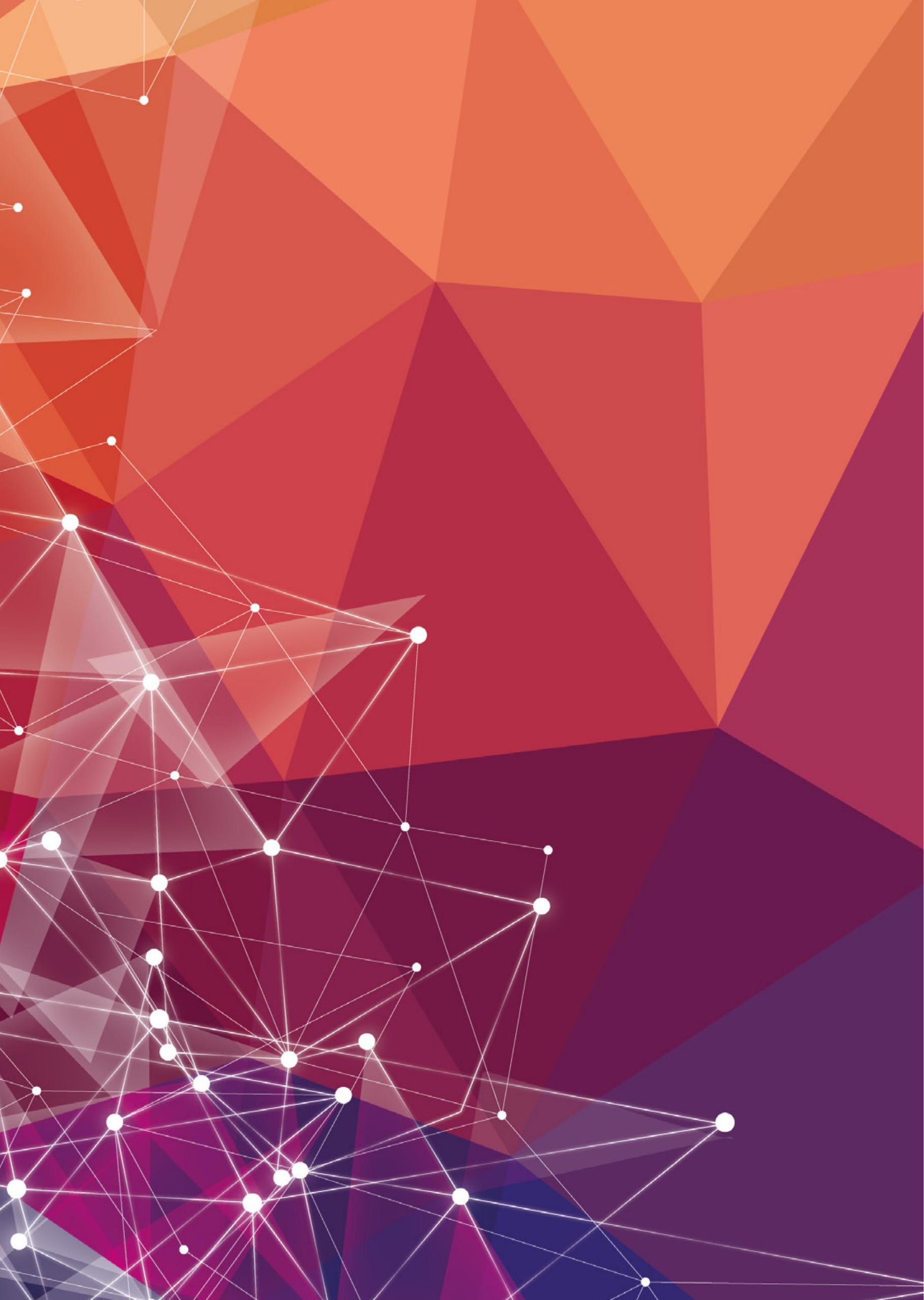

